\title{
MECHANICAL CHARACTERIZATION OF SELECTIVELY LASER MELTED 316L STAINLESS STEEL BODY CENTERED CUBIC UNIT CELLS AND LATTICE OF VARYING NODE RADII AND STRUT ANGLE
}

\author{
A Thesis \\ presented to \\ The Faculty of California Polytechnic State University \\ San Luis Obispo \\ In Partial Fulfillment \\ of the Requirements for the Degree \\ Master of Science in Industrial Engineering
}

By

Christopher James Hornbeak

June 2018 
(C)2018

Christopher James Hornbeak

All Rights Reserved 


\section{COMMITTEE MEMBERSHIP}

TITLE: Mechanical Characterization of Selectively Laser Melted 316L Stainless Steel Body Centered Cubic Unit Cells and Lattice of Varying Node Radii and Strut Angle

AUTHOR: Christopher James Hornbeak

DATE SUBMITTED: June 2018

COMMITTEE CHAIR: Xuan Wang, Ph.D.

Professor of Industrial Engineering

COMMITTEE MEMBER: Thomas Mackin, Ph.D.

Professor of Mechanical Engineering

COMMITTEE MEMBER: Kaveh Kabir, Ph.D.

Professor of Aerospace Engineering 


\begin{abstract}
Mechanical Characterization of Selectively Laser Melted 316L Stainless Steel Body Centered Cubic Unit Cells and Lattice of Varying Node Radii and Strut Angle
\end{abstract}

Christopher James Hornbeak

An experimental study of several variants of radius and strut angle of the body centered cubic unit cell was performed to determine the mechanical properties and failure mechanisms of the mesostructure. Quasi static compression tests were performed on an Instron ${ }^{\circledR}$ universal testing machine with a 50kN load cell at $0.2 \mathrm{~mm} / \mathrm{min}$. The test samples were built using a SLM Solutions 125 selective laser melting machine with $316 \mathrm{~L}$ stainless steel. Test specimens were based on $5 \mathrm{~mm}$ cubic unit cells, with a strut diameter $10 \%$ of the unit cell size, with skins on top and bottom to provide a cantilever boundary constraint. Specimens were inspected for dimensional accuracy using precision calipers and inspected for morphology using a $\mathrm{MicroVu}^{\circledR}$ macroscope. The compressive properties of the mesostructure was compared to the compressive properties of macrostructure. The BCC unit cell behaves significantly different at the boundary layer of a constrained lattice. The failure mode at the boundary is characterized by plastic bending within the microstruts while the non boundary layer cells fail via plastic bending at the node. Manufacturing compensation parameters were determined for part shrinkage and droop. Two predictive numerical models were developed, based on the Gibson-Ashby model of cellular solids, as well as a finite element model. Numerical results did not agree well with the experimental results, indicating that the droop observed on the structures significantly affects the mechanical properties of the overall structure. The $25 \%$ radius cubic unit cell and $3^{\wedge} 3$ lattice withstood the greatest stress of all specimens tested and exhibited nearly ideal plastic deformation behavior. 


\section{ACKNOWLEDGMENTS}

This work was made possible by the faculty and students of Cal Poly San Luis Obispo, most notably my committee members. Thank you Dr. Xuan Wang for your constant support, extremely effective guidance, enlightening conversations, and encouragement to push to the next step. Thank you Dr. Kaveh Kabir for your determined push for success, guidance on compression testing, and guidance on completion of this degree. Thank you Dr. Thomas Mackin for your advice and vast knowledge of mechanical structures, helping me to understand and comprehend the behavior of metallic structures. Thank you Moira Foster for helping me fabricate the necessary specimens on the SLM machine. Finally, I would like to thank the entire Industrial and Manufacturing Engineering department at Cal Poly, San Luis Obispo. 


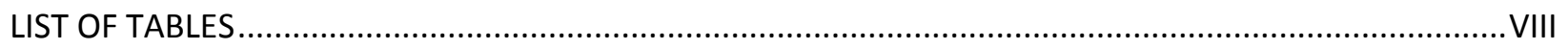

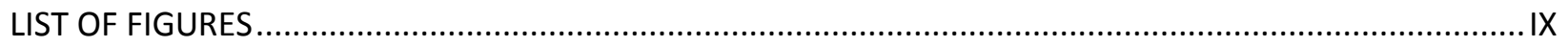

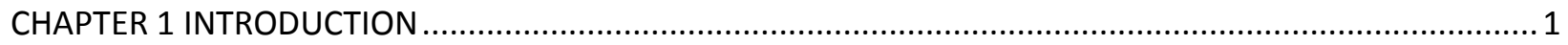

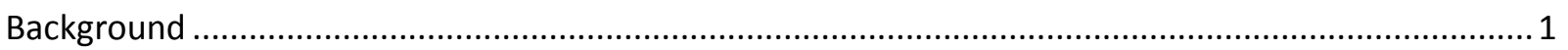

Applications of Lattice Structures for Energy Absorption ....................................................... 1

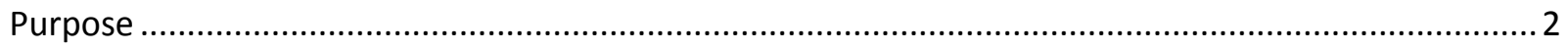

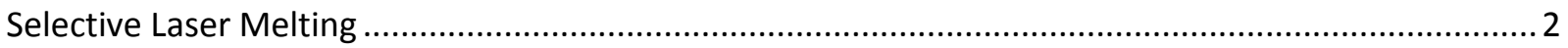

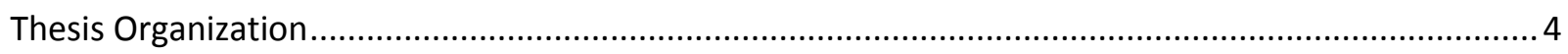

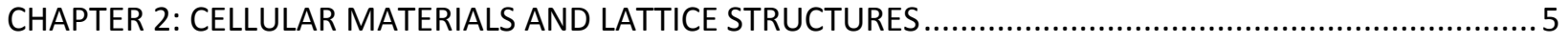

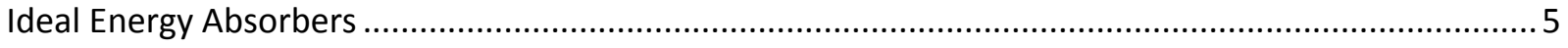

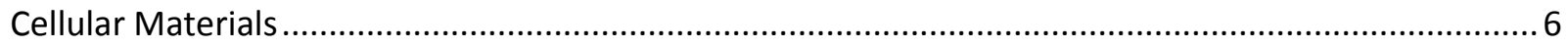

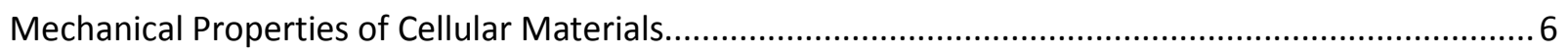

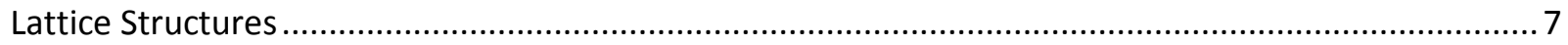

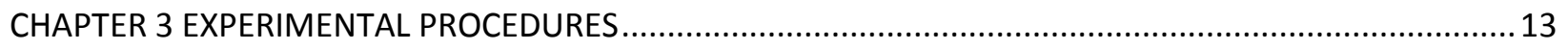

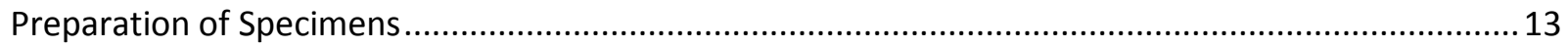

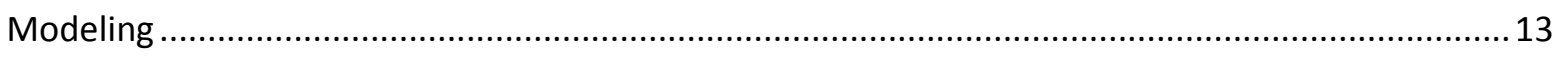

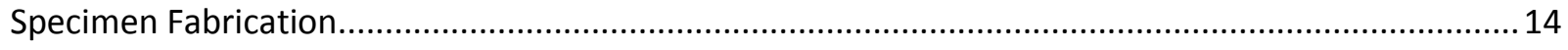

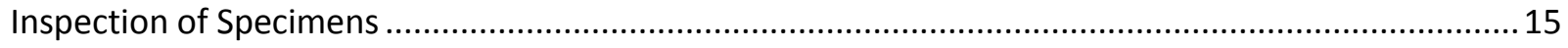

Discussion of Up Skin Parameter, Heat Tint Oxides, Surface Defects ..........................................19

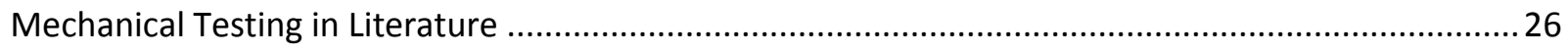

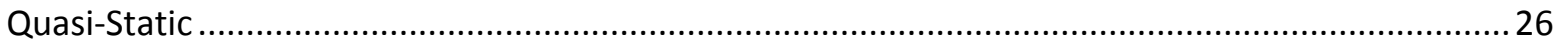

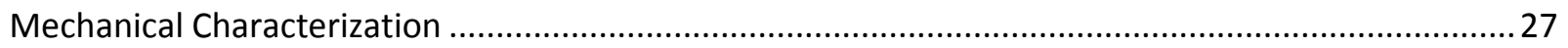




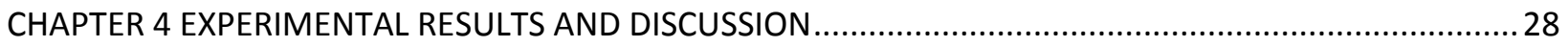

Mechanical Characterization of Unit Cells in Compression ................................................................ 28

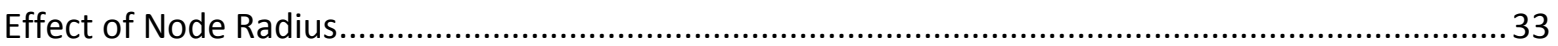

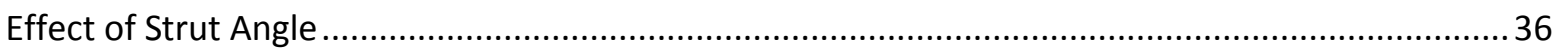

Mechanical Characterization of $3^{\wedge} 3$ BCC Lattice Structures in Compression.........................................37

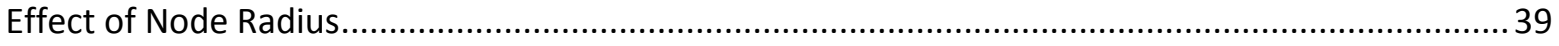

Mechanical Characterization of $3^{\wedge} 3$ BCC Upskin “OFF" Specimens .................................................. 42

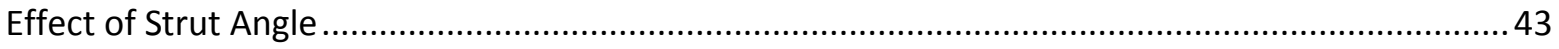

Discussion of Approximated Relative Density and Specific Values .................................................... 44

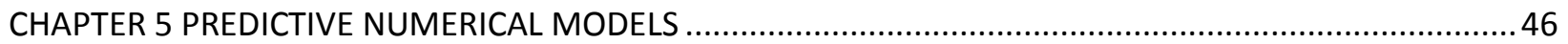

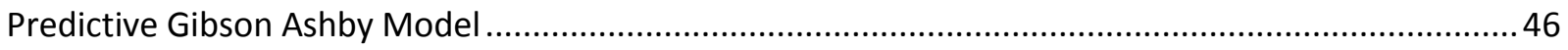

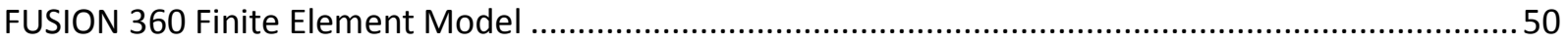

CHAPTER 6 CONCLUSIONS AND RECOMMENDATIONS FOR FUTURE WORK ........................................53

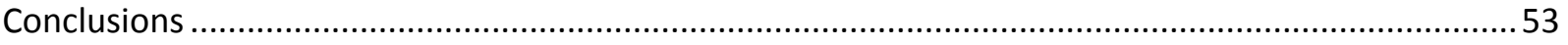

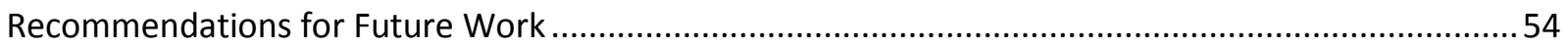

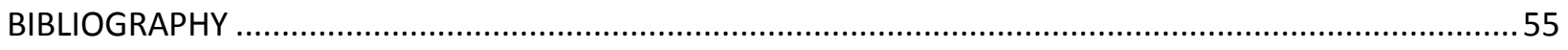

APENDIX A: UNIT CELL MODELS AND MACROSCOPIC INSPECTION OF UNIT CELLS..................................61

APPENDIX B: STRESS STRAIN CURVES AND TESTING OBESERVATIONS ................................................. 70

APPENDIX C: SPECIMEN MEASUREMENTS AND MANUFACTURING PARAMETERS …............................. 75 


\section{LIST OF TABLES}

Page

Table 1: Unit Cell Specimen Measurements and Dimensional Deviations

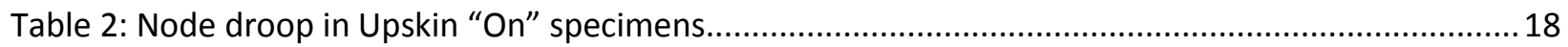

Table 3: Heat tint colors and temperatures for 316L Stainless Steel ..................................................22

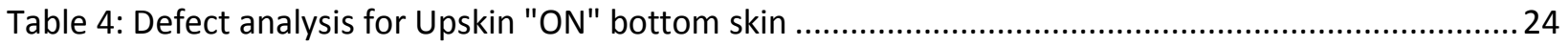

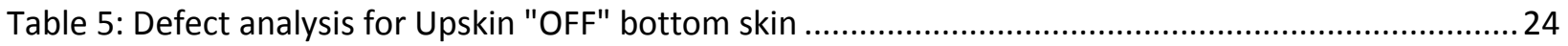

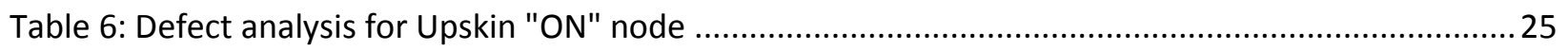

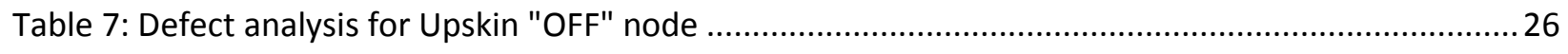

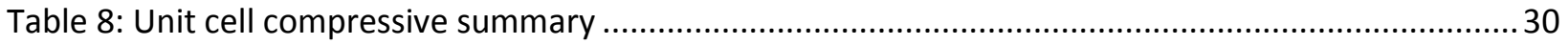

Table 9 : Approximate relative density and specific values based on theortical mass.............................45

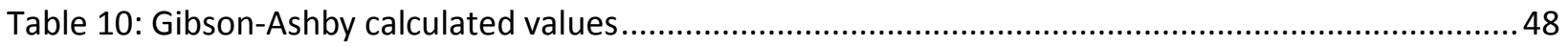

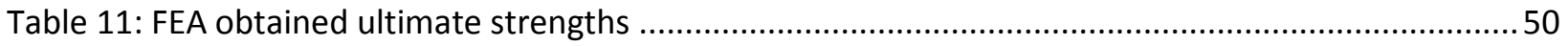




\section{LIST OF FIGURES}

Page

Figure 1: Typical Selective Laser Melting System (Tsopanos et al., 2010) 3

Figure 2: Typical ideal energy absorber stress strain curve (Evans et al., 2010) ...................................... 5

Figure 3: Two different typical lattice structure geometries built using selective laser melting ................ 7

Figure 4: (a) Unconstrained BCC Unit Cell, (b) Constrained Unit Cell, (c) Constrained Lattice................... 13

Figure 5: Grooved aluminum fixture for support removal on $5 \mathrm{~mm}$ unit cells....................................... 14

Figure 6: Arrows indicating the location of measurements taken with precision calipers, with

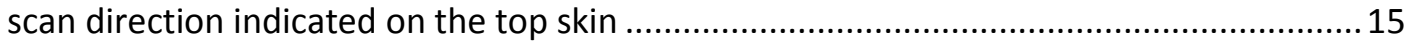

Figure 7: Nominal Overlay on $\{1 \mathrm{BCC}\} 1,25$ displaying droop above and below the node ....................... 16

Figure 8 : Illustration of the layered melt process of SLM manufacturing (Yan et al., 2014) ................... 19

Figure 9: Poor morphological properties of $\{1 \mathrm{BCC}\} 1,25$ Upskin "OFF" specimen..................................2 20

Figure 10: \{3BCC\}3 Compressive Response Upskin "ON" and Upskin "OFF"........................................21

Figure 11: Heat tint colors on top surfaces of unit cell specimens ......................................................22

Figure 12: 273X magnified images showing non-melted particles on surfaces.....................................23

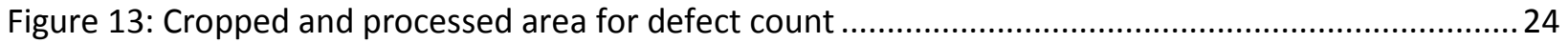

Figure 14: Non-melted particles on bottom skin of Upskin "OFF" specimen (left), Cropped and processed area for defect count (right)

Figure 15: Non-melted particles on unit cell node of Upskin "ON" specimen (left), Cropped and processed area for defect coun (right) 25

Figure 16: Non-melted particles on unit cell node of Upskin "OFF" specimen (left), Cropped and processed area for defect count (right)

Figure 17: Compressive response of BCC unit cells. $\{1 \mathrm{BCC}\} 1,25$

$,\{1 \mathrm{BCC}\} 1,0,6.25,12.5,18.75$, 29 
Figure 18: BCC unit cell initial and secondary ultimate compressive stress comparison.......

Figure 19: BCC unit cell compressive modulus of elasticity (MPa)

Figure 20: Plastic hinge locations on collapsed 45 degree BCC unit cells ranging from $0 \%$ radius

(far left) to $25 \%$ radius (far right) 33

Figure 21: $\{1 \mathrm{BCC}\} 1$ at increasing values of strain ....... 34

Figure 22: Compressive stress - strain response of $\{1 \mathrm{BCC}\} 1$ 34

Figure 23: $\{1 \mathrm{BCC}\} 1,25$ at increasing values of strain ...... 35

Figure 24: Compressive stress - strain response of $\{1 \mathrm{BCC}\} 1,25$ 35

Figure 25: Deformation of $1 \mathrm{BCC} 1,0.862,0.862,1.232$ at various values of strain 37

Figure 26: Compressive stress - strain curve for $1 \mathrm{BCC} 1,0.862,0.862,1.232$ with fracture

(circled) 37

Figure 27: Compressive stress - strain response of $3^{\wedge} 3 \mathrm{BCC}$ lattice specimens 38

Figure 28: Comparison between 55 degree $0 \%$ radius unit cell specimens and $3^{\wedge} 3$ lattice 39

Figure 29: $\{3 \mathrm{BCC}\} 3$ lattice specimen at increasing values of strain. 40

Figure 30: $\{3 \mathrm{BCC}\} 3,25$ specimen at increasing values of strain

Figure 31: Stress - strain curves for Upskin "OFF" Specimens ranging from 0\% radius to $18.75 \%$

radius

Figure 32 : Upskin "OFF" lattice structure specimens at 0.25 strain 43

Figure 33: 3BCC3,0.862, 0.862, 1.232 at increasing values of strain with unstable buckling

failure mode circled .44

Figure 34: Compressive Stress - Strain curve for $3^{\wedge} 355$ degree lattice specimen 44

Figure 35: Gibson-Ashby formulas for estimating compressive modulus and compressive strength of open cell metallic foams 46

Figure 36: Comparison of numerical and experimentally obtained values of compressive strength 48 
Figure 37: Comparison of numerical and experimentally obtained values of compressive

modulus

Figure 38: Comparison of FEA obtained strength and experimentally obtained strength 51

Figure 39: $\{1 \mathrm{BCC}\} 1$ and $\{1 \mathrm{BCC}\} 1,25$ with yield points at the nodes circled ............ 51

Figure $40:\{3 B C C\} 3$ and $\{3 B C C\} 3,25$ with yield locations at the bottom microstrut nodes of the centermost unit cell circled. .52 


\section{CHAPTER 1 INTRODUCTION}

\section{Background}

In recent years, the manufacturing of metallic lattice structures has become increasingly feasible with improvements in additive manufacturing technologies such as electron beam melting, selective laser sintering, and selective laser melting. Depending on the unit cell topology, lattice structures can exhibit ideal energy absorbing mechanical properties which may be useful for aerospace, automotive, and military applications.

Lattice structures are classified as a metamaterial. Bonatti (Bonatti \& Mohr, 2017) discusses metamaterials as being defined by 3 distinct sub-structures in the following scales: macroscopic, mesoscopic, and microscopic. Macroscopic mechanical properties view the material as a homogenous solid. Mesoscopic properties view the material as a two phase material containing a porous structure consisting of unit cells and a fluid phase such as air or water. Finally, microscopic properties view the material as a heterogenous material where occurrences such as grain boundaries and crystal structures are considered.

\section{Applications of lattice structures for energy absorption}

The mechanical properties of lattice structures lend them well to multi-functional applications which combine properties such as strength and thermal conductivity. In addition, lattice structures outperform polymer energy absorbing structures at high temperatures. (Deshpande, Fleck, \& Ashby, 2001) Aerospace applications include sandwich panels in impact prone areas such as the leading edges of wings or the bottom of fuselages. Jet turbine housings need to contain the extreme forces of blade off events. Satellites need lightweight ballistic impact protection from high velocity micrometeorites. Military applications include lightweight ballistic protection for armored vehicles and soldiers. (Rashed, Ashraf, Mines, \& Hazell, 2016) 
Lattice structures can be used in any application where an energy absorber is demanded, but the maximum plateau stress provided by the material needs to be higher than provided by polymers or honeycomb.

\section{Purpose}

This study was initialized with the intention of investigating the use of selectively laser melted lattice structures for use as lightweight structural armor on satellites, soldiers, and vehicles. Before lattice structures are tested for their ballistic resistance however, the mechanical properties and failure modes of primitive lattice unit cells must be understood. Therefore the purpose of this study is to determine and analyze the mesoscopic properties of the body centered cubic lattice structure. The meso-strucure determines the mechanical properties of the macrostructure. By understanding the mesoscopic level mechanical properties, the macroscopic mechanical properties of lattice structures can be further understood and optimized.

\section{Selective Laser Melting}

Selective laser melting is an additive manufacturing process which allows for the construction of extremely intricate geometry which is impossible by standard manufacturing processes. A typical selective laser melting process is shown in figure 1. Also known as SLM, the process uses a highperformance fiber laser to sequentially melt and rapidly cool layers of powdered metal together to form a 3D shape. Resolution of selective laser melting is approaching the micrometer scale. (Rashed et al., 2016) Because of its excellent resolution, and capability to manufacture trapped features, SLM can produce fine metallic lattice structures with struts approximately $150 \mu \mathrm{m}$ in diameter. (Tsopanos et al., 2010) Despite the incredible capabilities of the SLM process, several significant drawbacks must be considered. High cost associated with powdered metals, long build times, limited part sizes, and high part defect content are the four main drawbacks. A typical SLM system is shown in figure 1. 


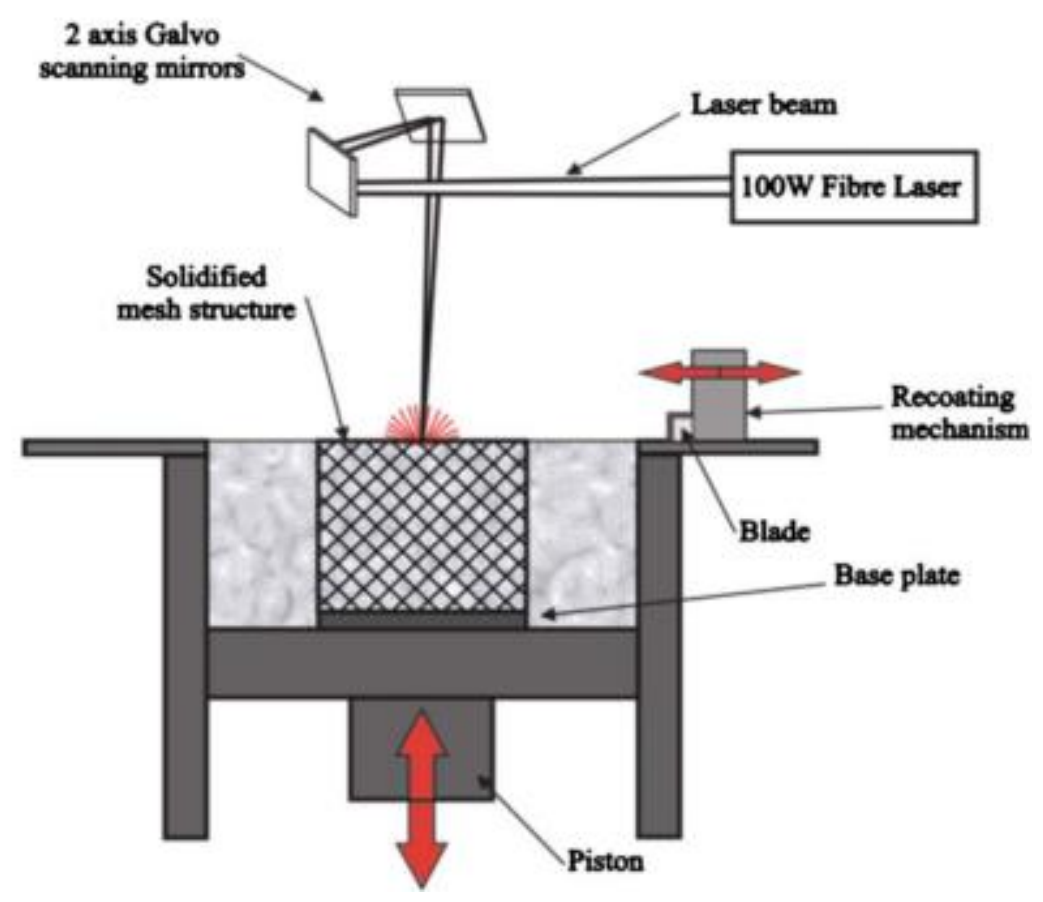

Figure 1: Typical Selective Laser Melting System (Tsopanos et al., 2010)

3 main defects commonly occur during SLM manufacturing. Non-melted metal particles bonded to surfaces reduce the surface finish quality, this can be improved with light sand blasting or heat treatment. Internal residual stresses resulting from uneven heating can cause cracks in the final part, this can be improved with heat treatment and temperature control during the build. Porosity is the result of the process itself, and can be improved with proper build parameters, but cannot be avoided all together. Another notable limitation of the SLM process is the inability to create horizontal struts. 25 degrees from the horizontal is typically considered limit of manufacturability. (Tsopanos et al., 2010) Tsopanos (Tsopanos et al., 2010) discusses the effects of processing parameters on stainless steel SLM parts. Laser power and laser exposure time are the 2 main parameters that control the resultant mechanical properties of a SLM part. Layer thickness and energy distribution are the 2 secondary parameters. Each parameter needs to be carefully selected in order to properly build a part. Tsopanos 
observed that low laser power allowed for the inclusion of non-melted metal particles within samples and resulted in low strength parts. High laser power resulted in nearly full density of the samples and much higher strength. The higher laser power resulted in samples that approached the bulk properties of the stainless steel.

\section{Thesis Organization}

Chapter 2 introduces the concept of ideal energy absorbing materials and discusses materials which can provide such mechanical properties. Chapter 3 discusses the experimental procedures useful in the study of lattice structures and outlines the preparation and parameters for of a series of compression tests performed for this study. Chapter 4 covers the results of the compression tests and discusses the

failure modes observed. Chapter 5 covers the development of a predictive numerical model for the properties of the structures tested. Chapter 6 summarizes the main findings of this study and recommends a course for future study. 


\section{CHAPTER 2: CELLULAR MATERIALS AND LATTICE STRUCTURES}

\section{Ideal energy absorbers}

Ideal energy absorbing materials are used in applications where impact loading and/ or deceleration of an object cannot exceed a specified value. The stress strain curve of these materials is rectilinear, as can be seen in figure 2 below. Upon impact loading the stress within an ideal energy absorber is immediately at the maximum and stays constant until the impulse ceases or the material densifies. This stress is commonly referred to as a plateau stress $\sigma_{p l}$, which results in constant deceleration of the impactor.

The area under the stress strain curve is the amount of energy absorbed during deformation of the material, thus the rectilinear curve as seen in figure 2 maximizes the energy absorbed. Throughout this study, the stress strain curves of the materials tested will be discussed in comparison to ideal energy absorbers.

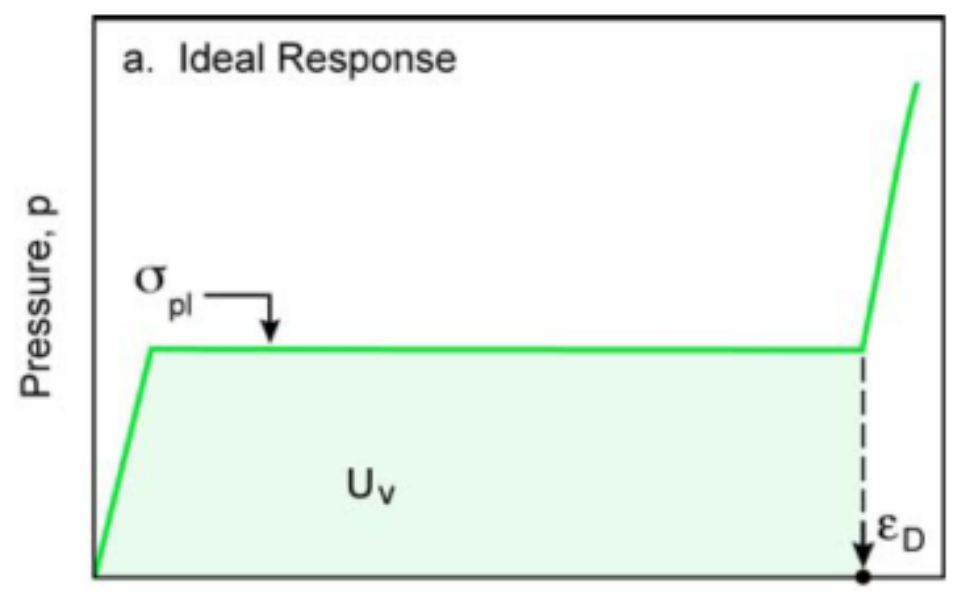

Figure 2: Typical ideal energy absorber stress strain curve (Evans et al., 2010)

Only some materials and structures exhibit this type of behavior. The most common ideal energy absorbing materials are cellular materials, which are discussed in detail in the next section. 


\section{Cellular materials}

Cellular materials commonly exhibit ideal energy absorbing properties and are therefore widely used in applications requiring impact protection.

A cellular material is composed of many repeating unit cells and are separated into two classifications, stochastic foams and periodic porous structures. (Fleck, Deshpande, \& Ashby, 2010)

Stochastic foams are characterized by unit cells where the specific topology cannot be precisely controlled and results in a randomized, heterogenous structure. Periodic porous structures are classified by the ability to control the design of the unit cell and have a precisely controlled homogenous structure. Cellular materials typically provide low weight, high specific stiffness, and excellent energy absorbing properties. (Wadley et al., 2013)

Lattice structures fall within the category of periodic porous structures.

\section{Mechanical properties of cellular materials}

The mechanical properties of stochastic foam structures are bending dominated while many lattice structures are stretching dominated. Stretching dominated structures are typically mechanically superior. (Fleck et al., 2010)

Baumeister discusses energy absorption of stochastic aluminum foams. Baumeister states that, "Compared to foamed organic materials, metallic foams are more advantageous if, due to a small available design space, a higher deformation stress with the same or uprated energy absorption is requested." (Baumeister, Banhart, \& Weber, 1997)

The mechanical properties of aluminum foams is dependent on the mechanical properties of the base material or matrix, the density, the unit cell size, and the unit cell shape. By controlling these 
parameters, aluminum foams can be optimized for specific applications. The ability to control the stress and resultant acceleration of an impacting body such that no damages occur to the protected object is feasible via the ideal plastic deformation provided by aluminum foams.

\section{Lattice structures}

Similar to aluminum foams, the ability to control the resultant deceleration of an impacting body is also feasible via selectively laser melted lattice structures. These structures offer complete control over the properties of the cellular material. Using software such as nTopology ${ }^{\circledR}$, the topology of the unit cells of a lattice structure can be precisely controlled. By modifying the topology, the stiffness, strength, density, energy absorption, and failure modes can all be modified and optimized to meet requirements demanded by a specific application. This optimization potential is what makes lattice structures attractive for applications requiring highly specific material properties. An example of a typical lattice structure can be seen in figure 3 below.

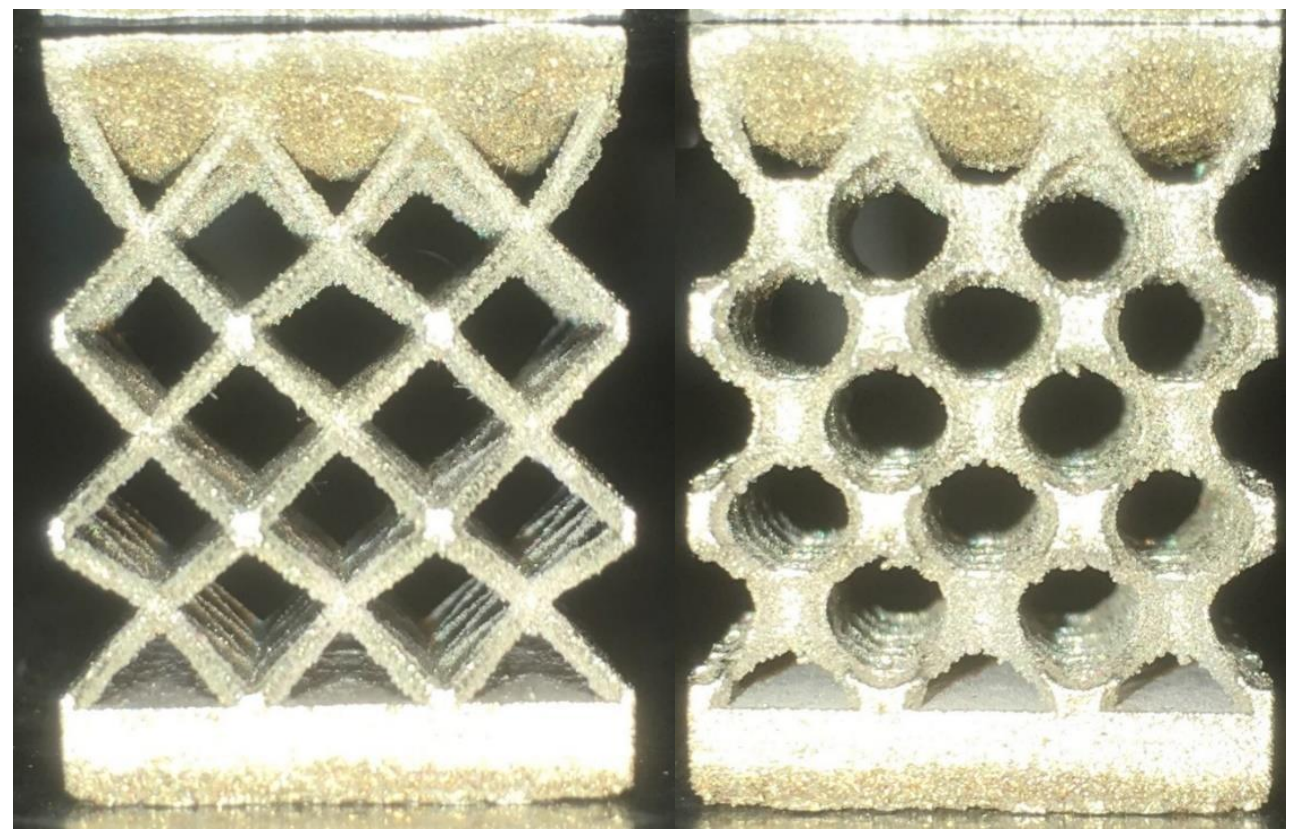

Figure 3: Two different typical lattice structure geometries built using selective laser melting 
Lattice structures can potentially act as ideal energy absorbers with proper topology design. Many lattice structures exhibit a stable collapse mechanism, caused by the progressive failure of unit cells. The unit cell topology determines the collapse mechanism of the macrostructure, thus unit cells with vertical members such as the face centered cubic-Z (FCC-Z) have complex collapse mechanisms where buckling dominates the failure. (Xiong et al., 2015) Even more complex is the addition of hollow vertical members, where thin walled buckling of the tubes dominates the failure. (Evans et al., 2010) Bonatti investigates four different meso-structures: solid octet truss, hollow sphere assembly, hollow octet truss, hybrid truss sphere. (Bonatti \& Mohr, 2017) Bonatti performed finite element analysis using Abaqus $^{\circledast} /$ Explicit solver to estimate small strain elastic modulus, large strain response, as well as determine specific energy absorption. In order to verify numerical models, experiments were performed on selectively laser melted 316 stainless steel lattice. The numerical models correlated well to the experiments, with the simulated response demonstrating higher stresses than experimental results. Bonatti concluded that the solid octet truss lattice has a $35 \%$ lower specific energy absorption than the hybrid truss sphere. The hollow dodecahedron shell mesostructure was computationally measured to have higher energy absorption capability than the other structures considered.

Deshpande (Deshpande et al., 2001) investigates the properties of the octet-truss unit cell. A FE model was compared against analytical calculations, where each cylindrical strut was modelled using Timoshenko beam elements (B32) in Abaqus ${ }^{\circledR} /$ Explicit Solver. Experiments were conducted on casted aluminum alloy and showed good correlation with numerical predictions, however experimental results showed lower strength than predicted. The strength and stiffness of the octet truss lattice structure can be compared to that of aluminum foams. It is worth noting that Deshpande was the first to focus specifically on the mechanical properties of the octet truss lattice unit cell, and his work was prior to the widespread use of selective laser melting technology. 
Dong (Dong, Deshpande, \& Wadley, 2015) investigated the mechanical properties of a snap-fit Ti-6Al-4V octet truss lattice constructed from water jet cut 2D pieces. Lower density lattices of this construction failed in compression via plastic buckling while higher density lattices failed via inelastic buckling. Dong expands on Deshpande's work and uses the assumptions and models previously found. (Deshpande et al., 2001)

Harris (Harris, Winter, \& McShane, 2017) used maraging steel Hopkinson bars to experimentally investigate the dynamic properties of selectively laser melted stainless steel square honeycomb, hybrid truss walled square honeycomb, and hybrid fine truss walled square honeycomb. A gas gun apparatus was used and specimens were tested with a cylindrical $100 \mathrm{~g}$ steel projectile at velocities of 50,100, and $150 \mathrm{~m} / \mathrm{s}$. Square honeycomb outperformed the lattice walled specimens in both energy absorption capacity and energy absorption efficiency, with the exception of truss walled square honeycomb at $100 \mathrm{~m} / \mathrm{s}$, which demonstrated a higher energy absorption efficiency. The fine truss walled honeycomb is hypothesized to have underperformed due to defects. It had features which approached the size of the laser spot, and thus approached the manufacturing process limitations.

Maskery (Maskery et al., 2016) introduces the concept of density graded lattice structures and performs quasi-static load testing to determine their mechanical properties. The benefits of heat treatment of selectively laser melted structures is confirmed by a higher failure strain in dog bone specimens, as well as by lattice structures which were able to retain strength after a partial collapse. Density graded body centered cubic lattice exhibited more stable collapse mechanism than uniform density, the 45 degree shear band which occurs in uniform density body centered cubic structures in compression did not appear, allowing for layer by layer collapse.

Xiao focuses on uniform, and density graded open cell rhombic dodecahedron lattice structures manufactured by electron beam melting (Xiao et al., 2016), and selectively laser melted Ti-6Al-4V. (Xiao 
\& Song, 2017) He performs static and dynamic testing on samples to determine their mechanical properties. He determined that density graded structures have higher specific energy absorption and higher specific strength than uniform density. DIC analysis reveals that the strain during impact is uniformly distributed and that the strain rate sensitivity is not associated with a shock wave. Xiao thus concluded that the strain rate sensitivity of the lattice structure was dominated by the properties of the base material.

Vrana (Vrana, Koutny, \& Palousek, 2016) tested the impact resistance of selectively laser melted lattice structures with several different unit cells. The mesostructures tested were BCC, BCC-Z, FCC, FBCC, FBCC-Z, Gyroid.

Rashed (Rashed et al., 2016) summarizes previous works into a usable guide for the mechanical properties of metallic lattice structures, and discusses applications, topology, experiments, simulations, and materials.

Gümrük (Gümrük, Mines, \& Karadeniz, 2013) performed quasi-static compression testing on BCC, BCCZ, and F2BCC selectively laser melted stainless steel lattice. One test was an unconstrained compression test using the flat platens of an Instron ${ }^{\circledR}$ machine, another was constrained, and the last was for pure shear using an Arcan rig. Findings include that the BCCZ lattice outperformed the others for compression and was unaffected by boundary constraints. The BCC lattice was heavily influenced by boundary constraints.

A significant challenge in the study of lattice structures is defining a nomenclature which effectively describes the mesostructure as well as the macrostructure. Tsopanos (Tsopanos et al., 2010) suggests a nomenclature for SLM manufactured lattice structures as follows:

architecture/parent material/laser power(W)/exposure time(s)/strut diameter $(\mathrm{m}) /$ cell size $(\mathrm{mm}) / \mathrm{unit}$ cell 
In this study, the various specimens can be identified by the nomenclature suggested by Tsopanos as follows:

Body Centered Cubic/ 316L SS / 100 - 400W Depending on Contour / $185-800$ mm/s Depending on Contour $/$ Strut Diameter $=0.2 \mathrm{~mm} /$ Cell Size $=5 \mathrm{~mm}^{3} /$ Node Radius $=0 \%-25 \%$

Due to the lengthy nature of this nomenclature system, it will not be used in this study.

Perhaps the most in depth guide for lattice nomenclature is provided by Frank Zok (Frank W. Zok, Ryan M. Latture, 2011), who develops an entire language allowing for the complete description of a lattice structure in a standardized numerical format.

Per Zok's nomenclature, the specimens in this study can be identified. The 45 degree non-radiused lattice specimens can be identified as $\{3 B C C\}^{3}$, while the 55 degree non-radiused lattice specimens can be identified as $\{3 B C C\}^{3},\langle 0.862,0.862,1.232\rangle$. This indicates that the lattice has 3 layers extending in 3 directions. The numbers following the 55 degree lattice specification indicate the stretch ratio in each of the 3 dimensions of $X, Y$, and $Z$ respectively. This nomenclature system does not currently account for variations in the design of the nodal connections, and thus cannot accurately describe a node radius. Furthermore, Zok's nomenclature does not account for strut cross section. In this study, Zok's nomenclature system will be used with the addition of an operator for node radius, specified by $\|r\|$, where $r$ denotes a node radius defined by a radius representing a $\%$ of the unit cell. For example, a $25 \%$ node radius of a $10 \mathrm{~mm}^{3}$ unit cell will be $2.5 \mathrm{~mm}$. Multiplying the unit cell dimension by a percentage gives the radius dimension. In this study, all strut diameters are $0.5 \mathrm{~mm}$. 
For example, $\{3 B C C\}^{3},\|25\|$ indicates a body centered cubic unit cell, 3 layers across in 3 dimensions, with a $25 \%$ node radius. Per Zok's definition,

Here the superscript (3) on \{ \}.. . indicates the number of directions in which the trusses are tiled in space and the numerical value within the \{\}$.$. brackets indicates the number of unit cells in each direction. (Frank W. Zok, Ryan M. Latture, 2011, p. 188) 


\section{CHAPTER 3 EXPERIMENTAL PROCEDURES}

\section{Preparation of Specimens}

\section{Modeling}

Specimens were modeled within a $5 \mathrm{~mm}$ cubic unit cell, connecting each corner with a circular cross section strut of diameter $0.5 \mathrm{~mm}$. Node radius was defined in five increments representing percentages of the unit cell. For example, a node radius of $12.5 \%$ represents a fillet of $0.625 \mathrm{~mm}$ within a $5 \mathrm{~mm}$ cubic cell. Strut angles were defined as projected angles from the horizontal plane. The 55 degree specimens were modelled to maintain the same strut length as the 45 degree specimens. All specimens were modelled with a skin on both top and bottom to constrain the unit cell. 45 degree specimens were built with a $2.5 \mathrm{~mm}$ skin top and bottom. 55 degree specimens were built with $1 \mathrm{~mm}$ skin on top and $2.5 \mathrm{~mm}$ skin on bottom. Examples of the modeled specimens can be seen in figure 4 .

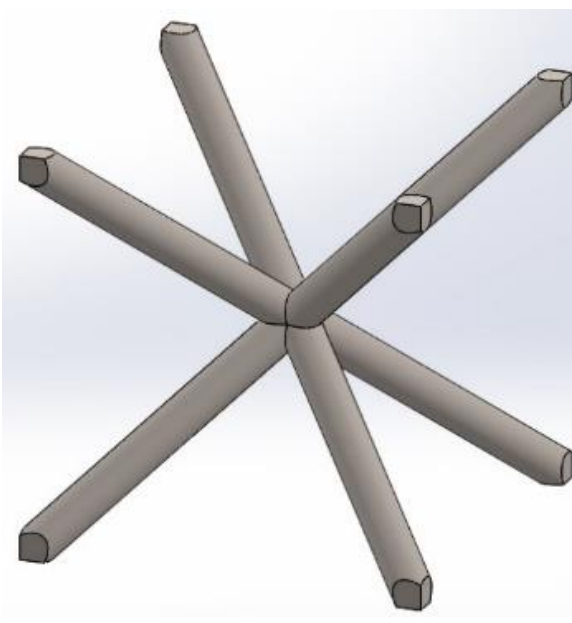

(a)

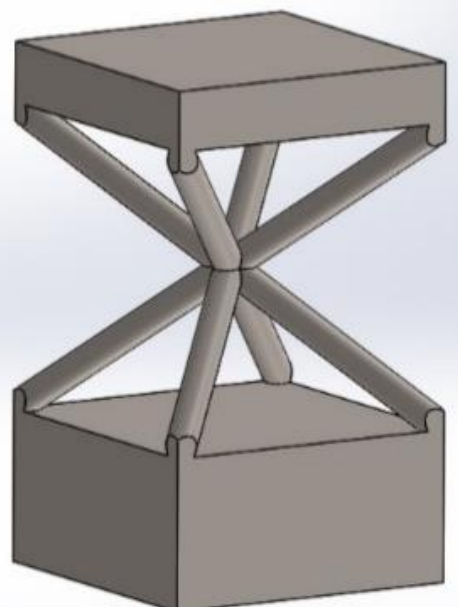

(b)

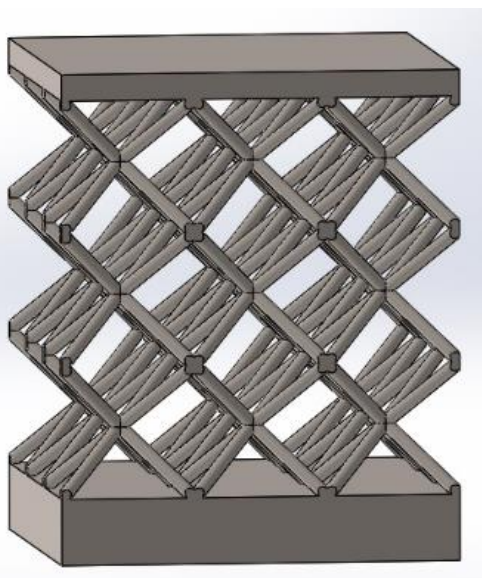

(c)

Figure 4: (a) Unconstrained BCC Unit Cell, (b) Constrained Unit Cell, (c) Constrained Lattice 


\section{Specimen Fabrication}

All specimens were manufactured using an SLM machine from SLM Solutions, model 125. The machine utilizes a singular $400 \mathrm{~W} \mathrm{Yb}$ fiber laser with a minimum beam focus diameter of $60 \mu \mathrm{m}$. The machine builds with a layer thickness ranging from $20 \mu \mathrm{m}-75 \mu \mathrm{m}$.

The detailed parameters used to build the test specimens can be seen in $\underline{A p p e n d i x ~} \mathrm{C}$.

The specimens were removed from the build plate with a band saw, and then support material was ground flat using a series of abrasive operations. Removing support material from such small parts was a significant challenge. To effectively hold the small specimens during grinding operations, a grooved aluminum fixture was machined to hold the parts on three sides via a $5 \mathrm{~mm}$ deep by $5 \mathrm{~mm}$ wide groove as seen in figure 5. This fixture allowed for the skins above and below the unit cell to be ground flat for compression testing. There exists scope for an improved method of support material removal beyond the extremely costly current option of wire electrical discharge machining.

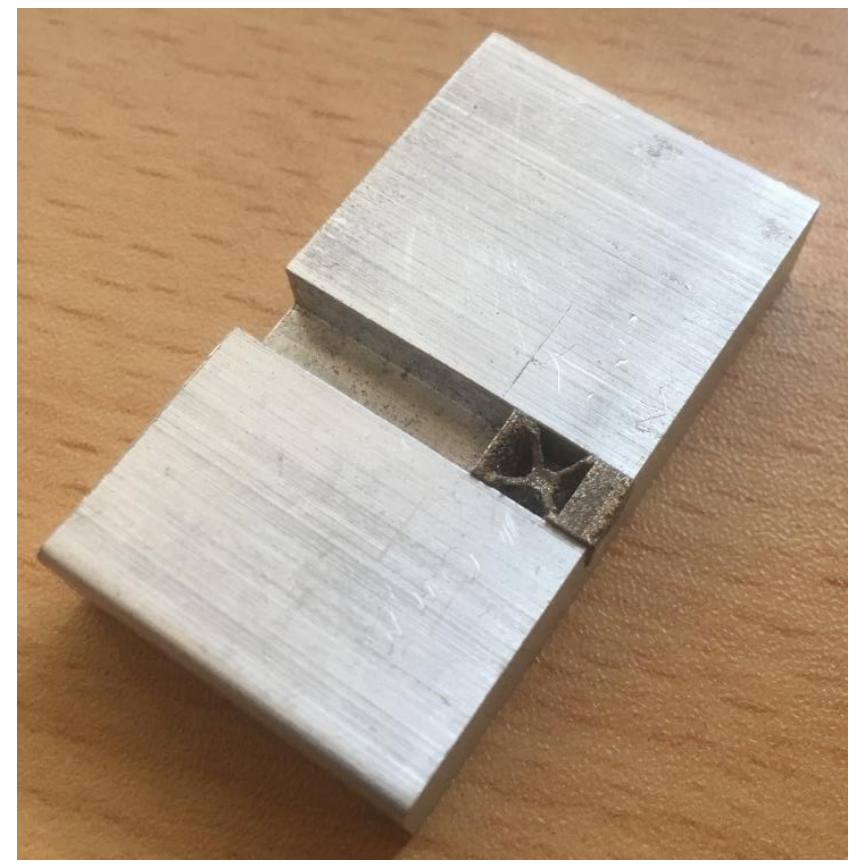

Figure 5: Grooved aluminum fixture for support removal on $5 \mathrm{~mm}$ unit cells 


\section{Inspection of Specimens}

Specimens were measured using $0.01 \mathrm{~mm}$ precision calipers of the overall specimen height, lattice height, lattice width, and lattice length. Locations of measurements can be seen in figure 6 . Lattice length was measured in the direction of the scan, while lattice width was measured perpendicular to the scan. Lattice length (L) and width (W) were defined as the dimensions at the top of the lattice. Lattice height $(\mathrm{H})$ was measured from the top of the bottom skin to the bottom of the top skin as close as possible to the lattice legs. These measurements can be found in Table 1 and Appendix C.

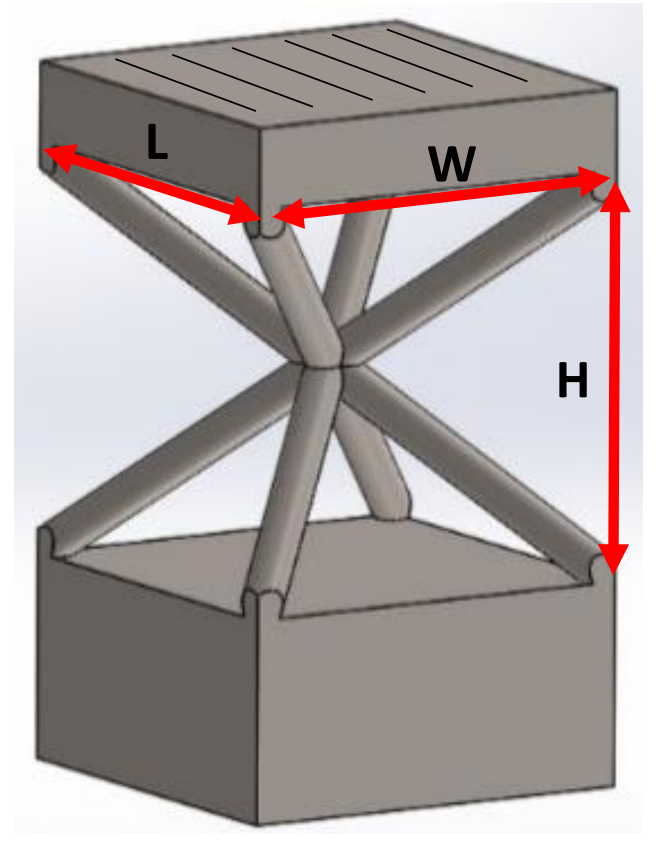

Figure 6: Arrows indicating the location of measurements taken with precision calipers, with scan direction indicated on the top skin

All unit cell specimens were inspected on a MicroVu macroscope at 25X and 100X magnification. Profiles of these specimens were compared to the nominal geometry as seen in figure 7 and Appendix A. It is of interest to determine the average dimensional deviation from the nominal dimensions in order to develop a guideline to compensate for shrinkage and droop on unsupported geometry. Percent deviations from nominal values were determined for each of the 6 unit cell topologies and averaged as 
can be found in Table 1. These values only apply when the UpSkin parameter is enabled, and the manufacturing parameters listed in Appendix $\mathrm{C}$ are adhered to. In a preliminary test, it was found that specimens fabricated without this parameter enabled displayed extremely poor morphological and mechanical properties. The Upskin parameter is discussed in the next section.

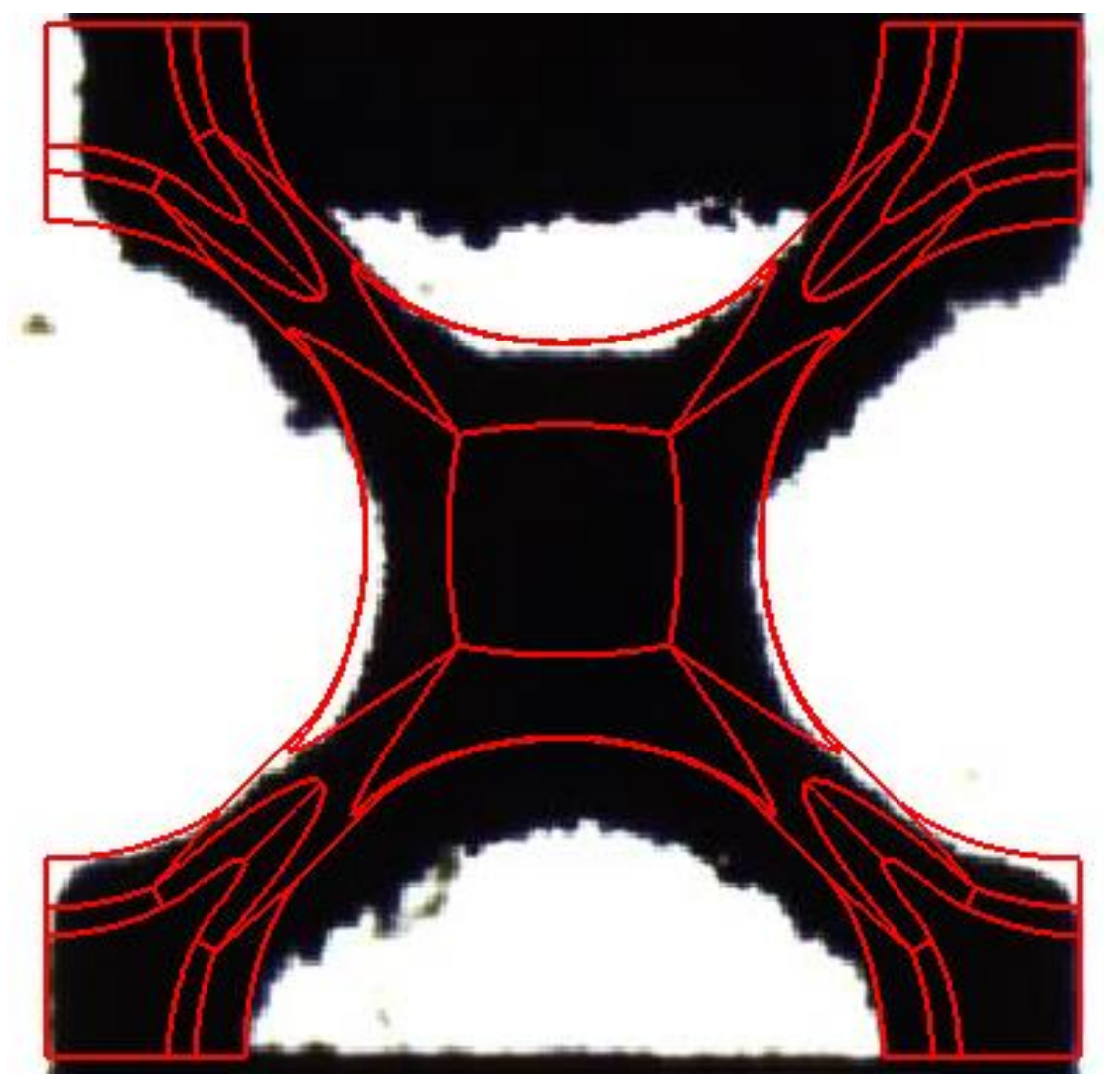

Figure 7: Nominal Overlay on $\{1 B C C\}^{1},\|25\|$ displaying droop above and below the node

Deviation percentages were calculated by dividing the measured geometry by the nominal geometry and converting to a percent difference. 
Table 1: Unit Cell Specimen Measurements and Dimensional Deviations

\begin{tabular}{|c|c|c|c|c|c|c|}
\hline Specimen ID \# & $\begin{array}{c}\text { Lattice } \\
\text { Height }\end{array}$ & $\begin{array}{c}\text { Lattice } \\
\text { Width }\end{array}$ & $\begin{array}{c}\text { Lattice } \\
\text { Length }\end{array}$ & $\begin{array}{c}\% \\
\text { Deviation } \\
\text { Height }\end{array}$ & $\begin{array}{c}\% \\
\text { Deviation } \\
\text { Width }\end{array}$ & $\begin{array}{c}\% \\
\text { Deviation } \\
\text { Length }\end{array}$ \\
\hline$\{1 B C C\}^{1}$ & 4.6 & 4.8 & 4.71 & $8.00 \%$ & $4.00 \%$ & $5.80 \%$ \\
\hline$\{1 B C C\}^{1}$ & 4.5 & 4.66 & 4.72 & $10.00 \%$ & $6.80 \%$ & $5.60 \%$ \\
\hline$\{1 B C C\}^{1},\|6.25\|$ & 4.51 & 4.82 & 4.63 & $9.80 \%$ & $3.60 \%$ & $7.40 \%$ \\
\hline$\{1 B C C\}^{1},\|6.25\|$ & 4.54 & 4.87 & 4.58 & $9.20 \%$ & $2.60 \%$ & $8.40 \%$ \\
\hline$\{1 B C C\}^{1},\|12.5\|$ & 4.62 & 4.83 & 4.54 & $7.60 \%$ & $3.40 \%$ & $9.20 \%$ \\
\hline$\{1 B C C\}^{1},\|12.5\|$ & 4.62 & 4.89 & 4.8 & $7.60 \%$ & $2.20 \%$ & $4.00 \%$ \\
\hline$\{1 B C C\}^{1},\|12.5\|$ & 4.62 & 4.86 & 4.72 & $7.60 \%$ & $2.80 \%$ & $5.60 \%$ \\
\hline$\{1 B C C\}^{1},\|18.75\|$ & 4.61 & 4.89 & 4.83 & $7.80 \%$ & $2.20 \%$ & $3.40 \%$ \\
\hline$\{1 B C C\}^{1},\|18.75\|$ & 4.69 & 4.85 & 4.8 & $6.20 \%$ & $3.00 \%$ & $4.00 \%$ \\
\hline$\{1 B C C\}^{1},\|18.75\|$ & 4.64 & 4.9 & 4.88 & $7.20 \%$ & $2.00 \%$ & $2.40 \%$ \\
\hline$\{1 B C C\}^{1},\|25\|$ & 4.6 & 4.89 & 4.81 & $8.00 \%$ & $2.20 \%$ & $3.80 \%$ \\
\hline$\{1 B C C\}^{1},\|25\|$ & 4.68 & 4.89 & 4.85 & $6.40 \%$ & $2.20 \%$ & $3.00 \%$ \\
\hline$\{1 B C C\}^{1},\|25\|$ & 4.64 & 4.88 & 4.83 & $7.20 \%$ & $2.40 \%$ & $3.40 \%$ \\
\hline$\{1 B C C\}^{1},\langle 0.862,0.862,1.232\rangle$ & 5.5 & 3.98 & 3.9 & $10.57 \%$ & $7.66 \%$ & $9.51 \%$ \\
\hline$\{1 B C C\}^{1},\langle 0.862,0.862,1.232\rangle$ & 5.63 & 3.78 & 4.01 & $8.46 \%$ & $12.30 \%$ & $6.96 \%$ \\
\hline$\{1 B C C\}^{1},\langle 0.862,0.862,1.232\rangle$ & 5.57 & 3.86 & 4.06 & $9.43 \%$ & $10.44 \%$ & $5.80 \%$ \\
\hline$\{1 B C C\}^{1},\langle 0.862,0.862,1.232\rangle$ & 5.61 & 3.78 & 4.1 & $8.78 \%$ & $12.30 \%$ & $4.87 \%$ \\
\hline$\{1 B C C\}^{1},\langle 0.862,0.862,1.232\rangle$ & 5.66 & 3.9 & 4.07 & $7.97 \%$ & $9.51 \%$ & $5.57 \%$ \\
\hline $\mathbf{I - ~} \mathbf{M E A N ~ D I M E N S I O N A L ~ D E V I A T I O N} \%$ & & $\mathbf{8 . 1 1 \%}$ & $\mathbf{5 . 4 2 \%}$ & $\mathbf{4 . 9 7 \%}$ \\
\hline STANDARD DEVIATION & & $\mathbf{1 . 2 6 \%}$ & $\mathbf{3 . 6 4 \%}$ & $\mathbf{2 . 0 8 \%}$ \\
\hline
\end{tabular}

Average droop on the unsupported bottom side and top side of the unit cell nodes was measured using the nominal overlay and can be seen in Table 2 .

The $\{1 B C C\}^{1},\|25\|$ specimens exhibited the most droop on the top of the node with an average of $0.098 \mathrm{~mm}$, the $\{1 B C C\}^{1}$ specimens exhibited the most droop on the bottom of the node with an average of $0.69 \mathrm{~mm}$. 
Table 2: Node droop in Upskin "On" specimens

Bottom of Node Droop from Nominal ( $\mathrm{mm}$ )

\begin{tabular}{|l|l|l|l|l|}
\hline Node Radius \% & Specimen 1 & Specimen 2 & Specimen 3 & AVG. \\
\hline 0 & 0.72 & 0.66 & & 0.69 \\
6.25 & 0.67 & 0.61 & 0.67 & 0.65 \\
12.5 & 0.67 & 0.62 & 0.62 & 0.636667 \\
18.75 & 0.52 & 0.46 & 0.74 & 0.573333 \\
25 & 0.47 & 0.72 & 0.577 & 0.589 \\
\hline
\end{tabular}

\begin{tabular}{|l|l|}
\hline $\begin{array}{l}\text { OVERALL AVG BOTTOM } \\
(\mathrm{mm})\end{array}$ & 0.623 \\
\hline STDDEV BOTTOM $(\mathrm{mm})$ & 0.089 \\
\hline
\end{tabular}

Top of Node Droop from Nominal ( $\mathrm{mm})$

\begin{tabular}{|l|l|l|l|l|}
\hline Node Radius \% & Specimen 1 & Specimen 2 & Specimen 3 & AVG. \\
\hline 0 & 0.059 & 0.03 & & 0.0445 \\
6.25 & 0.02 & 0.072 & 0.023 & 0.038333 \\
12.5 & 0.07 & 0.08 & 0.07 & 0.073333 \\
18.75 & 0.04 & 0.094 & 0.054 & 0.062667 \\
25 & 0.12 & 0.1 & 0.074 & 0.098 \\
\hline
\end{tabular}

\begin{tabular}{|l|l|}
\hline OVERALL AVG TOP $(\mathrm{mm})$ & 0.0647 \\
\hline STDDEV TOP $(\mathrm{mm})$ & 0.0295 \\
\hline
\end{tabular}

Node droop is an important factor to consider when building and modelling unsupported lattice structures. The droop can be attributed to non-melted powders sticking to the melt pool above it, as well as the effect of gravity on the melt pool during fabrication. Another key factor which causes droop is the layered nature of the manufacturing process itself. In figure 8 below, the excess material is shown to appear above the nominal line, however in the specimens fabricated for this study, the excess material appears below the nominal line. (Yan, Hao, Hussein, Young, \& Raymont, 2014) 


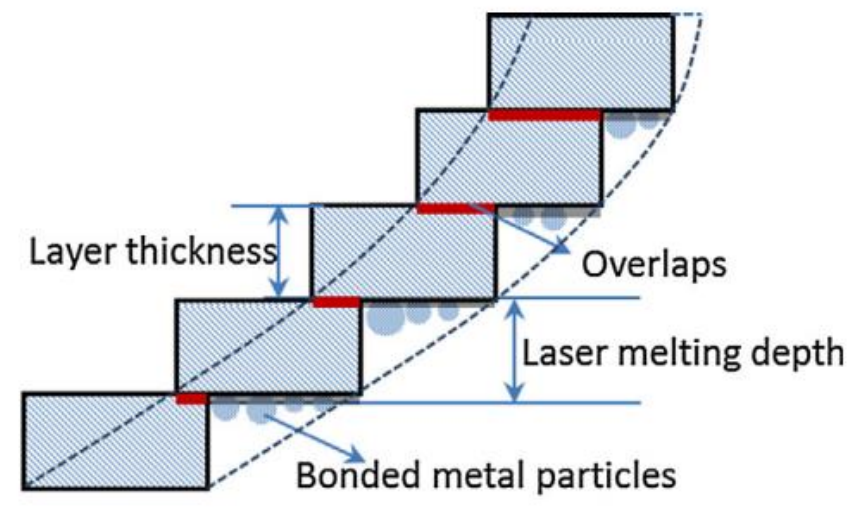

Figure 8 : Illustration of the layered melt process of SLM manufacturing (Yan et al., 2014)

\section{Discussion of Up Skin Parameter, Heat Tint Oxides, Surface Defects}

Several specimen sets were fabricated for this study, however only specimens which were fabricated with the Up Skin parameter switched "ON" are thoroughly studied for their mechanical properties. As described in the SLM user manual,

Area on a layer, above which there is no area to be exposed, is termed as Up Skin. To determine whether there is an Up Skin area present in a slice, the current slice is compared with one slice above. The offset value sets a border offset on the current slice to calculate the area difference between the current slice and the slice above. If the value is positive it indicates that there is an upside surface. Then the next volume area is changed into an In Skin area. (Materialise NV, n.d., p.125)

The Up Skin parameter enables the machine to make an additional laser pass over the part without adding additional material or moving the build platform.

Preliminary inspection of parts with Up Skin "OFF" indicated poor morphological properties as can be seen in figure 9 and Appendix B. Parts printed with Up Skin "OFF" consistently displayed geometry which did not conform to the nominal geometry. Due to the poor fabrication quality, these specimens were not tested in depth for their mechanical properties, and only inspected via macroscope. 

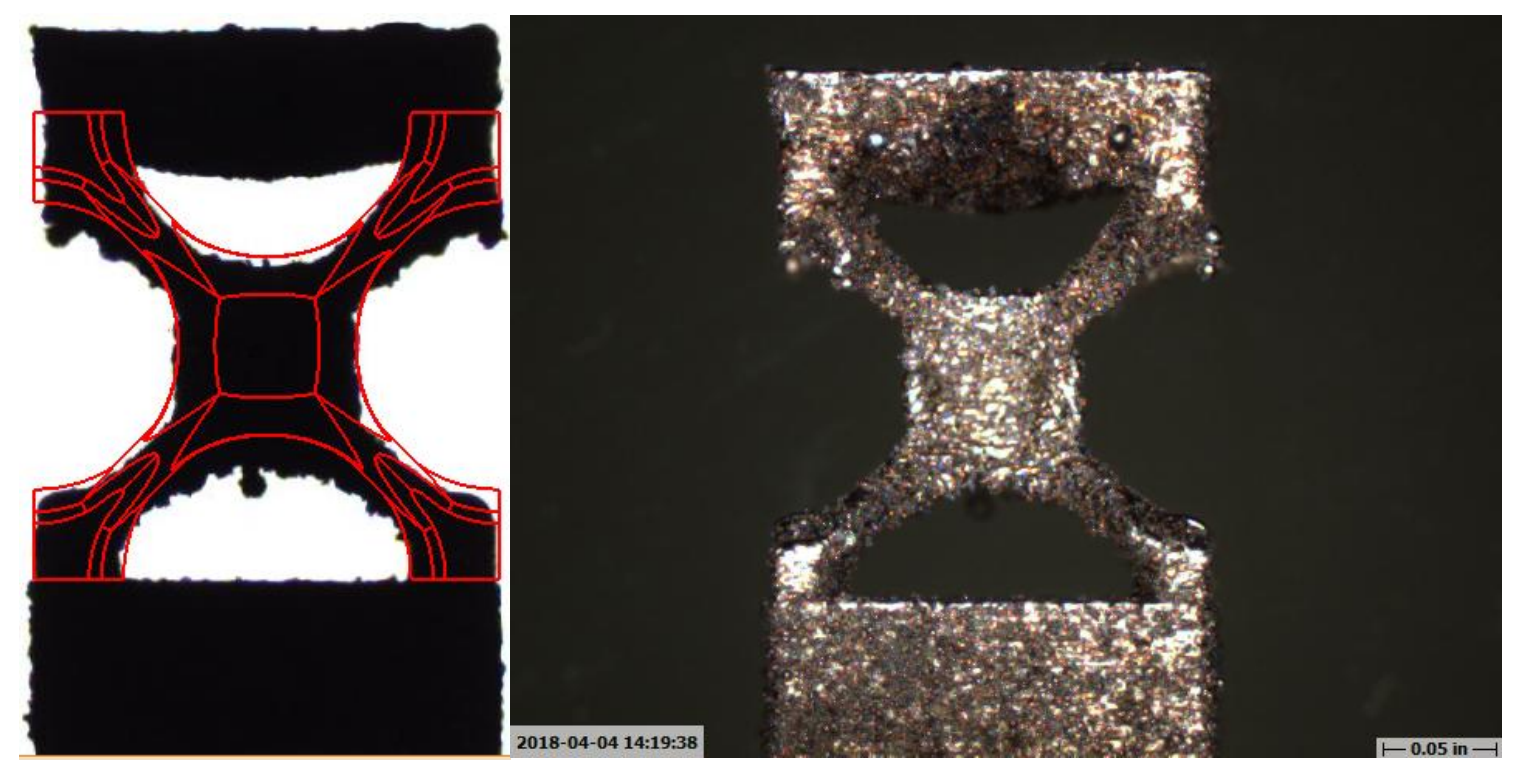

Figure 9: Poor morphological properties of $\{1 B C C\}^{1},\|25\|$ Upskin "OFF" specimen

Preliminary compression tests on parts with Upskin "OFF" displayed an ultimate stress $46 \%$ lower than parts with Upskin "ON". The difference in compressive strength is clearly displayed in the compressive stress strain curve shown in figure 10, which displays the compressive response of one specimen each of the $\{3 B C C\}^{3}$ geometry. Further detail on the compressive response of Upskin "OFF" specimens will be discussed in Chapter 4. 


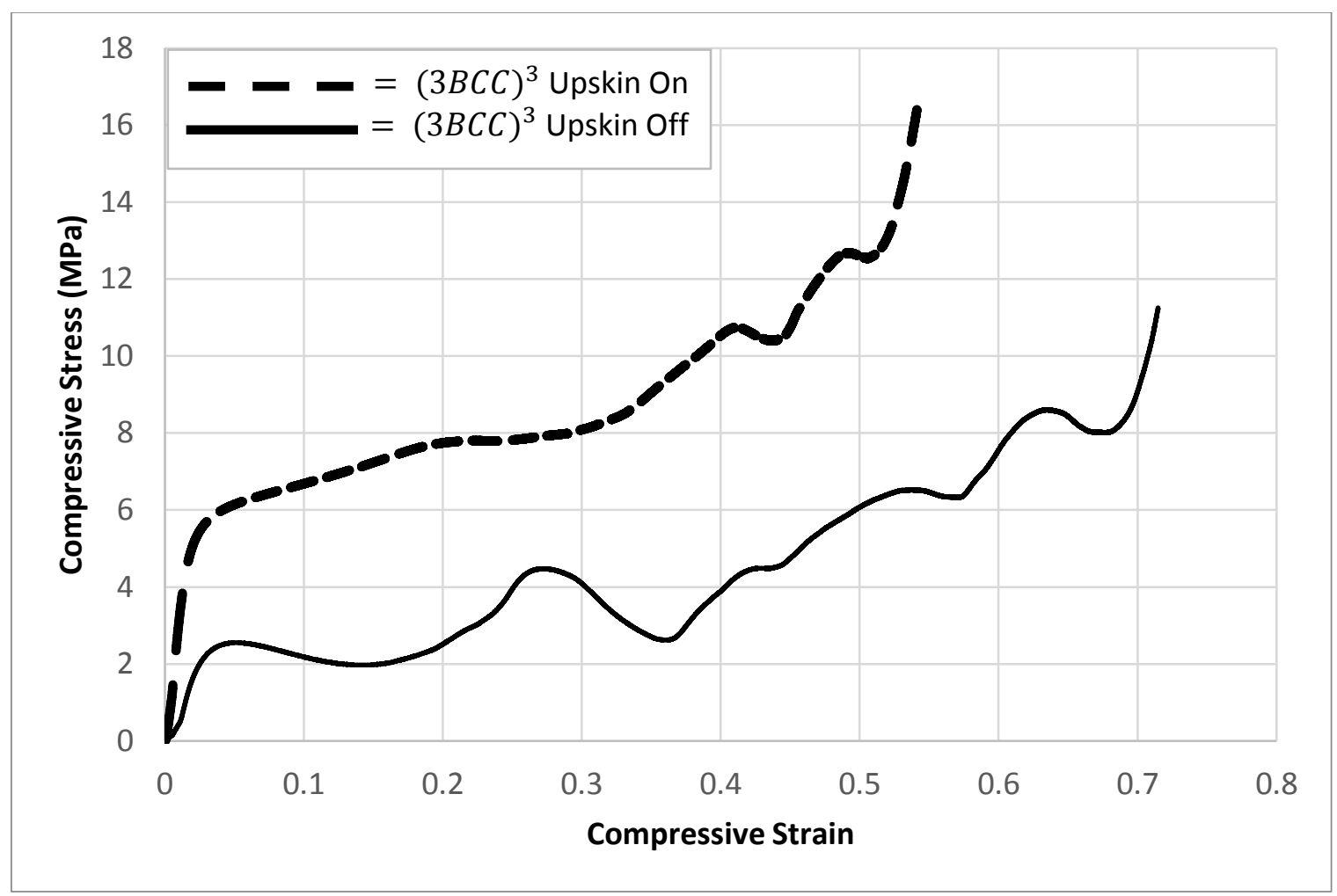

Figure 10: $\{3 B C C\}^{3}$ Compressive Response Upskin "ON" and Upskin "OFF"

An interesting phenomenon observed in the Up Skin "ON" specimens is the presence of a heat tint on the upward facing surfaces. Brightly colored surfaces ranging from yellow to blue can be seen in figure 11. The temperatures associated with each heat tint color for $316 \mathrm{~L}$ stainless steel is shown in table 3.

The variety of colors on the surfaces of the unit cells from specimen set 1 indicates the presence of oxygen while the specimens were at an elevated temperature. From these colors, we can observe a dramatic heat gradient on the SLM build plate from the edges to the center. The top surfaces of the outermost edge unit cells are pale yellow, indicating a temperature of about 290 degress $C$. The top surfaces of the innermost unit cells are dark purple and blue, indicating a temperature of about 500 degrees $\mathrm{C}$. Heat treatment of stainless steel significantly affects the mechanical properties, and heat tints indicate an unintentional heat treatment. A hypothesis that the heat tint only applies to the last 
layer melted was assumed, therefore for the purposes of this study, the effects of the build plate heat gradient is not considered.

Table 3: Heat tint colors and temperatures for Stainless Steel (www.bssa.com, 2017)

\begin{tabular}{|l|l|l|l|l|l|l|l|l|}
\hline Temperature & $290 \mathrm{C}$ & $340 \mathrm{C}$ & $370 \mathrm{C}$ & $390 \mathrm{C}$ & $420 \mathrm{C}$ & $450 \mathrm{C}$ & $540 \mathrm{C}$ & $600 \mathrm{C}$ \\
\hline Color & Pale & Straw & Dark & Brown & Purple & Dark & Blue & Dark \\
& yellow & yellow & yellow & & brown & purple & & blue \\
\hline
\end{tabular}
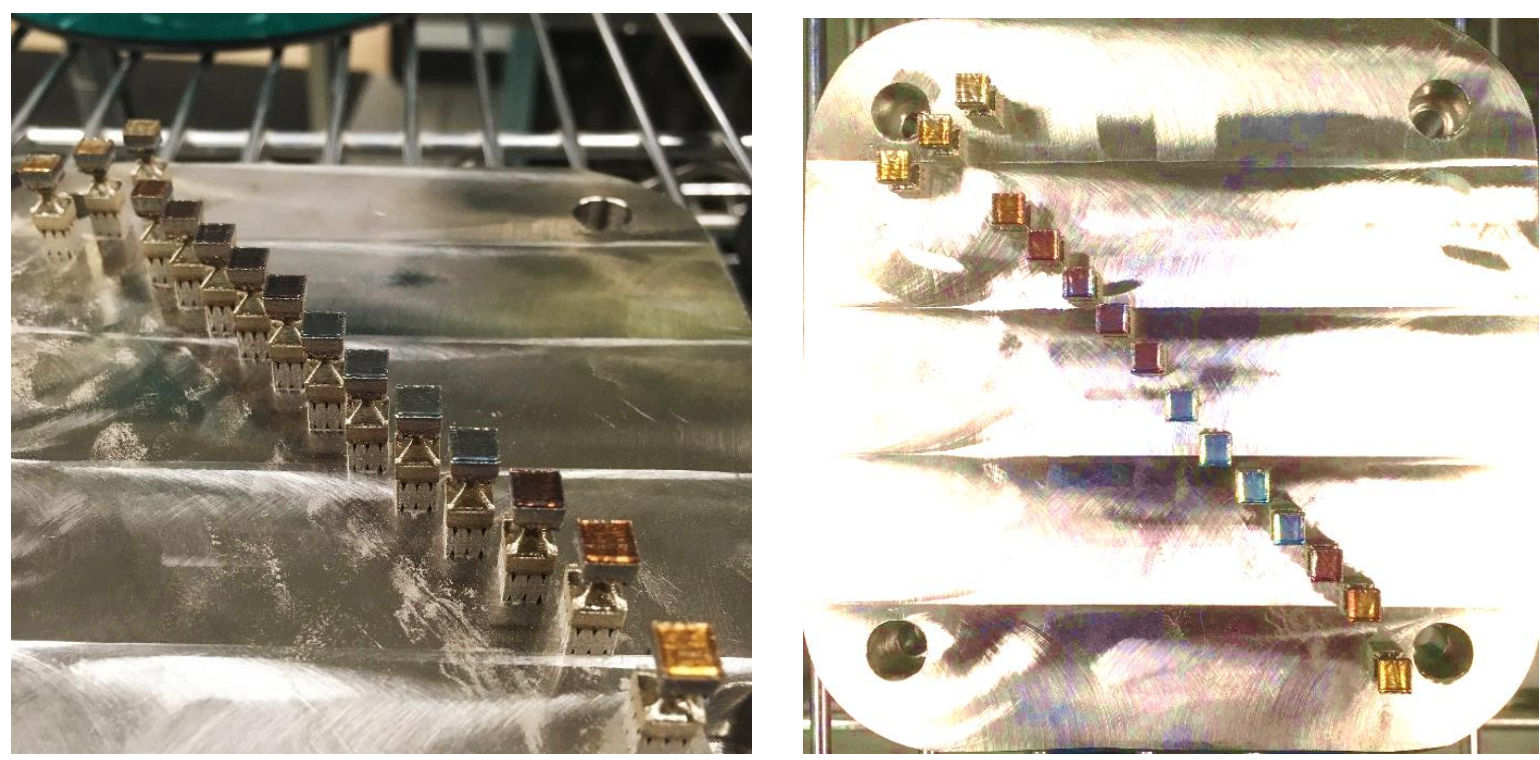

Figure 11: Heat tint colors on top surfaces of unit cell specimens

There exists scope for a study on the formation of these heat tints, and whether they indicate an unintentional heat treatment applied to the entire structure, or just the top layer of the specimens. Furthermore, these parts are the only parts to be built on this specific machine which have displayed these dramatic colors. A hypothesis for this phenomenon is that the low thermal conductivity of the structures below the top skin significantly affected the cooling rate of the top skin. This combined with trace amounts of oxygen in the build chamber during cooling resulted in the observed colors. 
The surface defects of the manufactured lattices can be observed in figure 12. The Up Skin parameter was turned on for specimen set 1 and turned off for specimen set 2 in order to allow for a comparison of surface defects. Using scaled images from the $\mathrm{MicroVu}^{\circledR}$ macroscope, a 250 pixel^ 2 area was compared via the Image $J^{\circledR}$ optical analysis software on a $\{1 B C C\}^{1},\|25\|$ specimen on both the vertical wall of the bottom skin, as well as the vertical wall of the unit cell node. These comparisons can be found in figures 14 through 16 . The results of the analysis can be found in tables $4,5,6$, and 7 . The software compares contrasting areas of the image and can count the number of instances where the contrast exceeds a certain threshold. In the case of determining relative surface finish of the specimens, different parameters are used for the vertical walls of the skin, and the vertical wall of the unit cell node. On the vertical wall of the bottom skin, dark areas indicate either a shadow behind a non-melted particle or pitting where a non-melted particle is embedded. On the unit cell node, bright areas indicate the presence of a non-melted particle bonded to the surface or a melt pool. On the 273X magnified images in figure 12 , the non-melted particles are clearly visible.
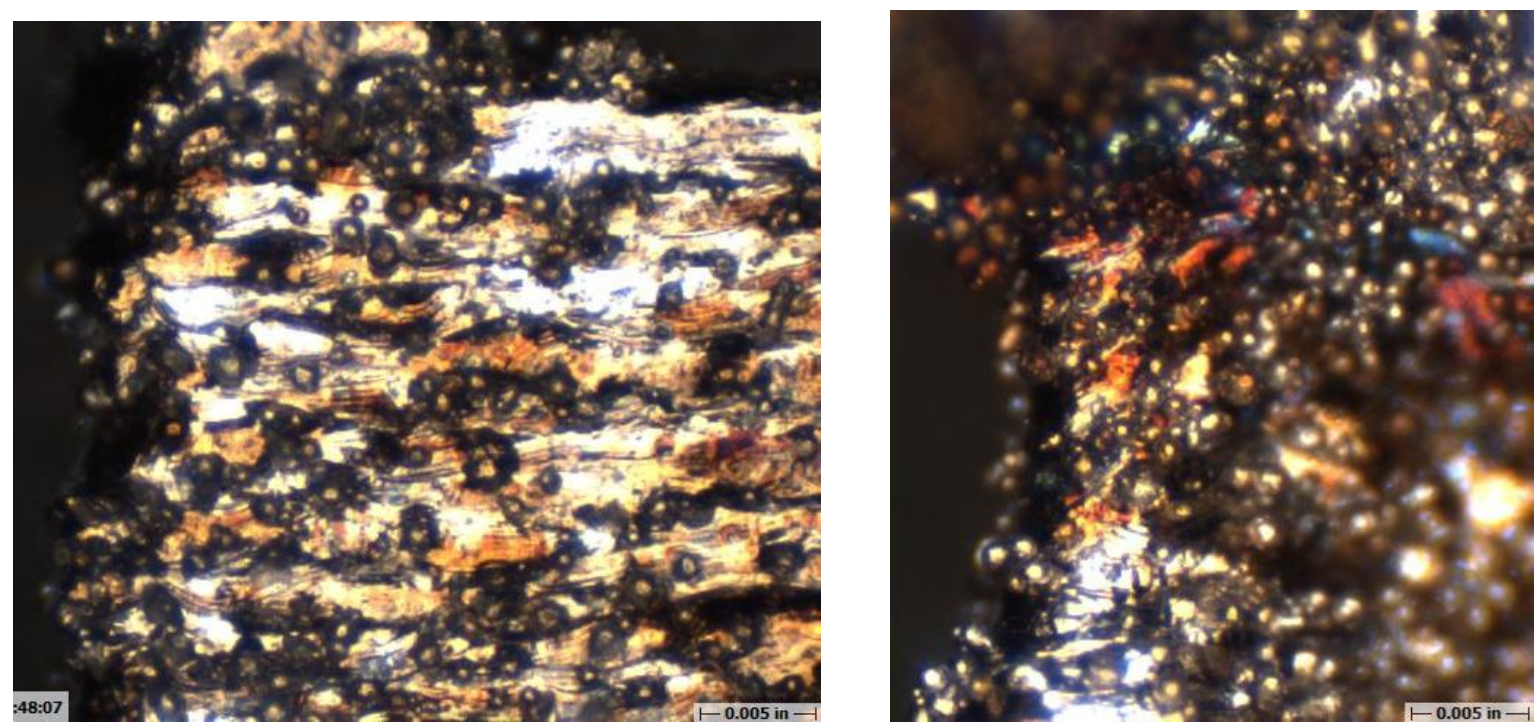

Figure 12: 273X magnified images showing non-melted particles on surfaces 
The images of the skin wall were cropped to a 250 by 250 pixel square, set to 16 bit grayscale, with a threshold of 53\%, no dark background, and a minimum particle size of 4 pixel^ 2 .
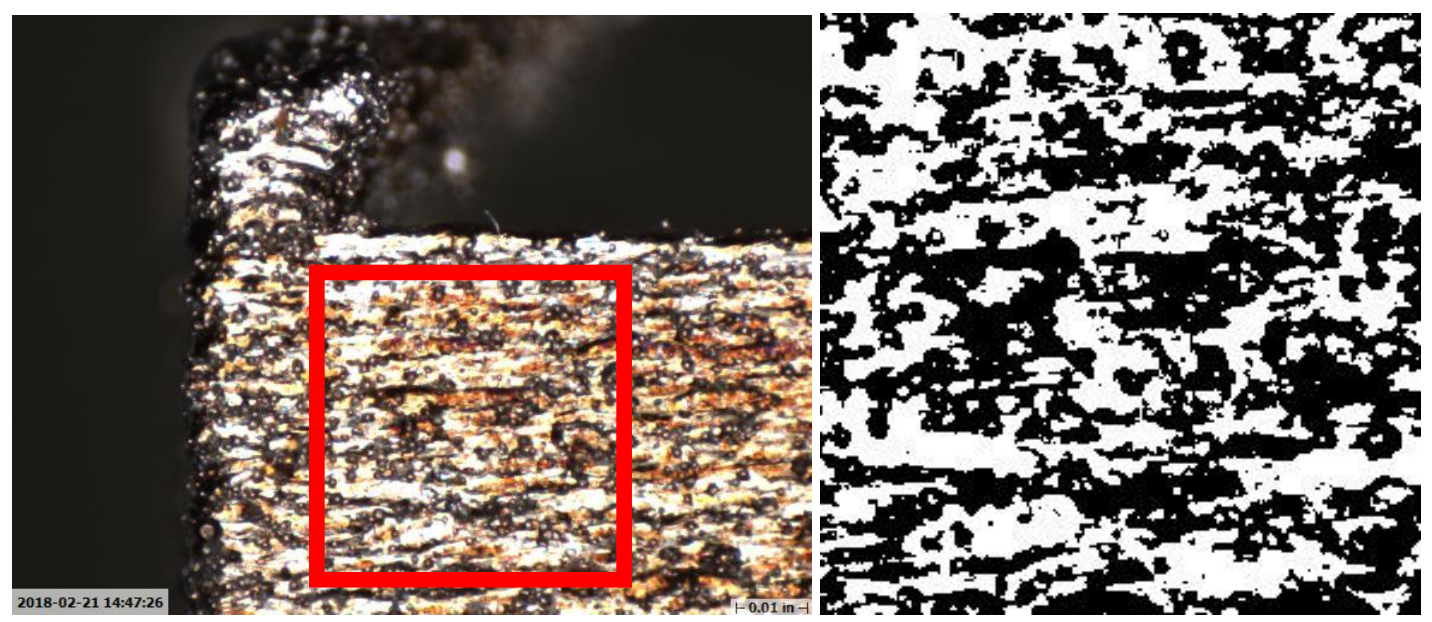

Figure 13: Cropped and processed area for defect count

Table 4: Defect analysis for Upskin "ON" bottom skin

\begin{tabular}{|c|c|c|c|}
\hline Count & Total Area & Average Size & \%Area \\
\hline 54 & 33238 & 615.519 & 53.181 \\
\hline
\end{tabular}
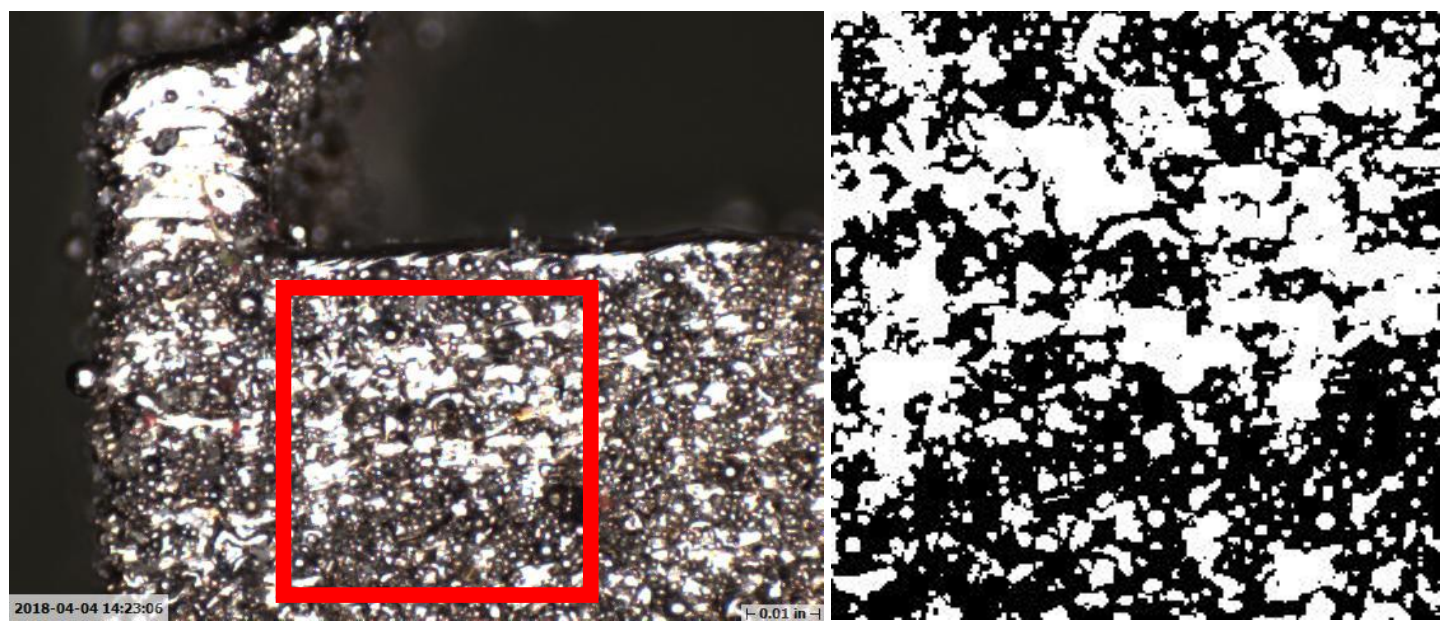

Figure 14: Non-melted particles on bottom skin of Upskin "OFF" specimen (left), Cropped and processed area for defect count (right)

Table 5: Defect analysis for Upskin "OFF" bottom skin

\begin{tabular}{|c|c|c|c|}
\hline Count & Total Area & Average Size & \%Area \\
\hline 42 & 33142 & 789.095 & 53.027 \\
\hline
\end{tabular}


The images of the unit cell node were cropped to a 250 by 250 pixel square, set to 16 bit grayscale, with a threshold of $30 \%$, with a dark background, and a minimum particle size of 4 pixel^ 2 .
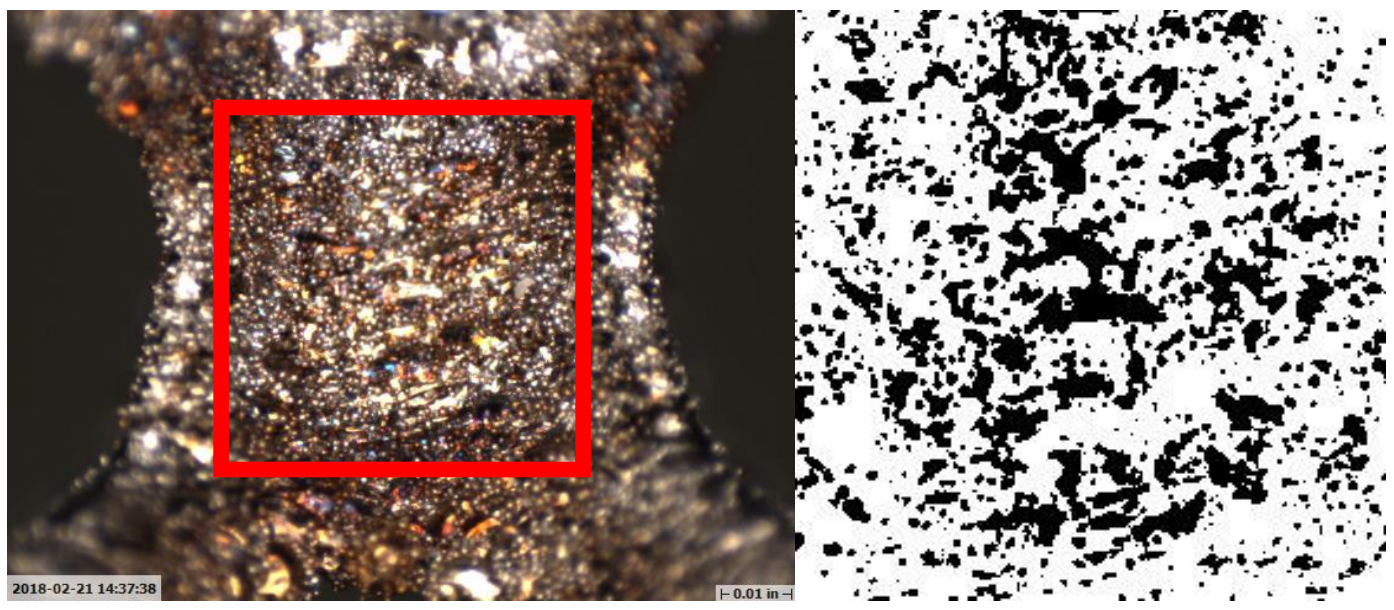

Figure 15: Non-melted particles on unit cell node of Upskin "ON" specimen (left), Cropped and processed area for defect coun (right)

Table 6: Defect analysis for Upskin "ON" node

\begin{tabular}{|c|c|c|c|}
\hline Count & Total Area & Average Size & \%Area \\
\hline 421 & 18573 & 44.116 & 29.717 \\
\hline
\end{tabular}
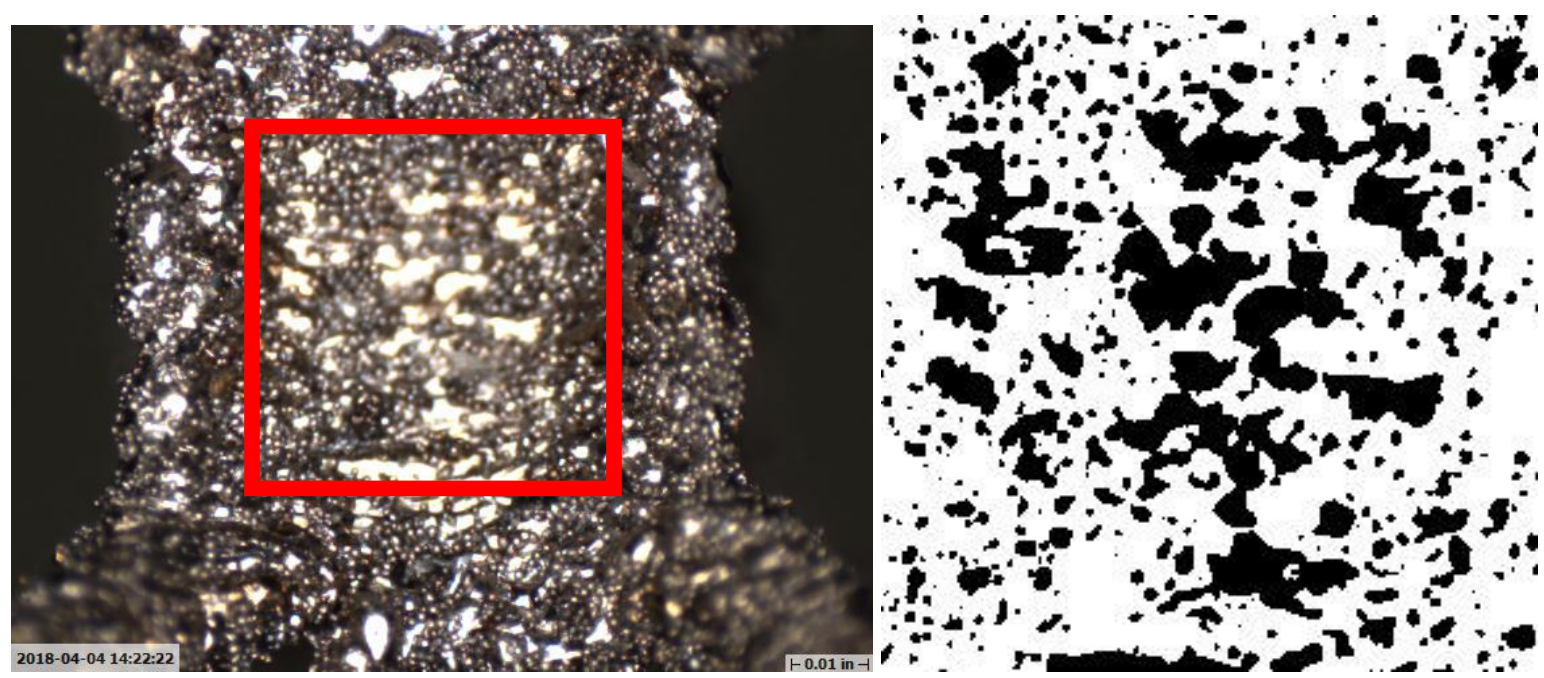

Figure 16: Non-melted particles on unit cell node of Upskin "OFF" specimen (left), Cropped and processed area for defect count (right) 
Table 7: Defect analysis for Upskin "OFF" node

\begin{tabular}{|c|c|c|c|}
\hline Count & Total Area & Average Size & \%Area \\
\hline 284 & 18765 & 66.074 & 30.024 \\
\hline
\end{tabular}

For both the vertical wall of the bottom skin and the vertical wall of the unit cell node, the Upskin "OFF" specimen contained less surface defects by number, but an equivalent $\%$ area and a greater average defect size. This indicates that the defects on the surface of the Uskin "OFF" specimens are larger and more localized and could significantly effect the mechanical properties of the structure, while the relatively homogenous spread of defects on the Upskin "ON" specimens has a lesser effect due to their small size.

At this magnification level of 100X, it is also readily visible that the Upskin "OFF" specimen has several defects on the sides of the node in the form of clumped, non-melted particles. The Upskin "OFF" specimens were observed to have a less cohesive and more inconsistent surface than the Upskin "ON" specimens.

\section{Mechanical Testing in Literature}

\section{Quasi-Static}

The quasi-static properties of lattice structures has been widely studied and tested. For nearly every study, a quasi-static test is performed to determine the lattice structure's static stress strain curve. Of all the unit cell topologies, the body centered cubic has been most studied. Gümrük, Li, Maskery, Tsopanos, and Smith all performed quasi-static compression testing on BCC structures and some BCC based unit cells: BCCZ, F2BCC, density graded BCC. (Gümrük et al., 2013; Li, 2016; Maskery et al., 2016; Smith et al., 2011; Tsopanos et al., 2010) Quasi-static compression tests on cubic, diamond cubic, and re-entrant cube were performed by Ozdemir (Ozdemir et al., 2015) in a preliminary study. Tancogne-Dejean (Tancogne-Dejean, Spierings, \& Mohr, 2016) tested the static compressive behaviors of the octet truss, 
Yan (Yan et al., 2015; Yan, Hao, Hussein, \& Raymont, 2012) tested the static compressive response of the gyroid unit cell, and Xiao (Xiao et al., 2016; Xiao \& Song, 2017) tested both uniform density and density graded rhombic decahedron unit cells.

From literature, compressive crosshead displacement rates ranged from $0.5 \mathrm{~mm} / \mathrm{min}$ to $0.05 \mathrm{~mm} / \mathrm{min}$ for quasi-static compression testing.

\section{Mechanical Characterization}

Mechanical characterization was performed via quasi-static compression testing to densification at $0.2 \mathrm{~mm} / \mathrm{min}$ for all specimens. All tests were performed on an Instron ${ }^{\circledR}$ universal test machine with a $50 \mathrm{kN}$ load cell with flat platens. Tests were started without preload. The resulting data output was force and displacement, which was used to calculate the meso-structure level stress. Due to its nature as a cellular material, the unit cells and lattice specimens were treated as space filling solids. Thus the cross sectional area was defined as the measured lattice width multiplied by the measured lattice length. If a lattice was measured to have an equal length and width of $5 \mathrm{~mm}$, the cross sectional area would be $25 \mathrm{~mm}^{2}$. Strain was calculated by taking the ratio of compressive displacement to the measured lattice height. Images were recorded at regular intervals throughout the tests and correlated with specific values of strain. This combination of images and stress strain data allows for a comprehensive understanding of the failure mode of the BCC unit cell in compression. Due to the nature of the fabrication and support removal process, it was impossible to measure an accurate mass of each individual structure without the skins. Therefore the mass was measured from the CAD model. While this measurement does not represent the actual mass of the structure, it allows for the development of an approximate relative density, specific energy absorption, specific stiffness, and a predictive numerical model for modulus and ultimate stress of the tested structures. 


\section{CHAPTER 4 EXPERIMENTAL RESULTS AND DISCUSSION}

\section{Mechanical Characterization of Unit Cells in Compression}

All of the unit cell specimens produced a two peaked stress strain curve with the exception of the

$\{1 B C C\}^{1},\|25\|$ specimens, which produced a curve that demonstrated nearly ideal plastic deformation. The compressive stress - strain curves are displayed in figure 17 for all unit cell specimens tested. For the $0 \%$ radius unit cells, 2 specimens were tested. For the $6.25 \%$ through $25 \%$ radius unit cells, 3 specimens were tested. For the 55 degree, $0 \%$ radius unit cells, 5 specimens were tested.

It is interesting to note that the bottom half of the unit cell always fails first. This observation is hypothesized to be attributed to slight dimensional disparities between the top of the unit cell and the bottom. Furthermore, the corners of the unsupported overhanging top skin welded to the top struts, further increasing their strength. Ideally, both peaks in the stress strain curve would reach the same value, and neither would necessarily fail prior to the other. Given ideal geometry, the yield location would randomly switch between the top struts of the unit cell and the bottom struts.

The collapse behavior which produces these two peaked stress strain curves can be clearly seen in figure 25 , which displays the 55 degree unit cell at various values of strain. The presence of plastic bending can be clearly seen in the microstrut in figure 21. 


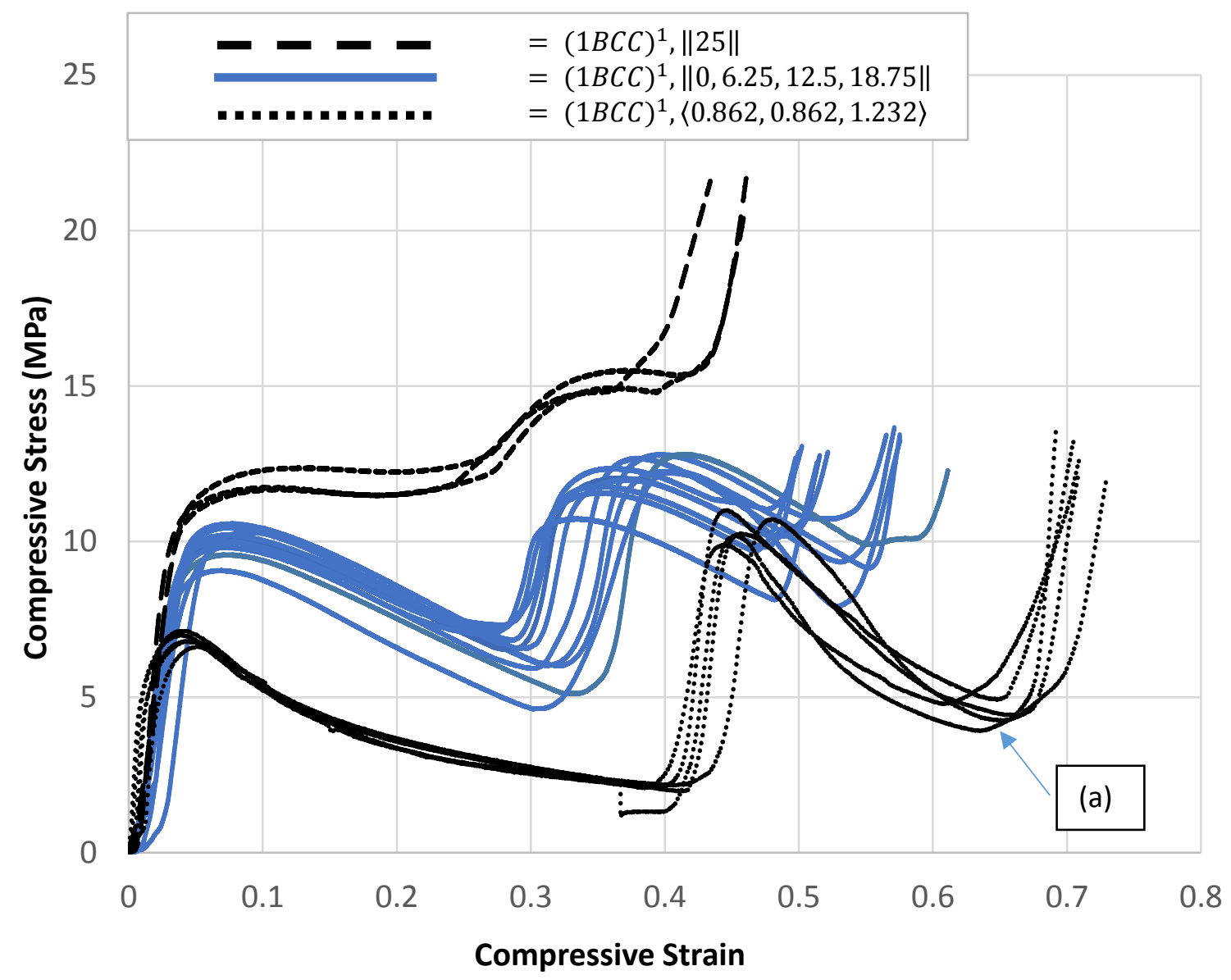

Figure 17: Compressive response of BCC unit cells. $\{1 B C C\}^{1},\|25\|,\{1 B C C\}^{1},\|0,6.25,12.5,18.75\|$, $\{3 B C C\}^{3},\langle 0.862,0.862,1.232\rangle$

In figure 17 , the unit cells with radius $0 \%$ to $18.75 \%$ were grouped together (non dashed blue lines) due to their minor differences in mechanical response. These can be seen as the non-dashed blue lines above. Various calculated values from the data which is represented in figure 17 can be found in Table 8 below. 
Table 8: Unit cell compressive summary

\begin{tabular}{|c|r|r|r|r|r|r|}
\hline & $\begin{array}{l}\text { Initial } \\
\text { Ultimate } \\
\text { Stress(Mpa) }\end{array}$ & $\begin{array}{l}\text { Final } \\
\text { Ultimate } \\
\text { Stress } \\
\text { Structure ID }\end{array}$ & $\begin{array}{l}\text { Densification } \\
\text { Strain }\end{array}$ & $\begin{array}{l}\text { Energy } \\
\text { Absorbed up } \\
\text { to } \\
\text { Densification(J) }\end{array}$ & $\begin{array}{l}\text { Energy } \\
\text { Density } \\
\text { (J/mm^3) }\end{array}$ & $\begin{array}{l}\text { Modulus } \\
\text { of } \\
\text { Elasticity } \\
\text { (Mpa) }\end{array}$ \\
\hline$\{1 B C C\}^{1}$ & 9.08 & 12.28 & 0.53 & 0.48 & 0.00465 & 259.40 \\
\hline$\{1 B C C\}^{1}$ & 9.59 & 12.82 & 0.56 & 0.54 & 0.00545 & 309.78 \\
\hline$\{1 B C C\}^{1},\|6.25\|$ & 10.47 & 12.81 & 0.53 & 0.53 & 0.00531 & 352.63 \\
\hline$\{1 B C C\}^{1},\|6.25\|$ & 10.04 & 12.26 & 0.55 & 0.52 & 0.00512 & 321.17 \\
\hline$\{1 B C C\}^{1},\|6.25\|$ & 10.01 & 12.69 & 0.53 & 0.53 & 0.00520 & 271.51 \\
\hline$\{1 B C C\}^{1},\|12.5\|$ & 10.12 & 12.06 & 0.45 & 0.52 & 0.00520 & 273.17 \\
\hline$\{1 B C C\}^{1},\|12.5\|$ & 10.32 & 12.00 & 0.49 & 0.52 & 0.00476 & 359.78 \\
\hline$\{1 B C C\}^{1},\|12.5\|$ & 10.59 & 12.37 & 0.48 & 0.51 & 0.00484 & 368.24 \\
\hline$\{1 B C C\}^{1},\|18.75\|$ & 10.03 & 11.59 & 0.47 & 0.50 & 0.00458 & 339.48 \\
\hline$\{1 B C C\}^{1},\|18.75\|$ & 10.23 & 11.80 & 0.48 & 0.50 & 0.00461 & 330.94 \\
\hline$\{1 B C C\}^{1},\|18.75\|$ & 9.83 & 10.75 & 0.48 & 0.50 & 0.00447 & 369.09 \\
\hline$\{1 B C C\}^{1},\|25\|$ & 12.39 & 15.52 & 0.41 & 0.64 & 0.00592 & 341.74 \\
\hline$\{1 B C C\}^{1},\|25\|$ & 11.70 & 16.93 & 0.4 & 0.60 & 0.00543 & 440.85 \\
\hline$\{1 B C C\}^{1},\|25\|$ & 11.75 & 15.04 & 0.43 & 0.63 & 0.00577 & 544.77 \\
\hline$\{1 B C C\}^{1},\langle 0.862,0.862,1.232\rangle$ & 6.635 & 10.736 & 0.700 & 0.304 & 0.00356 & 551.46 \\
\hline$\{1 B C C\}^{1},\langle 0.862,0.862,1.232\rangle$ & 7.135 & 11.021 & 0.660 & 0.310 & 0.00363 & 567.53 \\
\hline$\{1 B C C\}^{1},\langle 0.862,0.862,1.232\rangle$ & 6.808 & 10.220 & 0.640 & 0.289 & 0.00331 & 814.67 \\
\hline$\{1 B C C\}^{1},\langle 0.862,0.862,1.232\rangle$ & 6.815 & 10.268 & 0.650 & 0.323 & 0.00372 & 734.86 \\
\hline$\{1 B C C\}^{1},\langle 0.862,0.862,1.232\rangle$ & 7.000 & 9.905 & 0.620 & 0.334 & 0.00371 & 694.23 \\
\hline
\end{tabular}

\begin{tabular}{|c|c|c|c|c|c|}
\hline $\begin{array}{l}\text { Initial } \\
\text { Ultimate } \\
\text { Stress(Mpa) }\end{array}$ & $\begin{array}{l}\text { Final Ultimate } \\
\text { Stress (Mpa) }\end{array}$ & $\begin{array}{l}\text { Densification } \\
\text { Strain }\end{array}$ & $\begin{array}{l}\text { Energy Absorbed up } \\
\text { to Densification(J) }\end{array}$ & $\begin{array}{l}\text { Specfic Energy } \\
\text { Absporption (J/g) }\end{array}$ & $\begin{array}{l}\text { Energy } \\
\text { Density } \\
\left(\mathrm{J} / \mathrm{mm}^{\wedge} 3\right)\end{array}$ \\
\hline 9.08 & 12.28 & 0.53 & 0.48 & 8.055 & 0.00465 \\
\hline 9.59 & 12.82 & 0.56 & 0.54 & 8.537 & 0.00545 \\
\hline 10.47 & 12.81 & 0.53 & 0.53 & 8.272 & 0.00531 \\
\hline 10.04 & 12.26 & 0.55 & 0.52 & 8.209 & 0.00512 \\
\hline 10.01 & 12.69 & 0.53 & 0.53 & 8.209 & 0.00520 \\
\hline 10.12 & 12.06 & 0.45 & 0.52 & 7.595 & 0.00520 \\
\hline 10.32 & 12.00 & 0.49 & 0.52 & 7.633 & 0.00476 \\
\hline 10.59 & 12.37 & 0.48 & 0.51 & 7.376 & 0.00484 \\
\hline 10.03 & 11.59 & 0.47 & 0.50 & 6.112 & 0.00458 \\
\hline 10.23 & 11.80 & 0.48 & 0.50 & 6.195 & 0.00461 \\
\hline
\end{tabular}




\begin{tabular}{|r|r|r|r|r|r|}
\hline 9.83 & 10.75 & 0.48 & 0.50 & 6.206 & 0.00447 \\
\hline 12.39 & 15.52 & 0.41 & 0.64 & 6.448 & 0.00592 \\
\hline 11.70 & 16.93 & 0.4 & 0.60 & 6.228 & 0.00543 \\
\hline 11.75 & 15.04 & 0.43 & 0.63 & 6.415 & 0.00577 \\
\hline 6.635 & 10.736 & 0.700 & 0.304 & 4.237 & 0.00356 \\
\hline 7.135 & 11.021 & 0.660 & 0.310 & 4.315 & 0.00363 \\
\hline 6.808 & 10.220 & 0.640 & 0.289 & 4.121 & 0.00331 \\
\hline 6.815 & 10.268 & 0.650 & 0.323 & 4.587 & 0.00372 \\
\hline 7.000 & 9.905 & 0.620 & 0.334 & 4.893 & 0.00371 \\
\hline
\end{tabular}

To determine the densification strain, the value of strain was recorded at the inflection point of the second valley on the stress strain curve, as seen labeled as (a) in figure 17. The energy absorbed up to densification was calculated by subtracting each data point of strain from the previous data point and multiplying it by the stress, then adding all of those values together. This closely approximates the integral of the curve and finds the area beneath it. The energy density is calculated by dividing the energy absorbed up to densification by the measured volume of the specimen. The modulus of elasticity was calculated by determining the slope of a line between two points within the linear region of the stress strain curve.

While the peak values may differ, all unit cells displayed the same failure mode. No unstable buckling modes were observed, only the stable bending-dominated mode. Images of all unit cells at increasing values of strain correlated with stress-strain curves can be found in Appendix B.

The first peak was recorded and identified as "Initial ultimate compressive stress" while the second peak was identified as "secondary ultimate compressive stress". The unit cell values of these ultimate stresses can be seen in figure 18. The compressive modulus of elasticity was also measured for the first peak and can be seen in figure 19. 


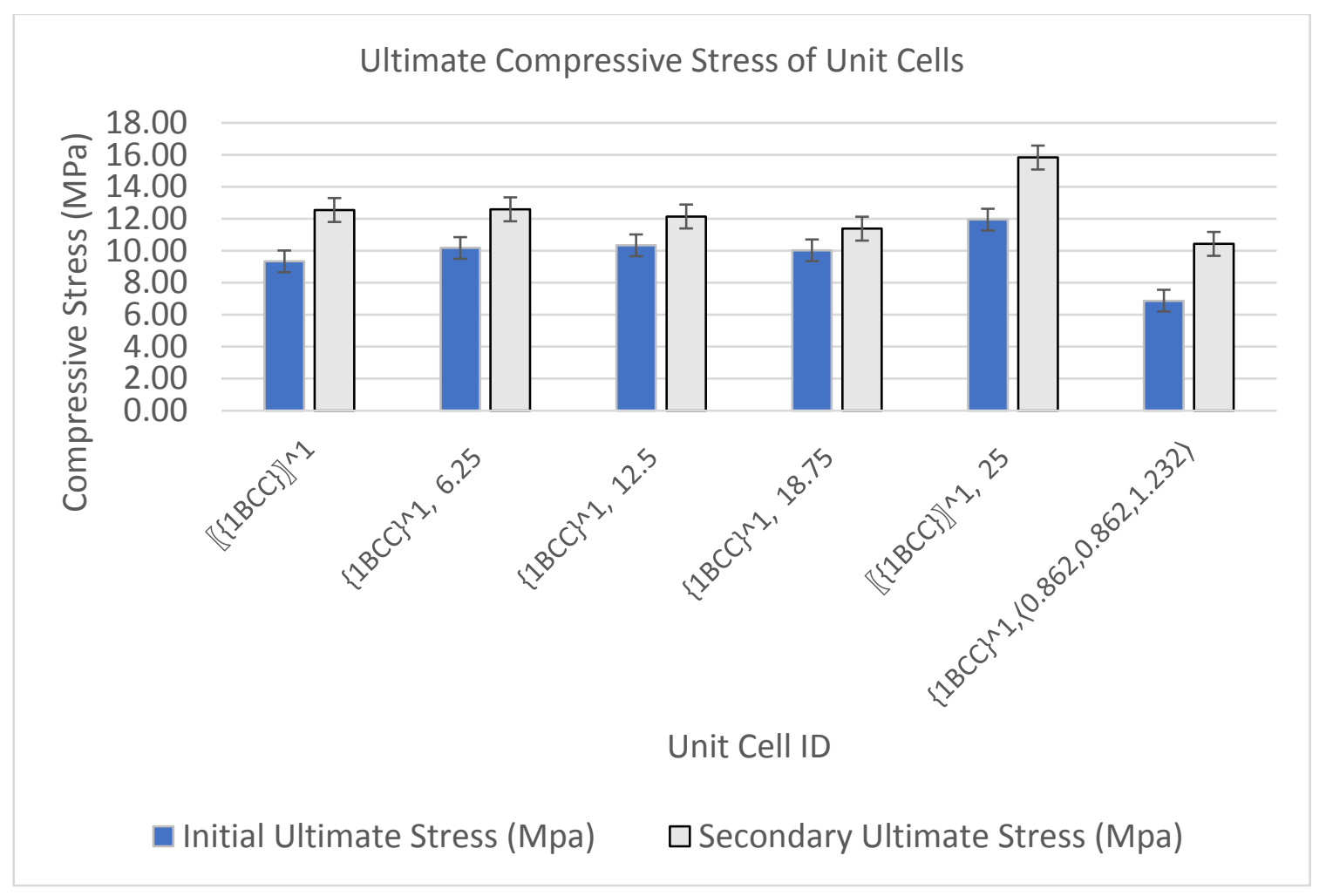

Figure 18: BCC unit cell initial and secondary ultimate compressive stress comparison

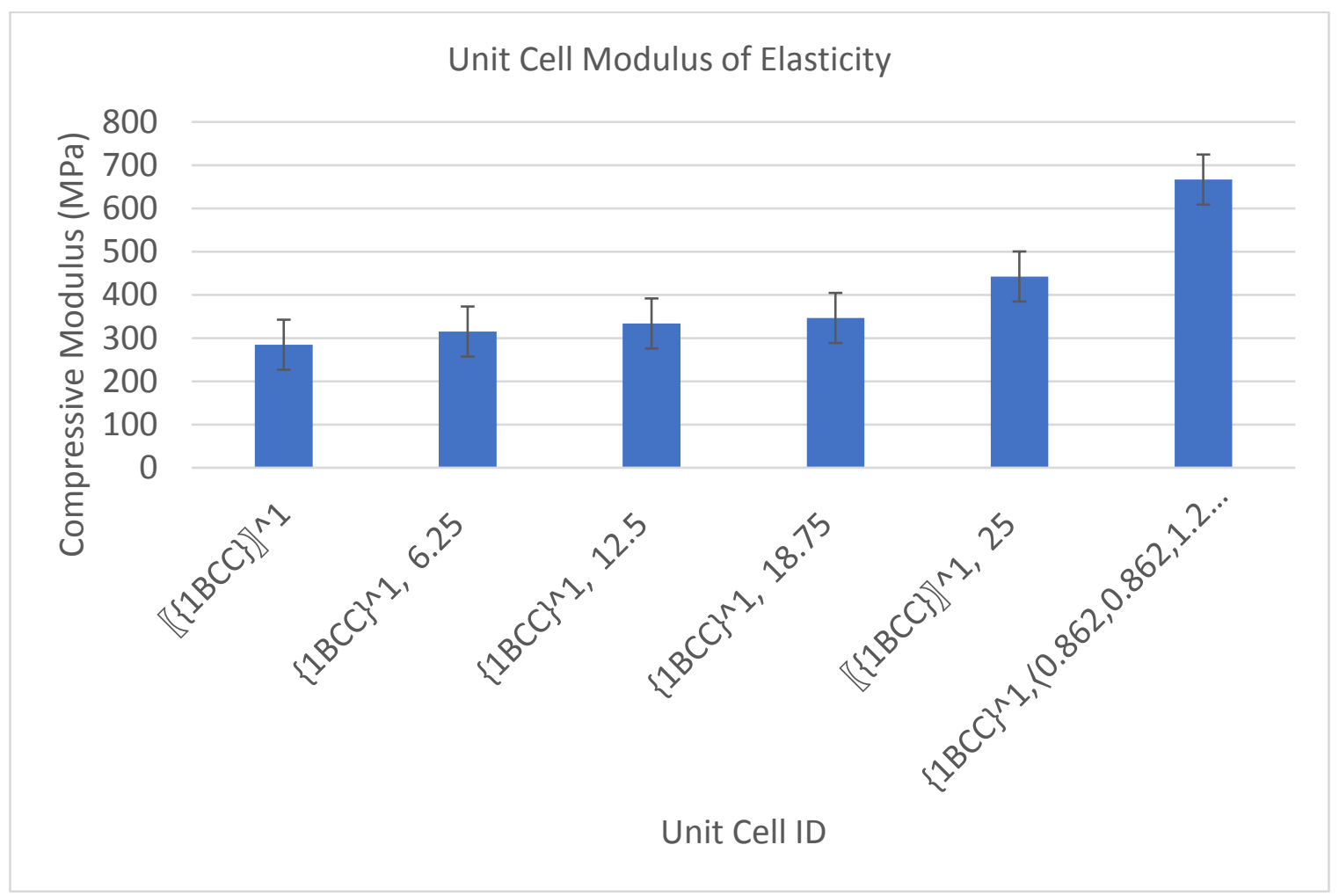


Figure 19: BCC unit cell compressive modulus of elasticity (MPa)

From the comparisons seen in figure 18 and 19, it is clear that increasing the node radius does not have a significant effect on the ultimate stress until a node radius of $25 \%$ is reached. Increasing the angle of the struts decreases the ultimate stress but significantly increases the modulus of elasticity. Increasing the node radius increases the modulus of elasticity.

\section{Effect of Node Radius}

The effect of the node radius on the unit cell is not significant until a radius of $25 \%$ of the unit cell is reached. For radii of $0 \%$ to $18.75 \%$, very minor differences were observed, with maximum strengths approximately the same for all 4 lattices below $25 \%$ radii. The failure of these unit cell specimens is dominated by plastic hinges located within the microstrut. This can be seen below in figure 20 on the bottom legs of the lattice structure.
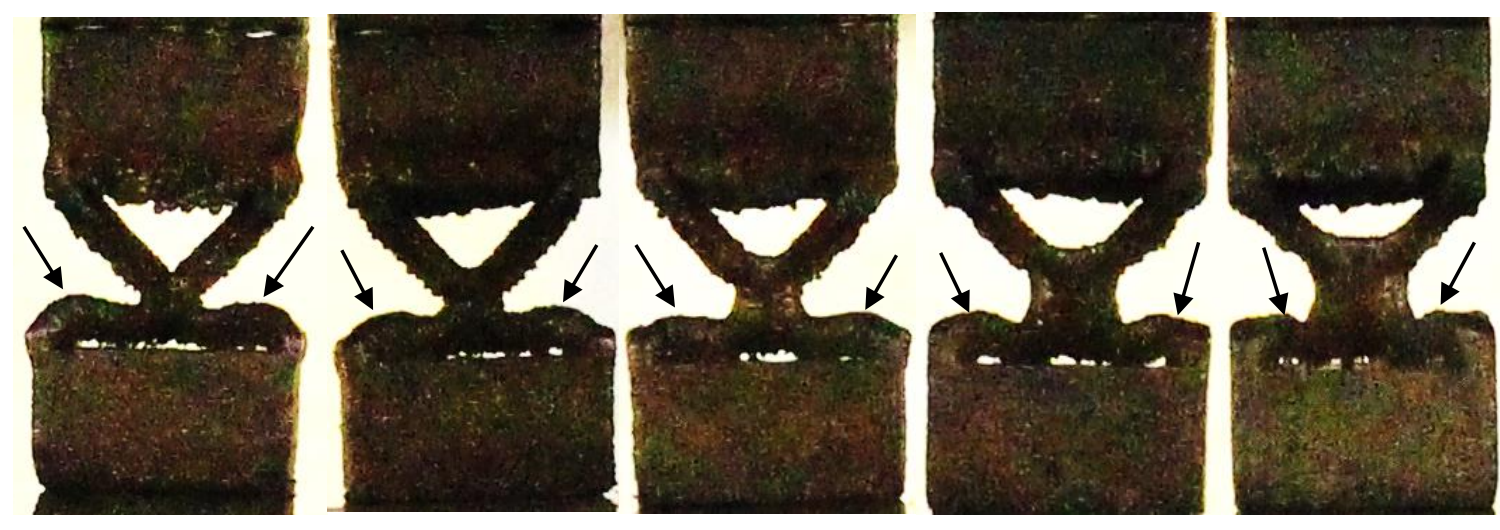

Figure 20: Plastic hinge locations on collapsed 45 degree BCC unit cells ranging from $0 \%$ radius (far left) to $25 \%$ radius (far right)

Gumruk (Gümrük et al., 2013) comments on this phenomenon and states that the peaks and valleys on the stress strain curve of the BCC lattice can be attributed to plastic buckling of the microstrut. This failure mode produces a "wavy" stress strain curve where each peak and valley is associated with a layer of a unit cell collapsing. 


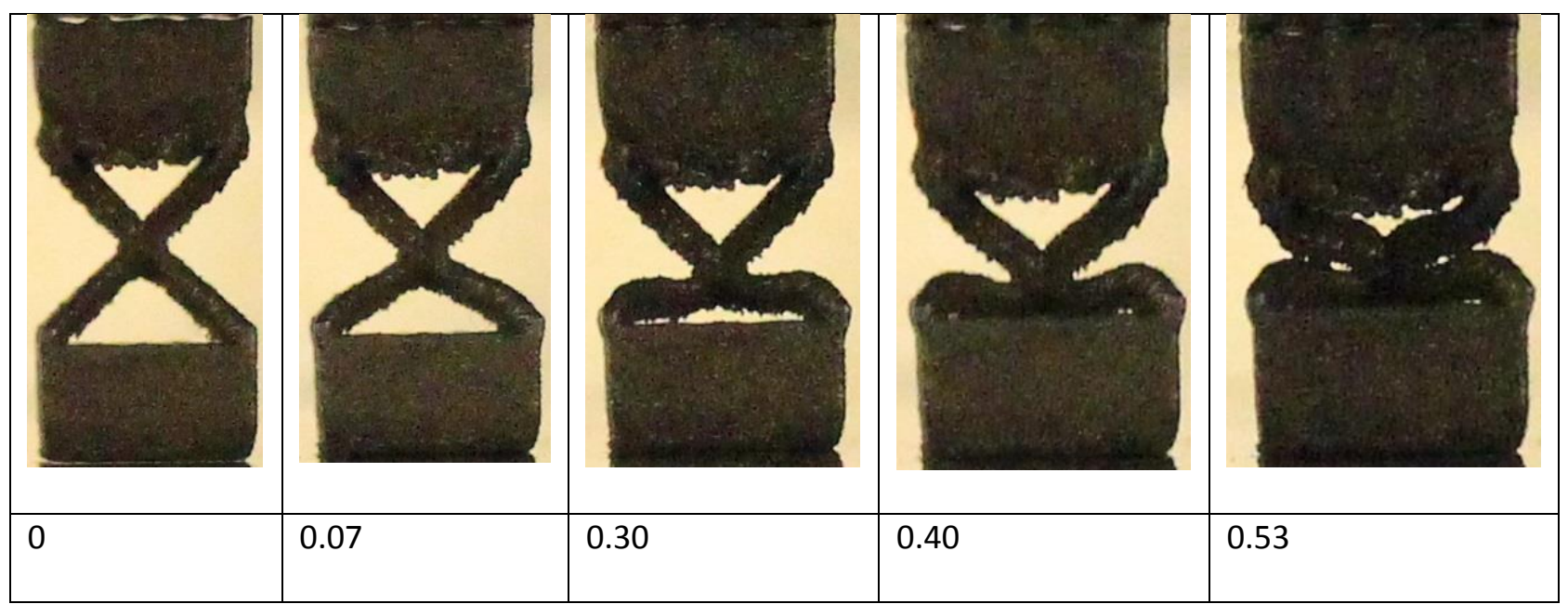

Figure 21: $\{1 B C C\}^{1}$ at increasing values of strain

Figure 21 depicts the $0 \%$ radius unit cell at increasing values of strain. The plastic deformation and plastic hinges which occur in within the micro-struts are clearly visible. Figure 22 depicts the stress strain curves of the 2 specimens tested with 0\% radius. This is the same data as table 8 and figure 17.

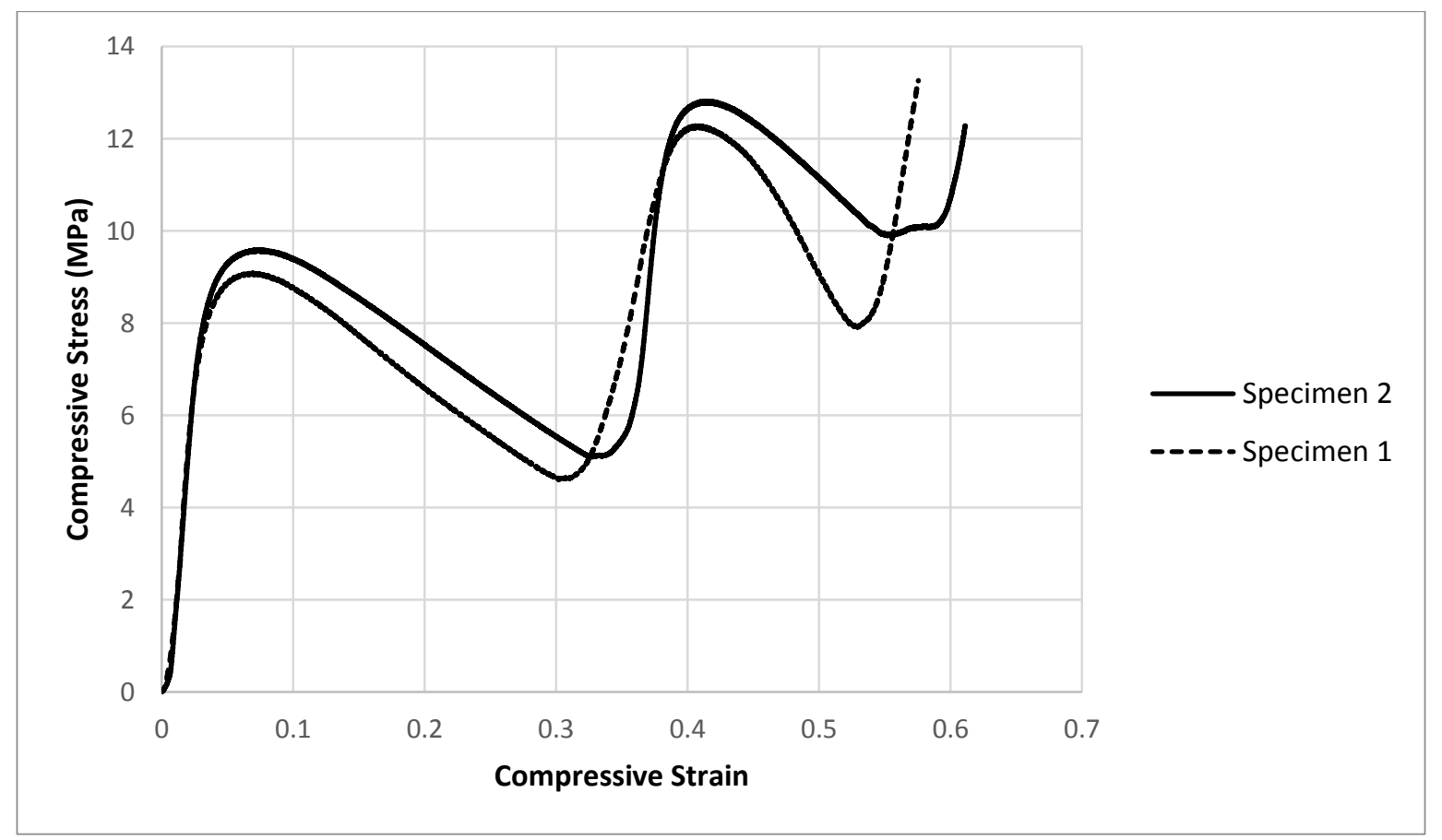

Figure 22: Compressive stress - strain response of $\{1 B C C\}^{1}$

At $25 \%$ radii however, a stress strain curve much closer to an ideal energy absorber is produced rather than a "wavy" curve. Similar to the smaller radii unit cells, the $25 \%$ radius shows a distinct 2 peak stress 
strain curve, but its strength is much greater than the other unit cells, and the curve is smoothed, with very minor peaks, and very minor valleys. This can be seen in figure 24 below. The $25 \%$ radius had a much smaller densification strain with an average of 0.4 . The $25 \%$ radius unit cell can be seen at increasing values of strain in figure 23. The same failure of the bottom struts first and top struts second is observed.

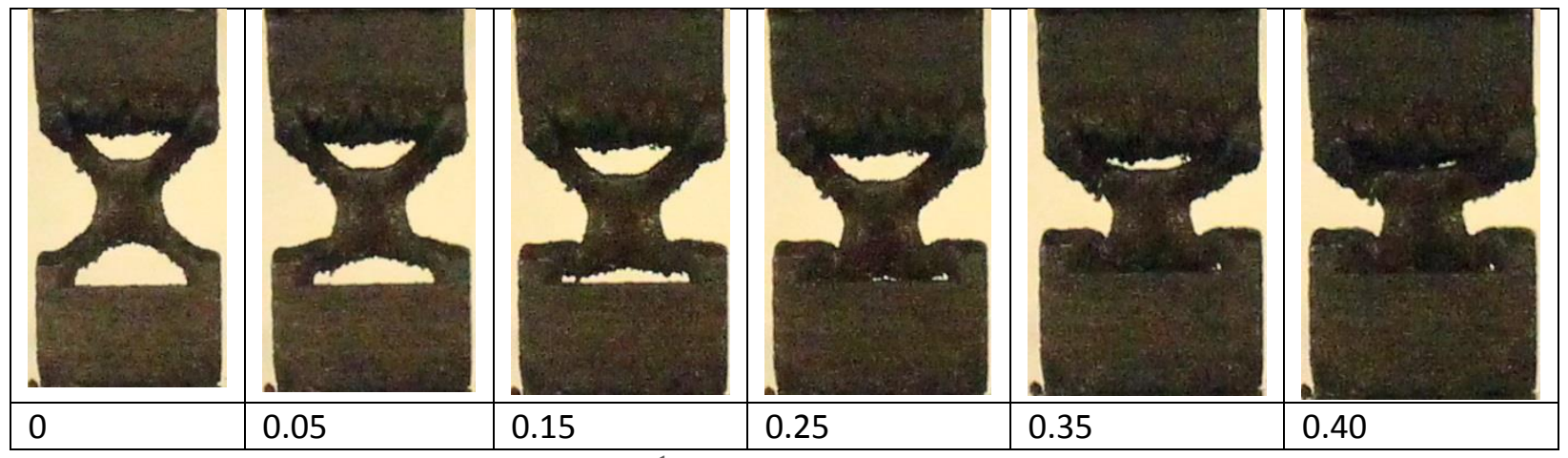

Figure 23: $\{1 B C C\}^{1},\|25\|$ at increasing values of strain

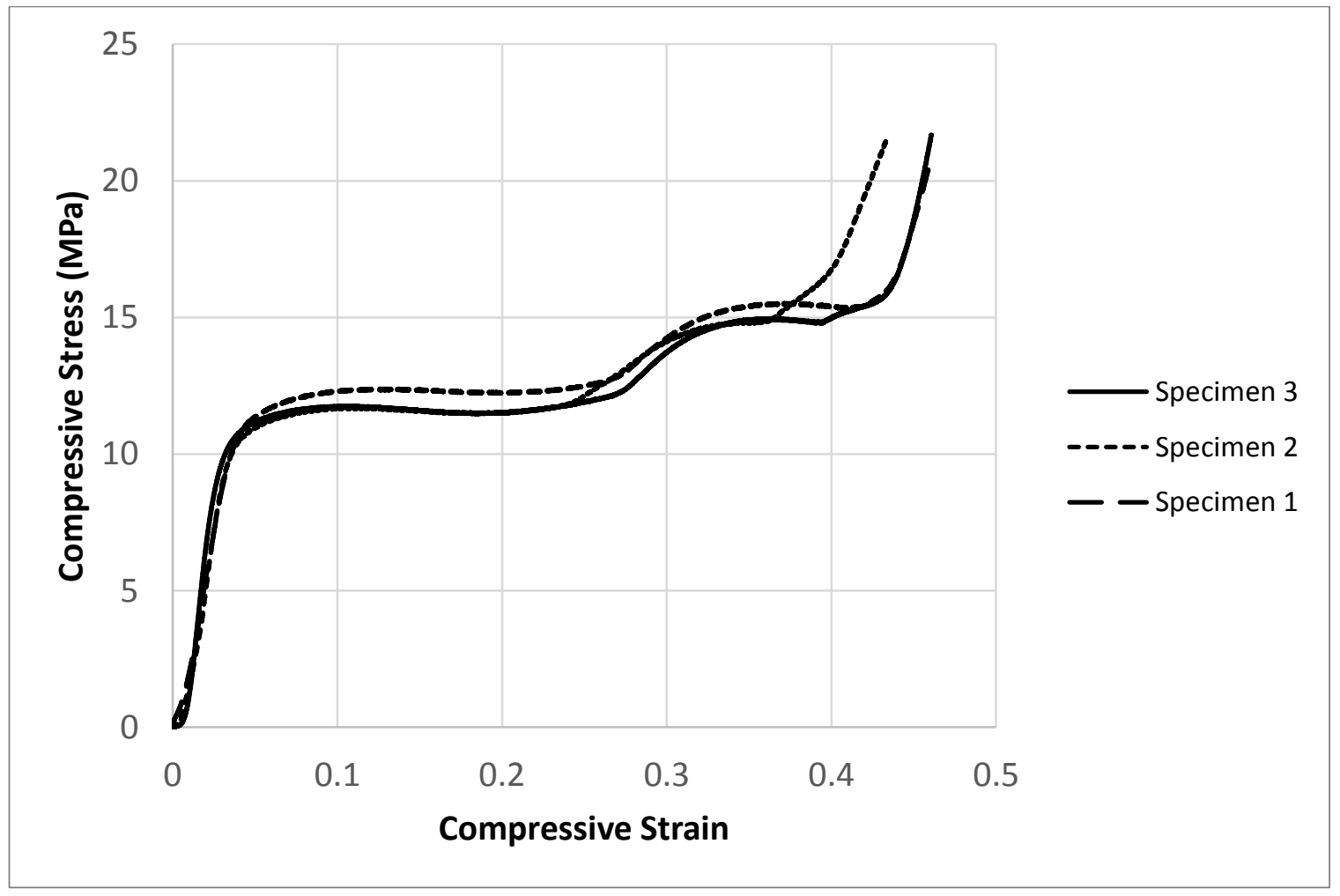

Figure 24: Compressive stress - strain response of $\{1 B C C\}^{1},\|25\|$ 
The $\{1 B C C\}^{1},\|25\|$ specimens compressive response can be seen in figure 24 , taken from the same data which controls Table 8 and figure 17. There were 3 specimens tested, each curve in figure 24 represents a single specimen of the same geometry. They were measured to have the highest initial and secondary ultimate stress of any tested unit cell specimen. Furthermore, this unit cell shape exhibited nearly ideal plastic deformation behavior. This unit cell has the highest energy density (energy per unit volume) of any of the unit cells tested. The $\{1 B C C\}^{1},\|25\|$ specimens were also measured to have the second highest compressive modulus of elasticity.

Given its ideal plastic deformation behavior, the $\{1 B C C\}^{1},\|25\|$ structure makes an excellent candidate for energy absorption applications.

\section{Effect of Strut Angle}

The strut angle of the unit cell plays a significant effect on the mechanical characteristics. Increasing the angle of the struts decreases the effective moment arm at the node. This subjects the microstruts to a greater axial load. It was predicted that the $\{1 B C C\}^{1},\langle 0.862,0.862,1.232\rangle$ specimens, also known as the 55 degree, $0 \%$ radius would display an unstable buckling failure mode, however the compression tests displayed a plastic hinge dominated failure similar to the $\{1 B C C\}^{1}$ specimens. Furthermore, the $\{1 B C C\}^{1},\langle 0.862,0.862,1.232\rangle$ (also known as 55 degree, $0 \%$ radius) specimens displayed the highest modulus of elasticity, highest densification strain, and lowest ultimate stress of any unit cell tested. It is interesting to note that this unit cell is the only one to fracture on one of the lower struts at the connection to the skin, see the sharp drop in stress in figure 26 . The 55 degree, $0 \%$ radius unit cell can be seen at increasing values of strain in figure 25 . 


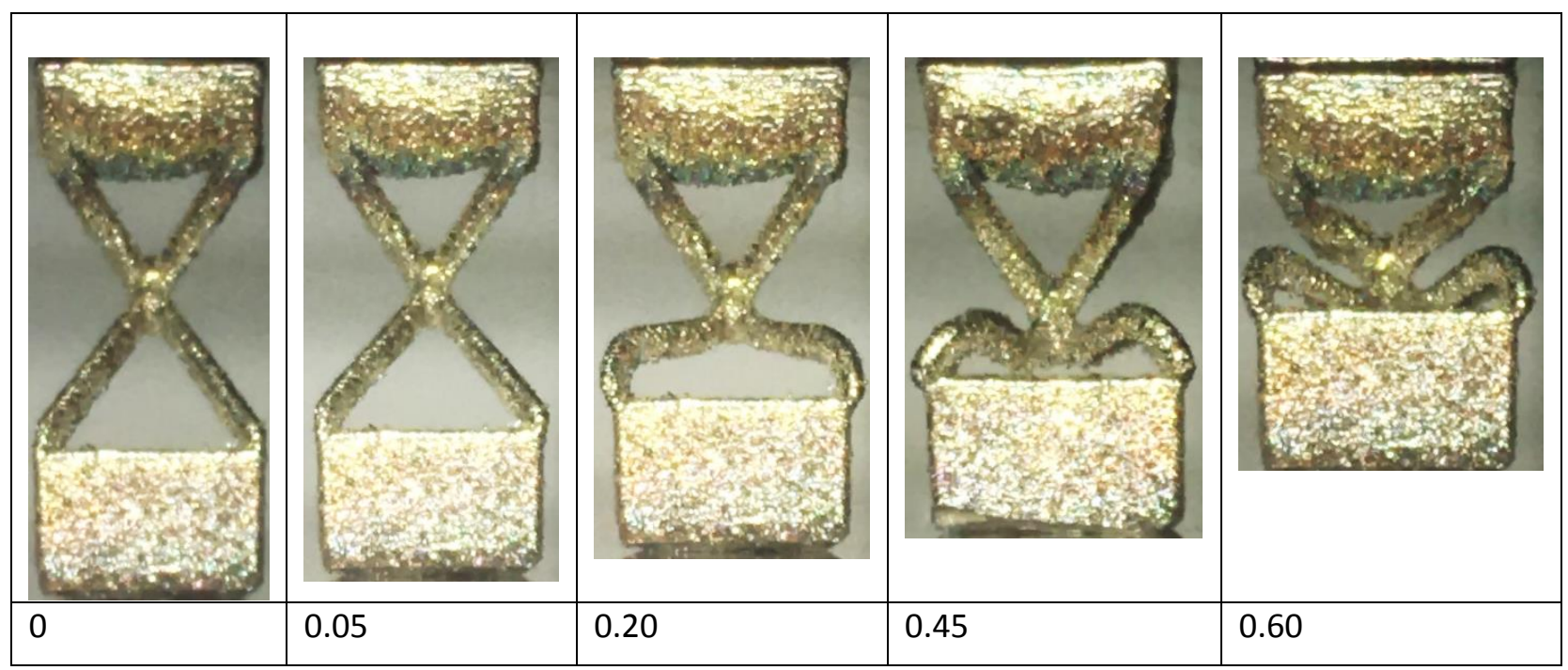

Figure 25: Deformation of $\{1 B C C\}^{1},\langle 0.862,0.862,1.232\rangle$ at various values of strain

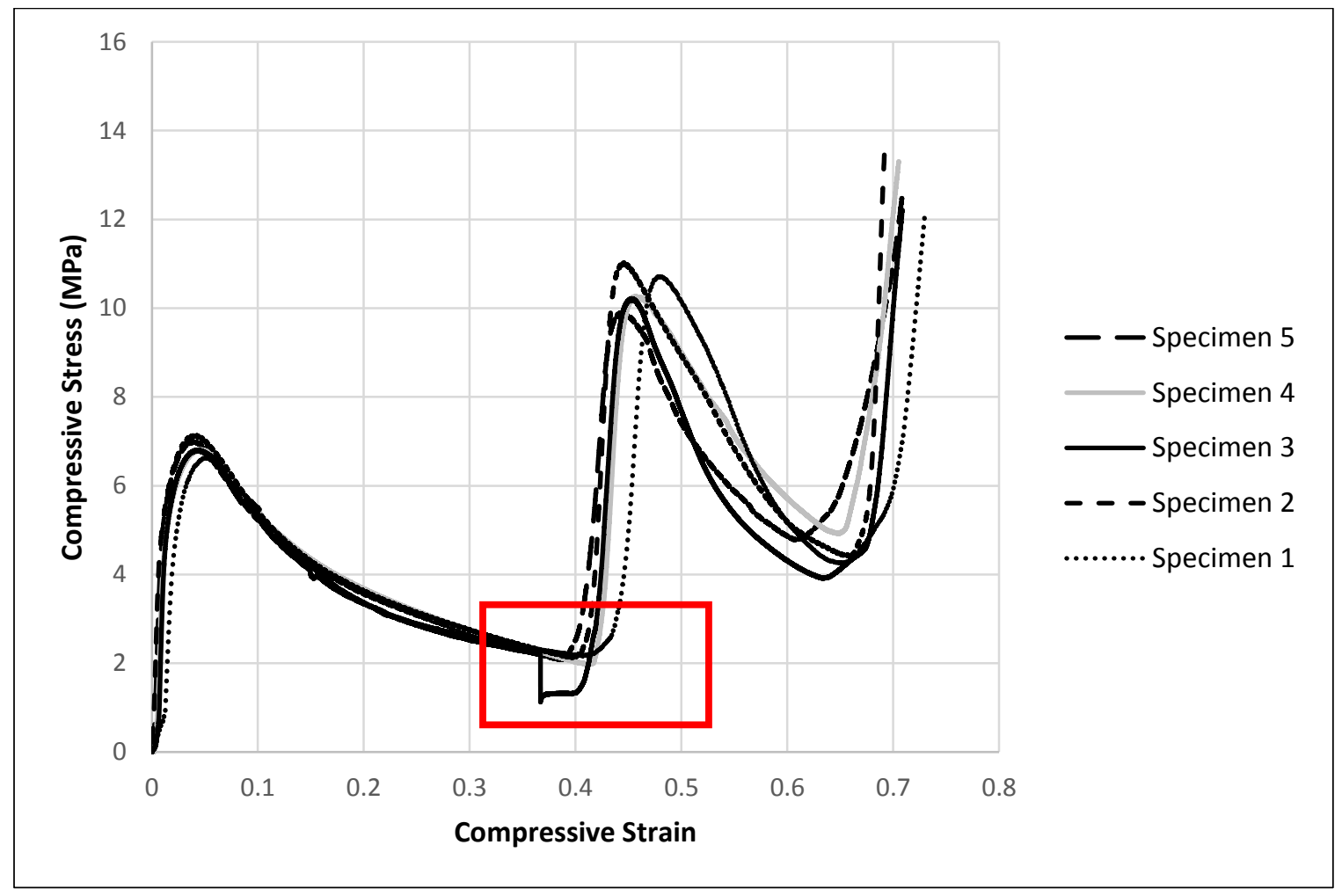

Figure 26: Compressive stress - strain curve for $\{1 B C C\}^{1},\langle 0.862,0.862,1.232\rangle$ with fracture (circled)

\section{Mechanical Characterization of $3^{\wedge} 3$ BCC Lattice Structures in Compression}


The compressive response of the $\{3 B C C\}^{3}$ specimens and variants differs from the response of the individual unit cells. The non-boundary layers of the lattice withstand lower levels of stress than the boundary layers, and in the $\{3 B C C\}^{3}$ specimens, collapse via plastic hinges located at the nodes. 2 distinct peaks can be observed at high values of strain. These peaks are associated with the progressive collapse of the bottom, and then the top boundary layers as seen in the $\{1 B C C\}^{1}$ specimens and variants. The $\{3 B C C\}^{3},\langle 0.862,0.862,1.232\rangle$ (Also known as 55 degree, $0 \%$ radius) did not display 2 distinct peaks. The relatively rough curve displayed in figure 27 (c) at high strain values $(>0.4)$ was dominated by numerous fractures occurring at the bottom boundary layer nodes of the lattice.

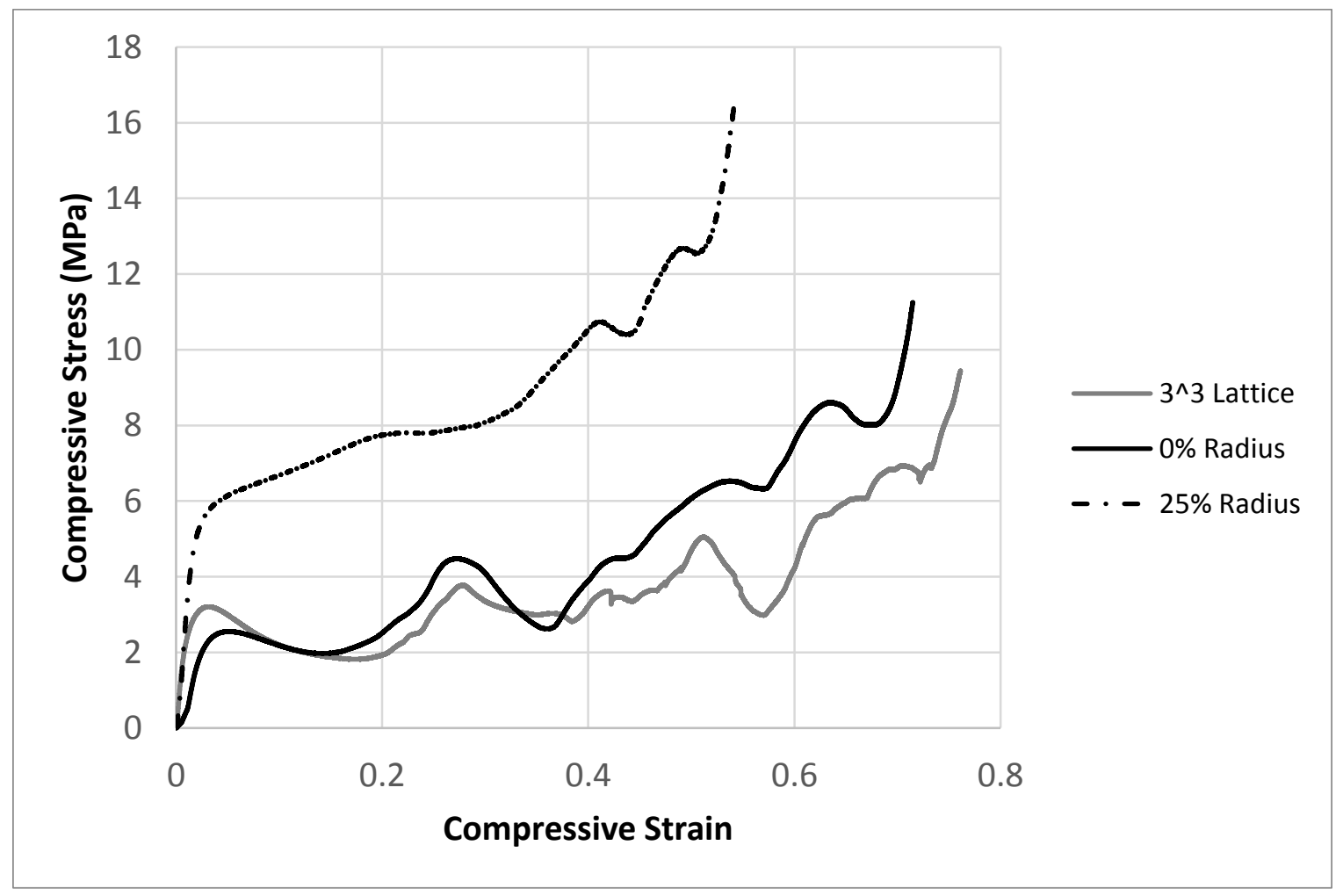

Figure 27: Compressive stress - strain response of $3^{\wedge} 3 \mathrm{BCC}$ lattice specimens

In figure 27 , the 3 different $3^{\wedge} 3$ stress-strain curves are displayed. One specimen of each geometry was tested. From this figure, we can see that the $25 \%$ radius has the highest mechanical properties, the $0 \%$ 
radius with medium properties, and the 55 degree, $0 \%$ radius with lowest mechanical properties, but not much lower than the $0 \%$ radius specimen. All of these specimens had much lower mechanical properties than the individual unit cell, suggesting that the boundary layer condition provides significant support to the unit cell. In figure 28 , the 55 degree, $0 \%$ radius unit cell is compared with the respective lattice to compare the difference.

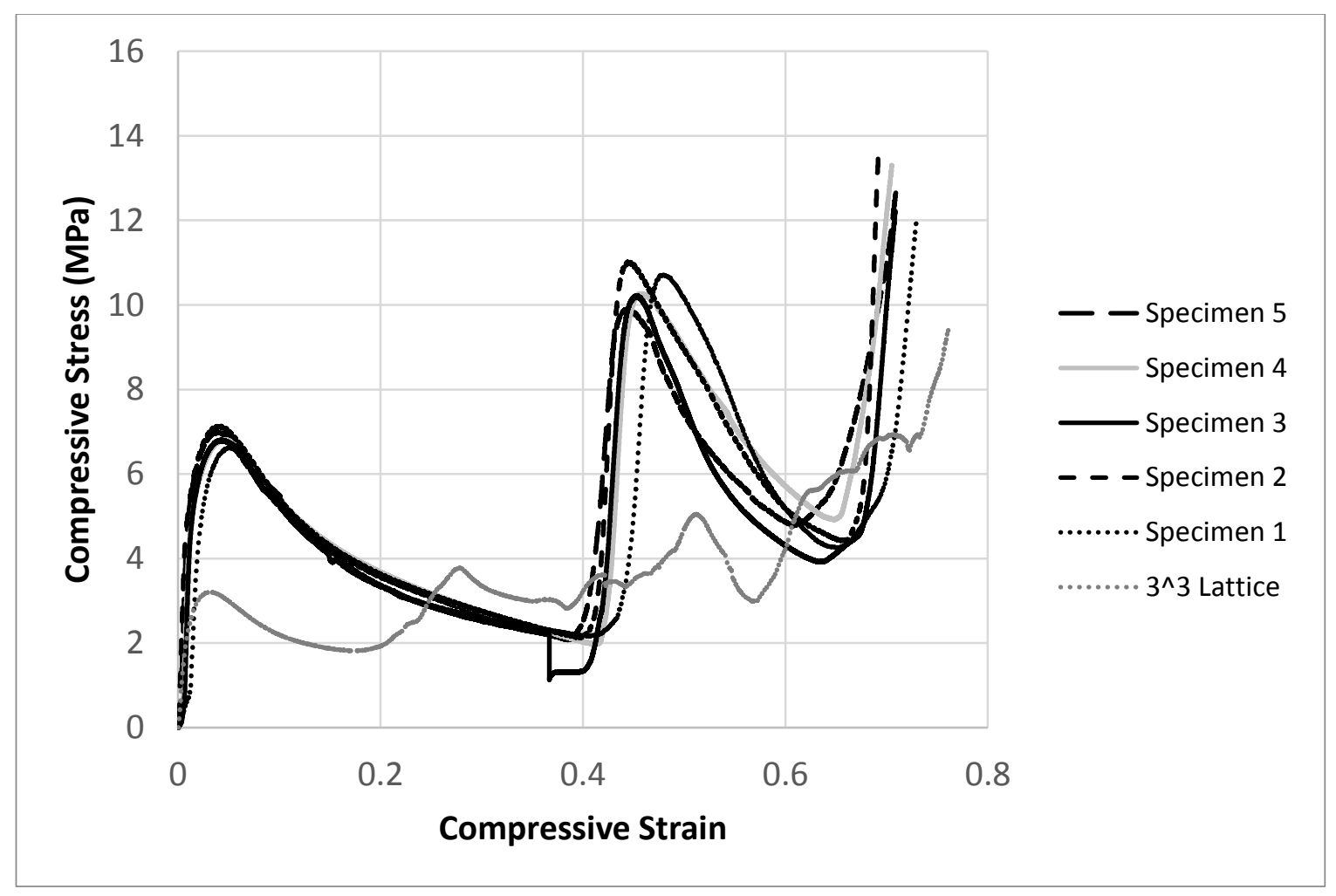

Figure 28: Comparison between 55 degree $0 \%$ radius unit cell specimens and $3^{\wedge} 3$ lattice In figure 28 , it is observed that the 55 degree, $0 \%$ radius lattice specimen displays significantly lower properties than the individual unit cell. From this figure, it can be concluded that the boundary layers provide a significant support to the unit cell and therefore increase the mechanical properties significantly.

\section{Effect of Node Radius}


The $\{3 B C C\}^{3}$ specimen responds to compression differently than the independent unit cell. In the nonboundary layers of the lattice, the independent unit cells fail via plastic hinges located at the nodes rather than in the microstrut. This changes again however as the non-boundary layers of the lattice fully densify before the boundary layers. At very high values of strain $(>0.5)$, the boundary layers fail in a manner consistent with the individual unit cells. The bottom boundary fails first, with plastic hinges forming in the microstruts, followed by the highest ultimate stress achieved by the structure occurring just before the collapse of the top boundary layer. This failure progression is consistent with Gumruk's work on constrained BCC lattice specimens. (Gümrük et al., 2013)

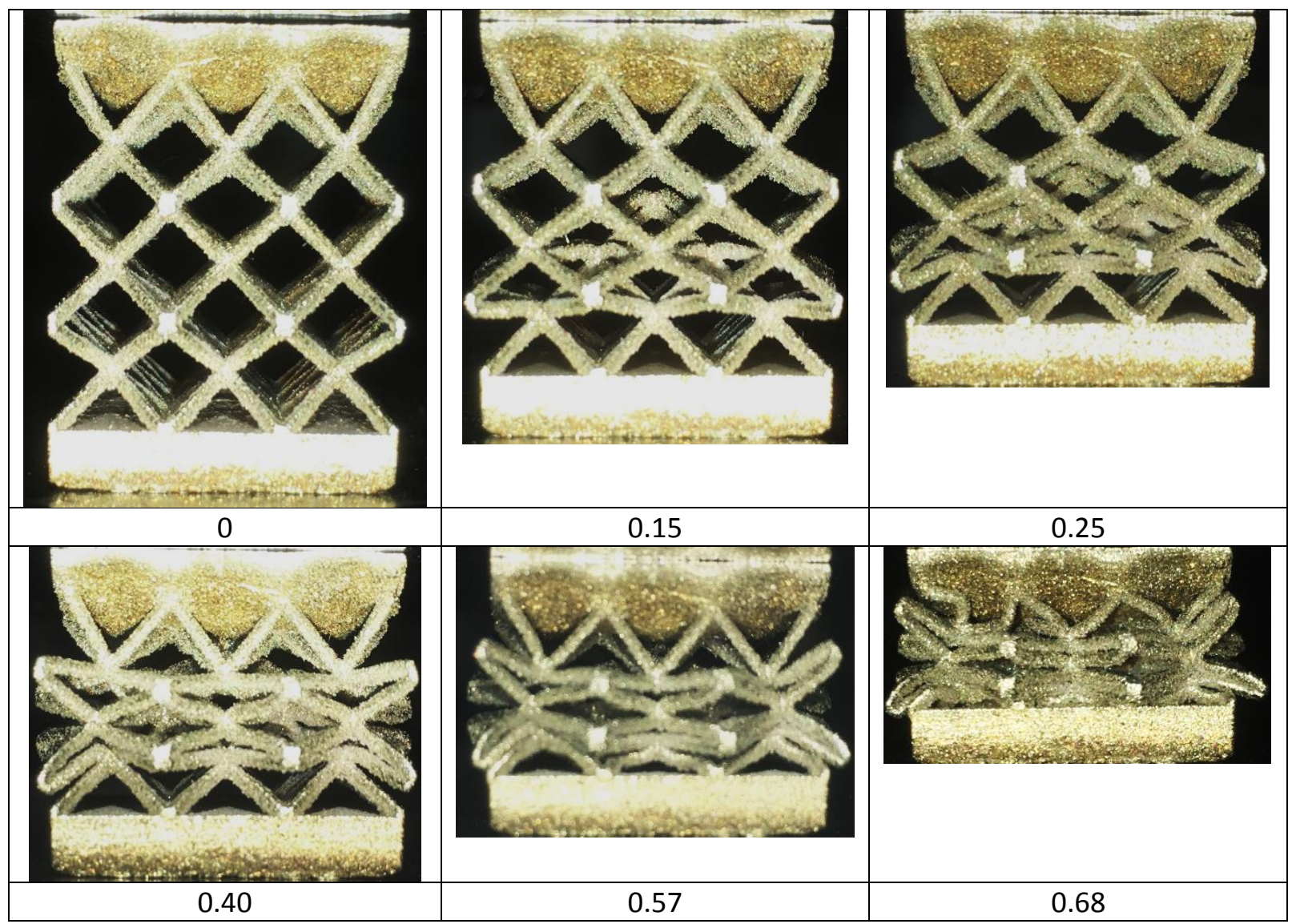

Figure 29: $\{3 B C C\}^{3}$ lattice specimen at increasing values of strain

In figure 29 above, it is interesting to note that the top layer of this specimen fails via the unstable twisting plastic buckling mode. This could be attributed to non-orthogonal normal forces applied from 
the densified layers below the boundary layer, and/or morphological asymmetry as a result of droop in the unsupported top skin.

Differing from the 45 degree $0 \%$ radius $3^{\wedge} 3$ lattice specimen, the $25 \%$ radius specimen did not fail via plastic hinges at the node in the non-boundary layers of the lattice, but rather each of the unit cells failed in a manner consistent with the failure of the independent unit cell. This is dominated by plastic hinges located in the microstruts. By increasing the radius, and therefore size of the node, the weak point of the structure is moved away from the node and into the microstrut.

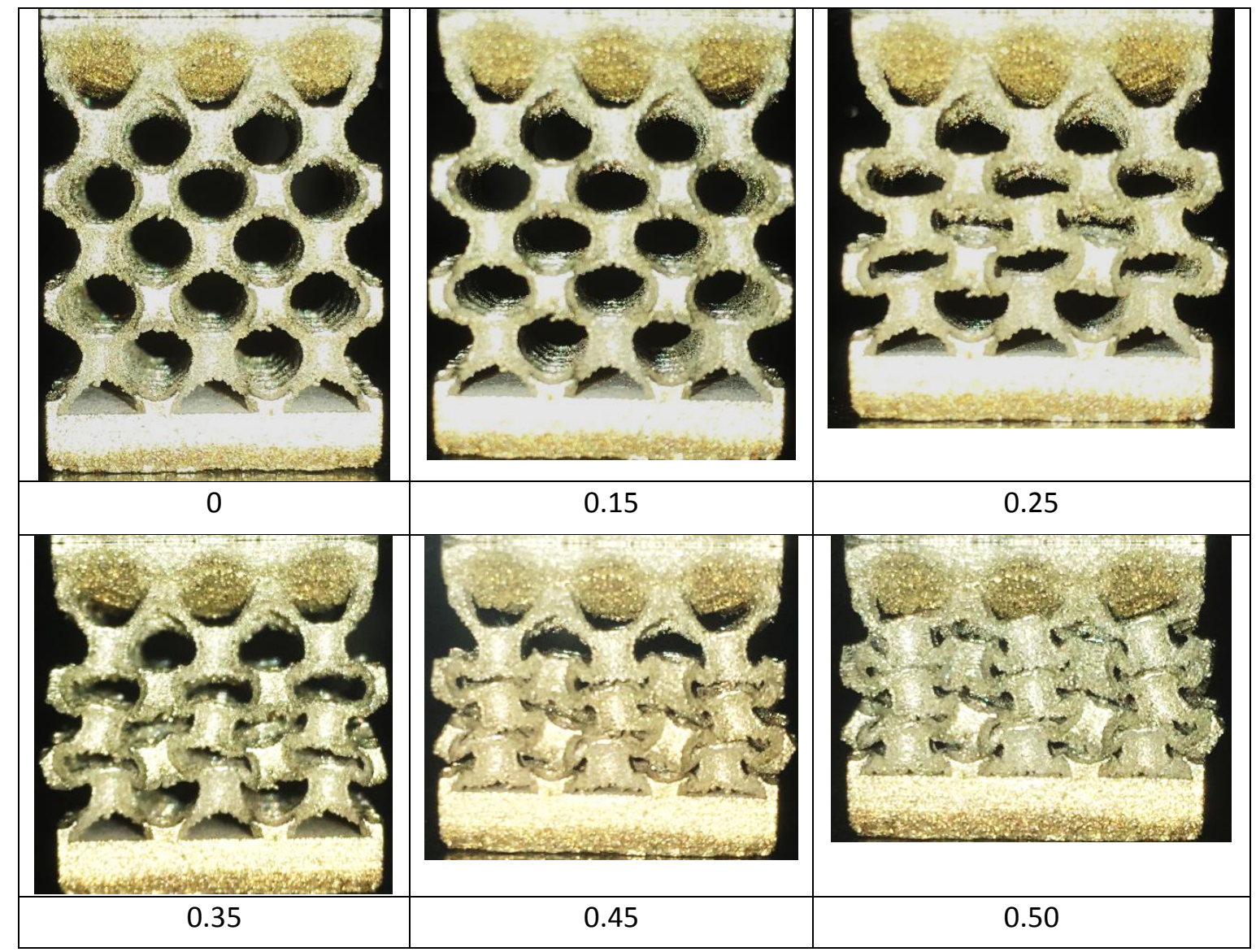

Figure 30: $\{3 B C C\}^{3},\|25\|$ specimen at increasing values of strain

Each of the independent unit cells of the lattice failed via plastic hinges located in the microstrut, lending to a very stable failure progression, where the non-boundary layer cells collapsed concurrently for strain values 0 to 0.3 , followed by the bottom boundary layer collapse and finally the top boundary 
layer collapse. This can be observed in figure 30 above. Consistent with the other specimens, the highest ultimate stress was recorded just before the collapse of the top boundary layer.

\section{Mechanical Characterization of 3^3 BCC Upskin “OFF” Specimens}

Four $3^{\wedge} 3$ lattice specimens of increasing radius were tested with the Upskin parameter turned "OFF".

The resulting stress strain - curves are shown in figure 31 below. In comparison to the Upskin "ON" specimens, these specimens exhibited very poor mechanical properties as can be seen in figure 10, which compares an upskin off specimen with an upskin on specimen of the same geometry. While inferior to the Upskin "ON" specimens, it is valuable to observe and discuss the increasing values.. One specimen of each geometry was tested. Figure 32 displays the four specimens tested at $25 \%$ strain.

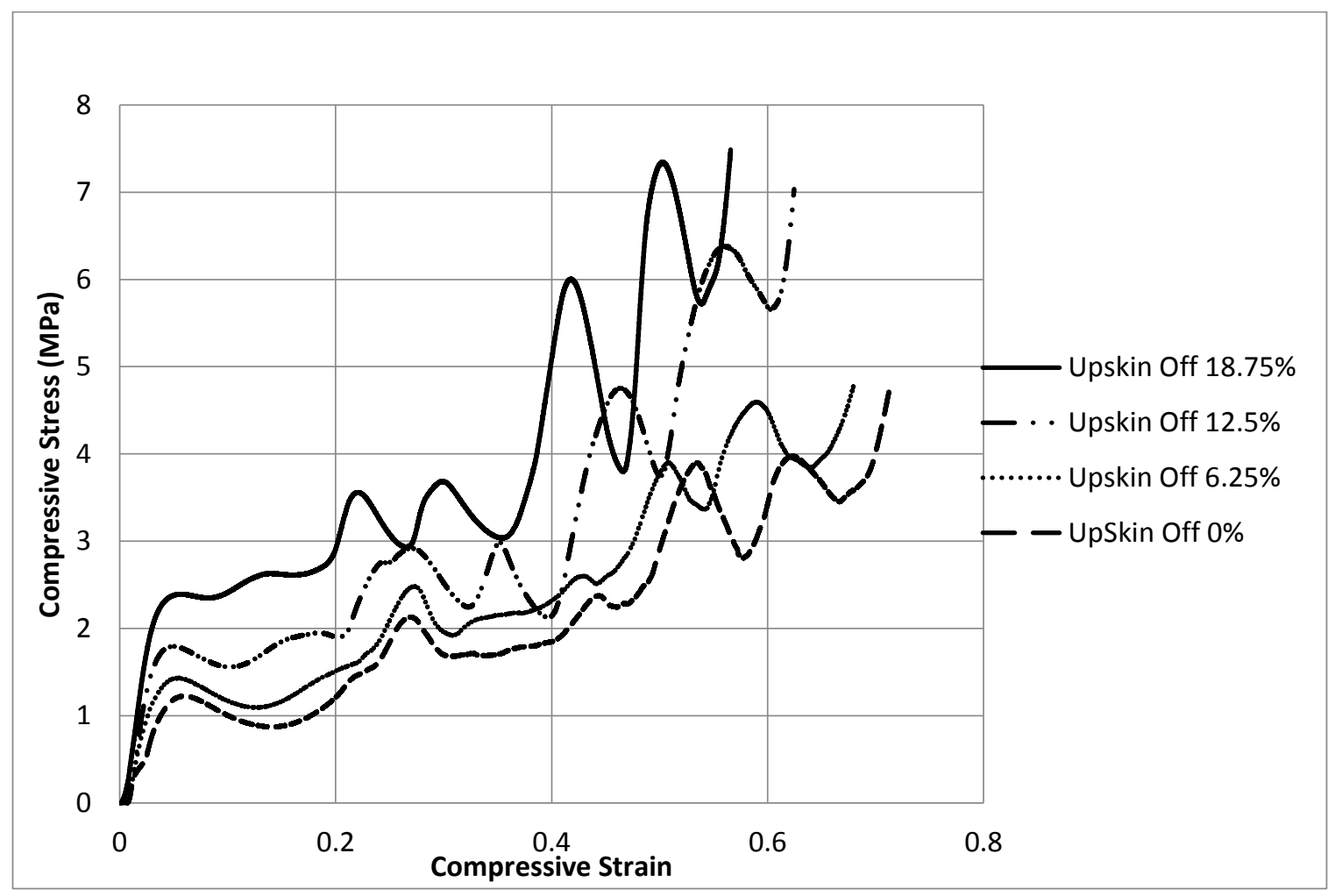

Figure 31: Stress - strain curves for Upskin "OFF" Specimens ranging from 0\% radius to $18.75 \%$ radius 
Increasing the node radius changes the failure mode in the non-boundary layers from a node bending dominated failure to a plastic hinge dominated failure within the microstrut. Increasing the node radius increases the overall size of the node, decreasing the length of the microstruts.

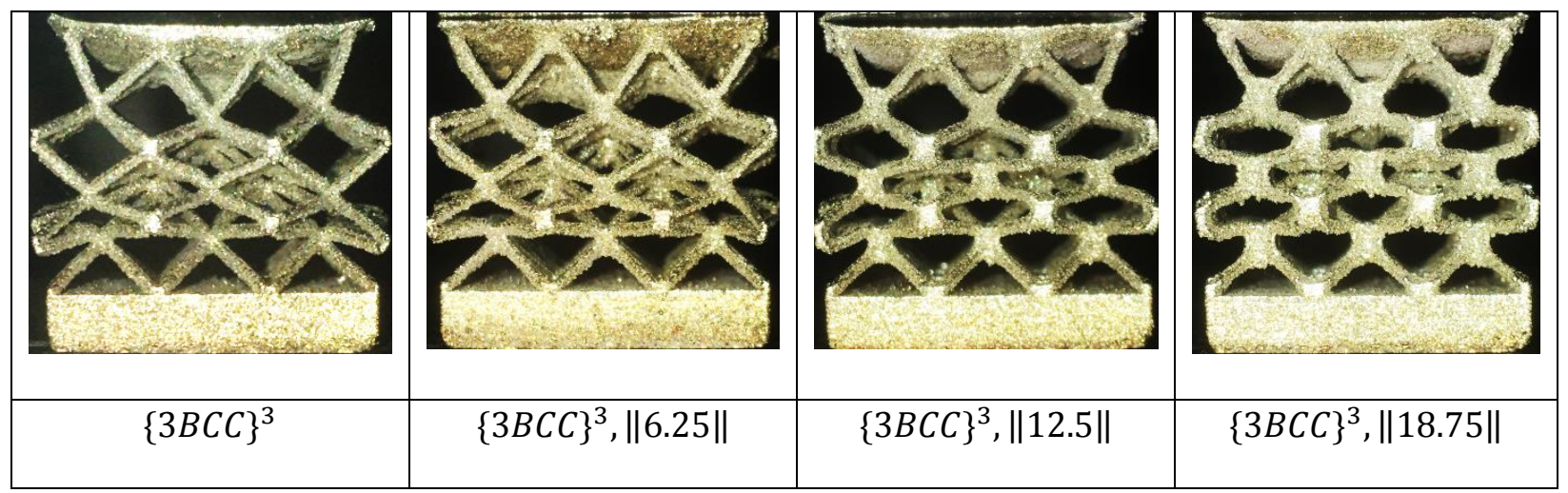

Figure 32 : Upskin "OFF" lattice structure specimens at 0.25 strain

\section{Effect of Strut Angle}

Similar to the unit cell specimens, increasing the strut angle increased the modulus of elasticity and densification strain, but decreased the ultimate stress. The increased strut angle increased the initial ultimate stress in comparison to the $\{3 B C C\}^{3}$, and led to a failure mode not seen in the $\{3 B C C\}^{3}$ specimens. Instead of the stable failure mode seen in all other specimens, the $\{3 B C C\}^{3},\langle 0.862,0.862,1.232\rangle$ specimen initially failed via the unstable twisting buckling mode seen in Gumruks work (Gümrük et al., 2013) as highlighted by the red box in figure 33.

The $\{3 B C C\}^{3},\langle 0.862,0.862,1.232\rangle$ was the only specimen tested to encounter several microstrut fractures at the nodes at high values of strain (>0.4). No distinct peaks are observed prior to densification due to these fractures. The stress strain curve for this 55 degree, $0 \%$ radius specimen can be seen in figure 34 . Only one specimen of this geometry was tested. 


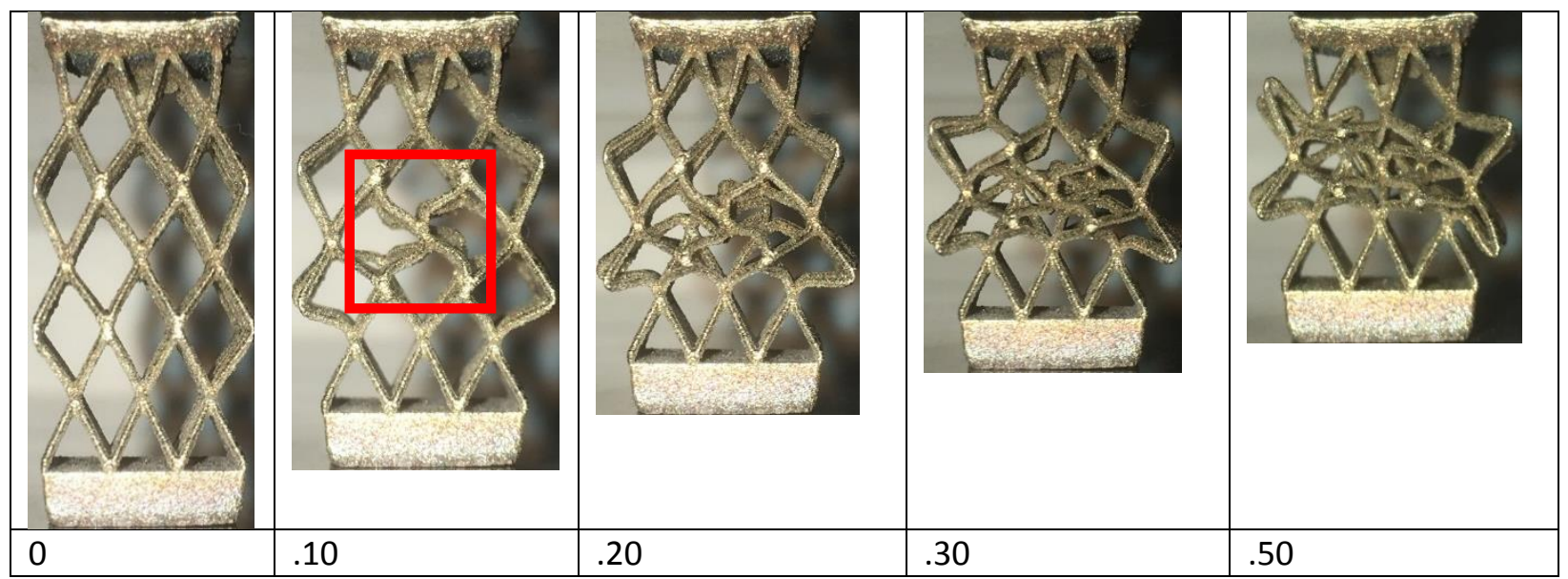

Figure 33: $\{3 B C C\}^{3},\langle 0.862,0.862,1.232\rangle$ at increasing values of strain with unstable buckling failure mode circled

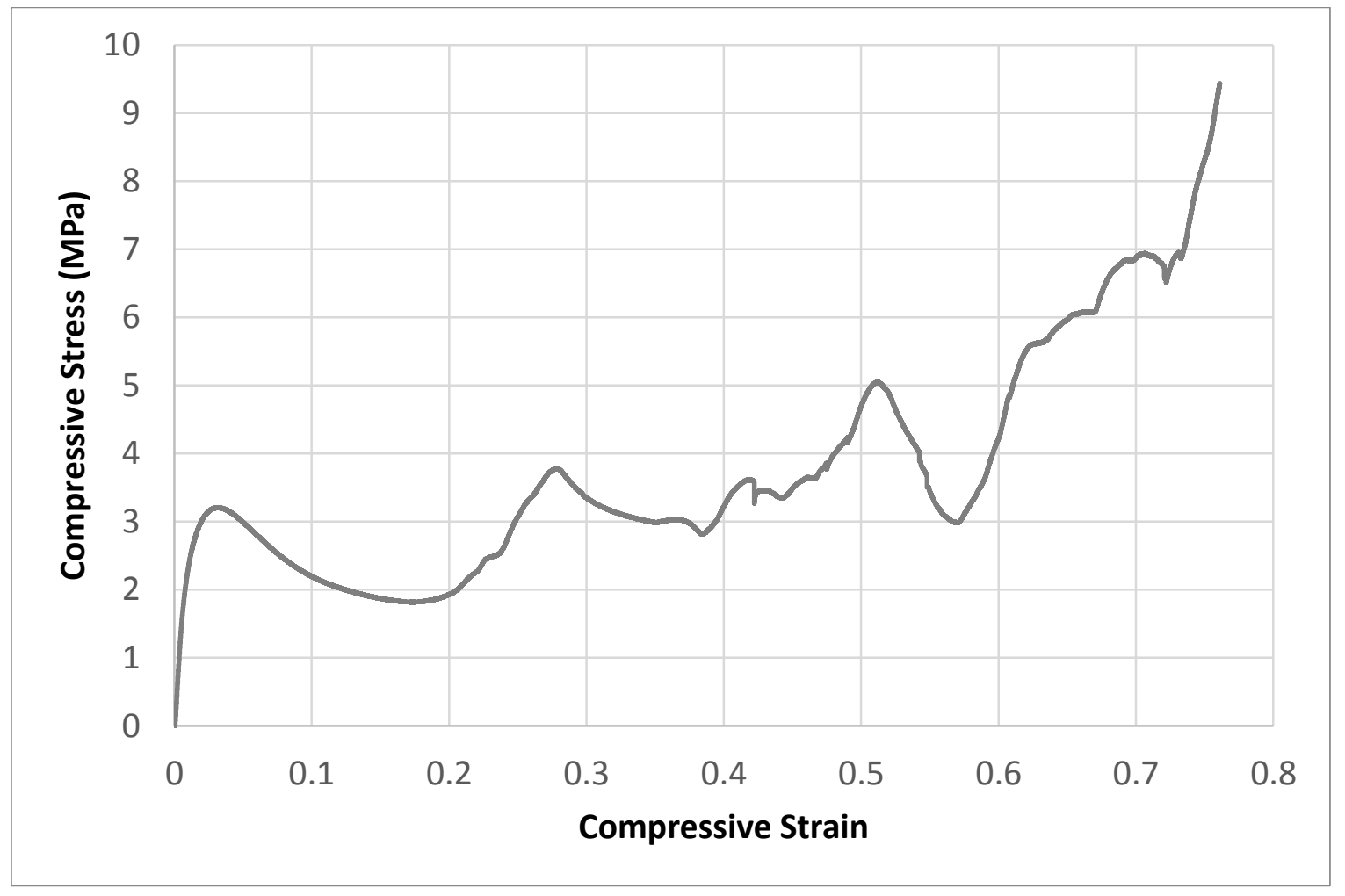

Figure 34: Compressive Stress - Strain curve for $3^{\wedge} 355$ degree lattice specimen

\section{Discussion of Approximated Relative Density and Specific Values}

The fabrication process of the test specimens rendered the measurement of a consistent, accurate mass impossible. The fabrication process required supports to raise the specimens off the build plate. These 
support structures can be seen in Figure 11, which displays the test specimens prior to removal from the build plate. In order to develop predictive numerical models of the mechanical properties of the structures, the relative density must be calculated. To approximate the relative density, the as built part density must be estimated. To find this, the CAD model's theoretical mass was divided by the measured volume. From the determined CAD theoretical mass, it is useful to determine the specific energy absorption, specific stiffness, and specific strength of the structures. These values can be found in table 9. The specific energy absorption and modulus was calculated using the experimentally measured energy absorbed up to densification and first peak modulus and dividing by the CAD theoretical mass.

Table 9 : Approximate relative density and specific values based on theortical mass

\begin{tabular}{|c|l|l|l|}
\hline Structure ID & $\begin{array}{l}\text { Relative } \\
\text { Density \% }\end{array}$ & $\begin{array}{l}\text { Specific Energy } \\
\text { Absorption (J/g) }\end{array}$ & $\begin{array}{l}\text { Specific } \\
\text { Stiffness } \\
\text { (MPa/g) }\end{array}$ \\
\hline$\{1 B C C\}^{1}$ & $6.2 \%$ & $\mathbf{1 0 . 2 3}$ & 5692 \\
\hline$\{1 B C C\}^{1},\|6.25\|$ & $6.4 \%$ & 10.18 & 6060 \\
\hline$\{1 B C C\}^{1},\|12.5\|$ & $6.8 \%$ & 8.7 & 5656 \\
\hline$\{1 B C C\}^{1},\|18.75\|$ & $8.1 \%$ & 7.0 & 4880 \\
\hline$\{1 B C C\}^{1},\|25\|$ & $\mathbf{9 . 8 \%}$ & 7.3 & 5145 \\
\hline$\{1 B C C\}^{1},\langle 0.862,0.862,1.232\rangle$ & $7.0 \%$ & 6.4 & 13608 \\
\hline$\{3 B C C\}^{3}$ & $5.0 \%$ & 8.0 & 104 \\
\hline$\{3 B C C\}^{3},\|25\|$ & $8.7 \%$ & 6.7 & 182 \\
\hline$\{3 B C C\}^{3},\langle 0.862,0.862,1.232\rangle$ & $6.9 \%$ & 5.2 & 267 \\
\hline
\end{tabular}

From these approximated values, the $\{1 B C C\}^{1},\|25\|$ had the highest relative density, the $\{1 B C C\}^{1}$ specimens exhibit the greatest specific energy absorption of the structures tested, and the $\{1 B C C\}^{1},\langle 0.862,0.862,1.232\rangle$ specimens exhibit the greatest specific stiffness. 


\section{CHAPTER 5 PREDICTIVE NUMERICAL MODELS}

\section{Predictive Gibson Ashby Model}

The Gibson-Ashby model (Gibson \& Ashby, 1997) provides an estimation of the mechanical properties of an open cell metallic foam via formulas that relate the relative density of a material to the bulk density.

$$
\frac{E}{E_{0}}=C_{1}\left(\frac{\rho}{\rho_{0}}\right)^{2} \quad \frac{\sigma}{\sigma_{0}}=C_{2}\left(\frac{\rho}{\rho_{0}}\right)^{1.5}
$$

Figure 35: Gibson-Ashby formulas for estimating compressive modulus and compressive strength of open cell metallic foams

All values which include the subscript 0 represent the properties of the bulk material, while all values

without a subscript represent the properties of the cellular material. ${ }^{\rho} / \rho_{0}$ is representative of the relative density of the cellular material. $\mathrm{E}$ is representative of the compressive modulus of the cellular material. $\sigma$ is representative of the compressive yield strength of the cellular material. The values of $C$ are constants used to fine tune the model after experimental testing.

The ultimate tensile strength and modulus of 633MPa and 184GPa sourced from the SLM Solutions user manual is used for this approximation, Using the relative densities calculated from the theoretical mass of the specimens, the above formulas are used to estimate the values of compressive initial ultimate stress and compressive modulus. These values are shown in the table and figure below and compared to experimentally obtained values of initial ultimate stress and compressive modulus.

To find $\mathrm{C} 1$ and $\mathrm{C2}$, the formulas shown in figure 35 are rearranged to solve for $\mathrm{C} 1$ and $\mathrm{C} 2$, and the experimentally achieved values of E and $\rho$ are inputted into the formula. The values of $C 1$ and $C 2$ are solved for, and then used for future estimations. In this manner, a predictive model with a corrective constant specific to a geometry can be created. 
The calculated values for $\mathrm{C} 1, \mathrm{C} 2$, and the pre-corrective constant values for ultimate stress and modulus are displayed in table 10. A visual comparison between the pre-corrective constant values of modulus can be found in figure 36. A visual comparison between the pre-corrective constant values of ultimate stress can be found in figure 37 . With corrective constants, the values which come from the GibsonAshby formulas match the experimentally achieved values. 
Table 10: Gibson-Ashby calculated values

\begin{tabular}{|l|l|l|l|l|l|}
\hline \multicolumn{1}{|c|}{ Structure ID } & $\begin{array}{l}\text { Relative } \\
\text { Density } \\
\%\end{array}$ & $\begin{array}{l}\text { G-A } \\
\text { Predicted } \\
\text { Modulus } \\
\text { (MPa) }\end{array}$ & $\begin{array}{l}\text { Modulus } \\
\text { Corrective } \\
\text { Constant C1 }\end{array}$ & $\begin{array}{l}\text { G-A } \\
\text { Predicted } \\
\text { Strength } \\
\text { (Mpa) }\end{array}$ & $\begin{array}{l}\text { Strength } \\
\text { Corrective } \\
\text { Constant C2 }\end{array}$ \\
\hline$\{1 B C C\}^{1}$ & $6.2 \%$ & 699 & 0.41 & 9.7 & 0.96 \\
\hline$\{1 B C C\}^{1},\|6.25\|$ & $6.4 \%$ & 761 & 0.41 & 10.3 & 0.99 \\
\hline$\{1 B C C\}^{1},\|12.5\|$ & $6.8 \%$ & 861 & 0.39 & 11.3 & 0.91 \\
\hline$\{1 B C C\}^{1},\|18.75\|$ & $8.1 \%$ & 1205 & 0.29 & 14.6 & 0.69 \\
\hline$\{1 B C C\}^{1},\|25\|$ & $9.8 \%$ & 1773 & 0.22 & 19.5 & 0.61 \\
\hline$\{1 B C C\}^{1},\langle 0.862,0.862,1.232\rangle$ & $7.0 \%$ & 914 & 0.73 & 11.8 & 0.58 \\
\hline$\{3 B C C\}^{3}$ & $5.0 \%$ & 868 & 0.30 & 7.2 & 0.36 \\
\hline$\{3 B C C\}^{3},\|25\|$ & $8.7 \%$ & 467 & 0.30 & 16.2 & 0.66 \\
\hline$\{3 B C C\}^{3},\langle 0.862,0.862,1.232\rangle$ & $6.9 \%$ & 1388 & 0.41 & 11.4 & 0.28 \\
\hline
\end{tabular}

Modulus Comparison Between Gibson-Ashby Model and Experimental Results

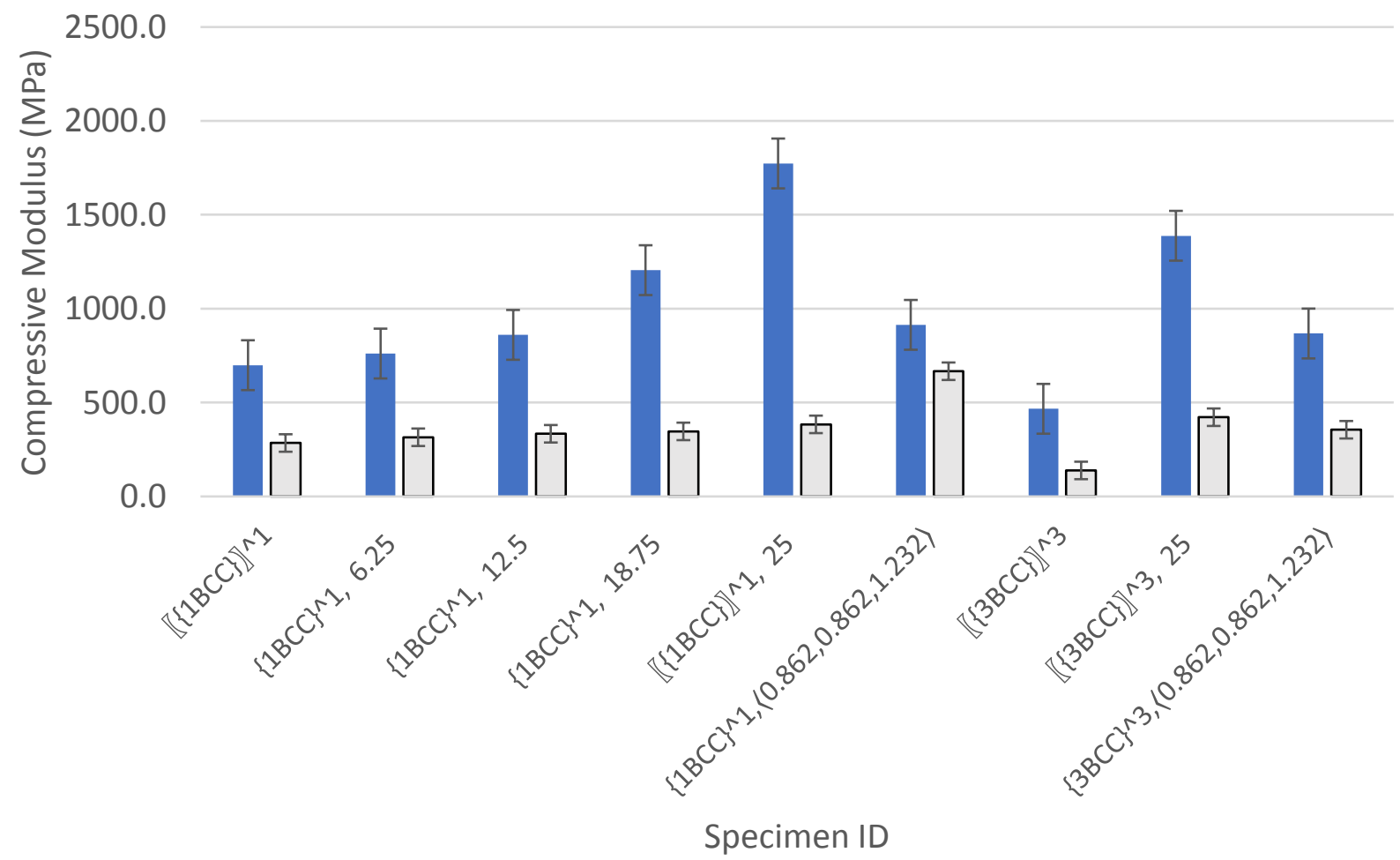

Numerical Modulus $\quad \square$ Experimental Modulus

Figure 36: Comparison of numerical and experimentally obtained values of compressive strength 


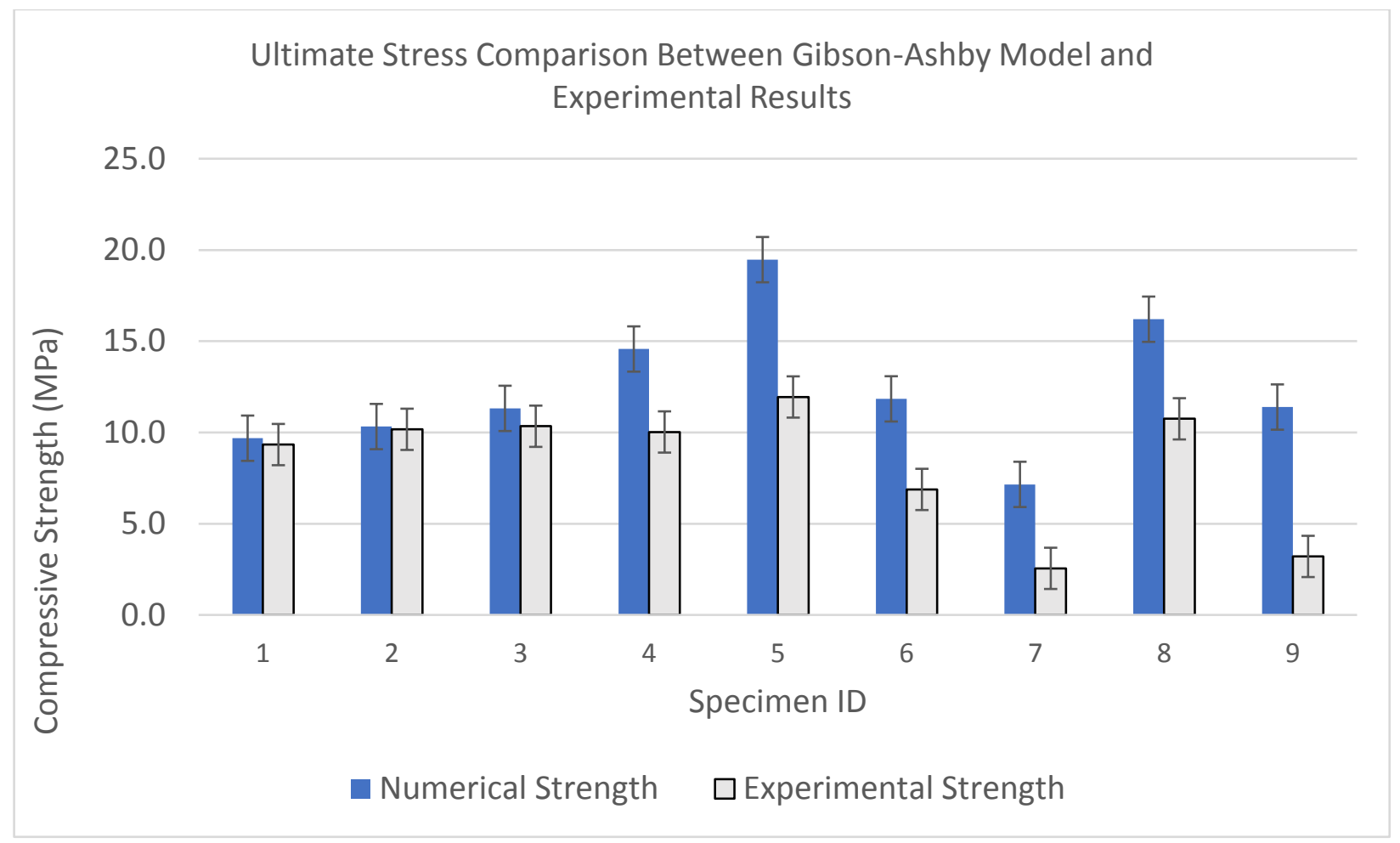

Figure 37: Comparison of numerical and experimentally obtained values of compressive modulus

The Gibson Ashby model accurately predicts which structure will be strongest, but does not accurately predict which structure will be stiffest. This unfortunately indicates that the Gibson Ashby model is not the best method to predict the values of these structures. While technically these structures are open cell metallic foams, the effect of the geometry of the unit cell is significant, while the relative density is not as significant. With the addition of the corrective constants however, these formulas could be used to effectively predict the properties of the tested specimens.

The major disparity between numerically calculated and experimentally obtained values indicates that this model is not ideal for accurately predicting the mechanical properties of individual lattice unit cells or $3^{\wedge} 3$ specimens. 


\section{FUSION 360 Finite Element Model}

Using the same properties used to develop the Gibson-Ashby model for this study (633MPa ultimate strength), a basic static stress linear FE analysis was performed using Fusion 360 to determine the ultimate yield stress.

The model was fully constrained on the bottom skin, and an arbitrary force was applied to the top skin. The factor of safety was set as 633MPa for internal stresses. From the analysis, the factor of safety was obtained and was multiplied by the applied force to obtain the predicted ultimate force which the structure can withstand prior to plastic deformation. The ultimate predicted force was then divided by the cross sectional area of the space filling structure to obtain the predicted ultimate strength. These predicted values of ultimate strength can be seen in Table 11 below.

Table 11: FEA obtained ultimate strengths

\begin{tabular}{|l|l|}
\hline Structure ID & FEA Predicted Ultimate Strength (Mpa) \\
\hline$\{1 B C C\}^{1}$ & 3.014 \\
\hline$\{1 B C C\}^{1},\|6.25\|$ & 2.704 \\
\hline$\{1 B C C\}^{1},\|12.5\|$ & 3.682 \\
\hline$\{1 B C C\}^{1},\|18.75\|$ & 3.984 \\
\hline$\{1 B C C\}^{1},\|25\|$ & 4.62 \\
\hline$\{1 B C C\}^{1},\langle 0.862,0.862,1.232\rangle$ & 3.314 \\
\hline$\{3 B C C\}^{3}$ & 0.768 \\
\hline$\{3 B C C\}^{3},\|25\|$ & 1.670 \\
\hline$\{3 B C C\}^{3},\langle 0.862,0.862,1.232\rangle$ & 1.125 \\
\hline
\end{tabular}

Similar to the Gibson-Ashby model, the FEA model effectively predicts which structure will be strongest, and which will be weakest. Unlike the Gibson-Ashby model however, the values obtained are significantly less than the experimentally obtained values. The FEA model indicates a failure location which always occurs at or near the node on the bottom microstruts of the unit cell as can be seen in figure 39 and figure 40 . Figure 40 displays a failure located in the central unit cell of the $3^{\wedge} 3$ lattice. 


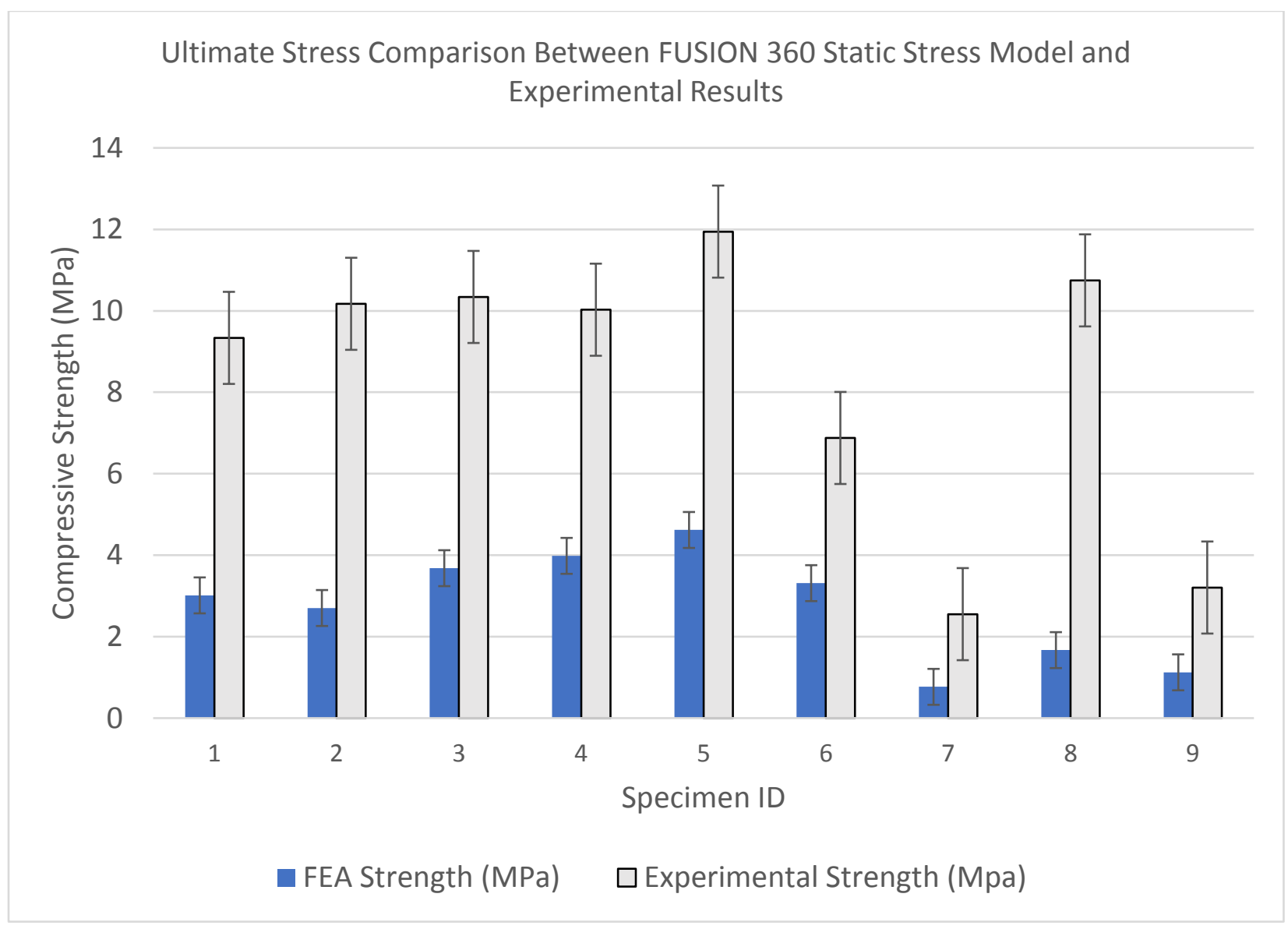

Figure 38: Comparison of FEA obtained strength and experimentally obtained strength
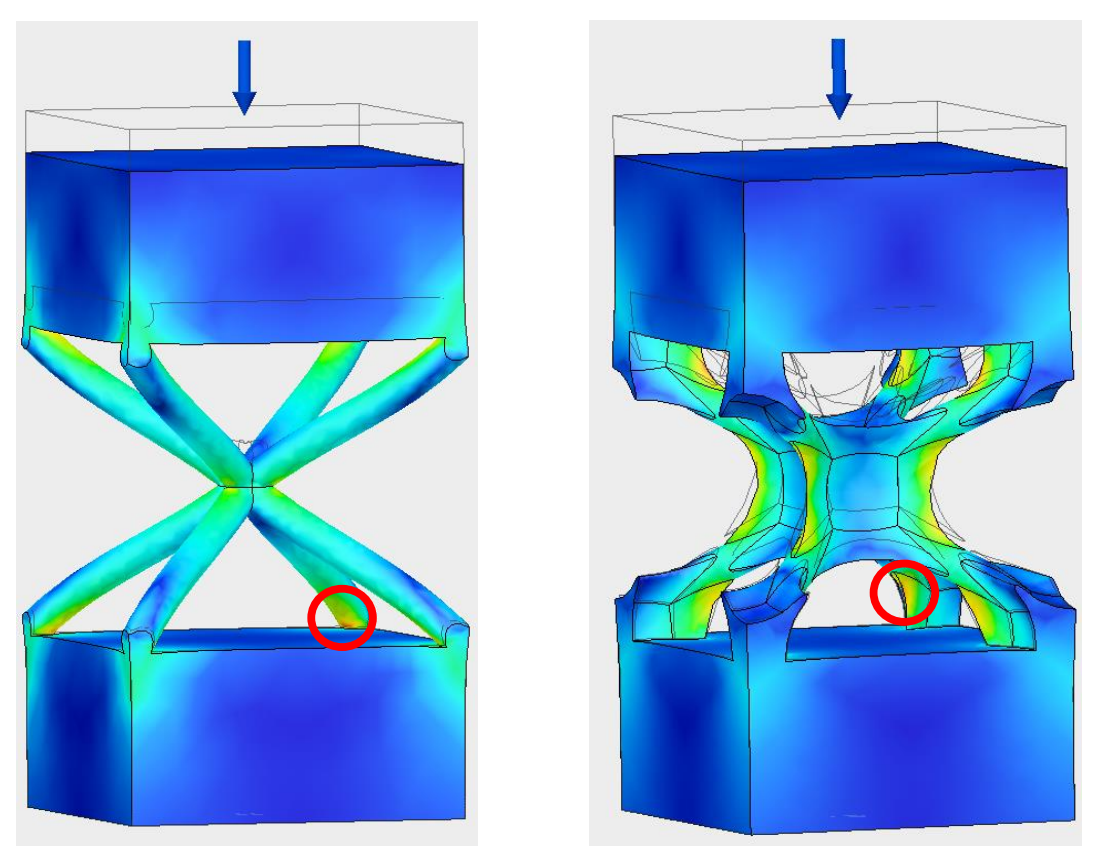

Figure 39: $\{1 B C C\}^{1}$ and $\{1 B C C\}^{1},\|25\|$ with yield points at the nodes circled 

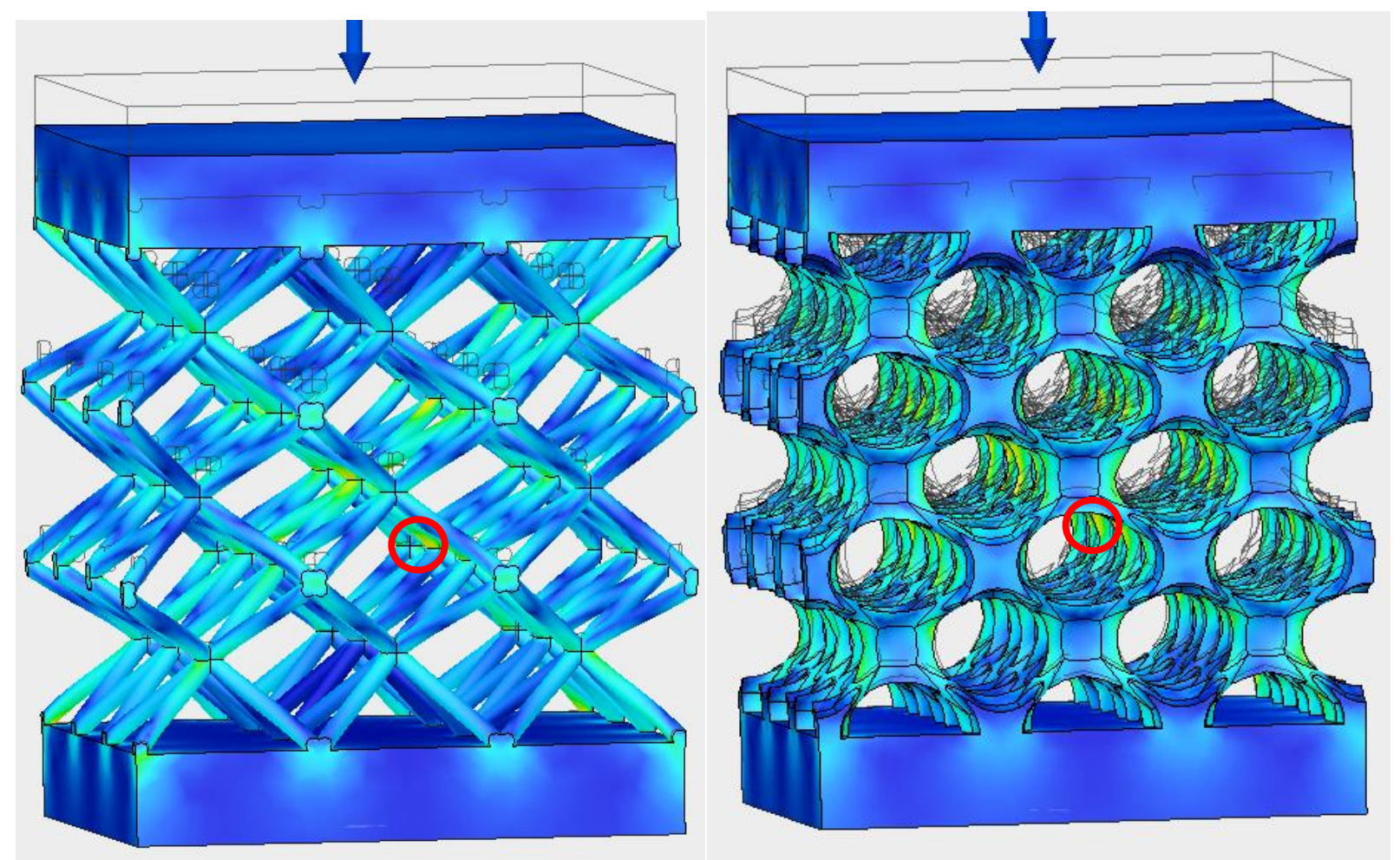

Figure 40: $\{3 B C C\}^{3}$ and $\{3 B C C\}^{3},\|25\|$ with yield locations at the bottom microstrut nodes of the centermost unit cell circled

While there is a vast disparity between the FEA obtained values and the experimentally obtained values, the FEA models raise the following two hypothesis regarding the differences.

It is hypothesized that during compression, the stresses within the microstruts reach the base material's ultimate stress well before the structure itself reaches its ultimate compressive stress. This indicates that as the microstruts within the structure plastically deform, the strength of the structure actually increases until a global failure of the unit cell occurs.

It can also be hypothesized that the observed droop and morphological deviations from the nominal geometry plays a significant role in the experimentally obtained values. 


\section{CHAPTER 6 CONCLUSIONS AND RECOMMENDATIONS FOR FUTURE WORK}

\section{Conclusions}

This work focuses on the mechanical characterization of body centered cubic unit cell, and modifications to its topology with regards to node radius and microstrut angle. The test specimens were fabricated using a SLM solutions 125 machine tool with a 400W laser. The results from this study are used to understand the mesostructural failure mode of the BCC lattice structure. Dimensional analysis suggests that $a+5 \%$ scaling should be used in the $X$ and $Y$ axis, and $a+8 \%$ scaling should be used in the $Z$ axis to compensate for shrinkage on this machine. The average droop at the bottom center of the node was $0.623 \mathrm{~mm}$ and the average droop at the top center of the node was $0.065 \mathrm{~mm}$. Mechanical compression testing indicates that increasing the node radius does not significantly affect the mechanical properties of the mesostructure until a radius of $25 \%$ is reached. Compression tests of $25 \%$ radius unit cells and $3^{\wedge} 3$ lattice specimens displayed near ideal elastic-plastic deformation behavior. Increasing the strut angle of the unit cell significantly increases the modulus of elasticity and significantly decreases the ultimate stress. Failure of the BCC unit cell is characterized by plastic hinge bending at the node in non-boundary layers, and plastic hinge bending at the microstrut in constrained boundary layers. The "Up Skin" parameter on the SLM solutions build software produces significantly better parts with improved surface finish, strength, modulus, and morphological accuracy. Using a theoretical mass to determine relative density, numerical models were developed using both the Gibson-Ashby model and Fusion 360 FEA solver. The Gibson Ashby model initially provides a poor predictor of the modulus and ultimate strength of the structures, however with the addition of a corrective constant, the models can accurately predict these values. The Fusion 360 FEA model was limited to linear static stress, and therefore the obtained results were far lower than those experimentally obtained. This indicates that the base material within the structure yields and plastically deforms prior to the global yielding of the entire structure. 


\section{Recommendations for Future Work}

During the course of this study, several uncontrolled variables were encountered. The main unexpected variable was the heat gradient encountered on the machine build plate. It is recommended that a study on the root cause of the heat tint observed on the specimens is performed, with a focus on build chamber oxygen levels and temperature variation. These shall be correlated with specimen mechanical properties. A significant challenge to this study was the effective removal of support material from the test specimens. A study on a cost effective and repeatable process to remove support material from small specimens could significantly benefit the AM community and Cal Poly.

With the discovery that the $\{1 B C C\}^{1},\|25\|$ and $\{3 B C C\}^{3},\|25\|$ respond with nearly ideal energy absorbing behavior, it is of interest to perform impact tests on the structure to determine its dynamic compressive response. Experimenting with a combination of increased microstrut angle and node radius could also result in increased stiffness, as well as an increased ultimate stress. 


\section{BIBLIOGRAPHY}

1. Ahn, J.-H., Nguyen, K.-H., Park, Y.-B., Kweon, J.-H., \& Choi, J.-H. (2010). A Numerical Study of the High-Velocity Impact Response of a Composite Laminate Using LS-DYNA. International Journal of Aeronautical and Space Sciences, 11(3), 221-226. https://doi.org/10.5139/IJASS.2010.11.3.221

2. Ashby, M. F. (1983). The mechanical properties of cellular solids. Metallurgical Transactions A, 14(9), 1755-1769. https://doi.org/10.1007/BF02645546

3. Babaee, S., Jahromi, B. H., Ajdari, A., Nayeb-Hashemi, H., \& Vaziri, A. (2012). Mechanical properties of open-cell rhombic dodecahedron cellular structures. Acta Materialia, 60(6-7), 2873-2885. https://doi.org/10.1016/j.actamat.2012.01.052

4. Baumeister, J., Banhart, J., \& Weber, M. (1997). Aluminium foams for transport industry. Materials \& Design, 18(4-6), 217-220. https://doi.org/10.1016/S0261-3069(97)00050-2

5. Bele, E., Bouwhuis, B. A., Codd, C., \& Hibbard, G. D. (2011). Structural ceramic coatings in composite microtruss cellular materials. Acta Materialia, 59(15), 6145-6154. https://doi.org/10.1016/j.actamat.2011.06.027

6. Bonatti, C., \& Mohr, D. (2017). Large deformation response of additively-manufactured FCC metamaterials: From octet truss lattices towards continuous shell mesostructures. International Journal of Plasticity, 92, 122-147. https://doi.org/10.1016/j.ijplas.2017.02.003

7. Clough, E. C. (2013). LARGE-DISPLACEMENT LIGHTWEIGHT ARMOR by. California Polytechnic State University, San Luis Obispo.

8. Davis, D. (2012). Finite element modeling of ballistic impact on a glass fiber composite armor. California Polytechnic State University, San Luis Obispo.

9. DEPARTMENT OF DEFENSE. TEST METHOD STANDARD V50 BALLISTIC TEST FOR ARMOR (1997). Washington D.C., United States of America. Retrieved from http://scholar.google.com/scholar?hl=en\&btnG=Search\&q=intitle:V50+BALLISTIC+TEST+ FOR+ARMOR\#0\%5Cnhttp://scholar.google.com/scholar?hl=en\&btnG=Search\&q=intitle: V50+Ballistic+Test+for+Armor\%230

10. Deshpande, V. S., Fleck, N. A., \& Ashby, M. F. (2001). Effective properties of the octettruss lattice material. Journal of the Mechanics and Physics of Solids, 49(8), 1747-1769. https://doi.org/10.1016/S0022-5096(01)00010-2

11. Dong, L., Deshpande, V., \& Wadley, H. (2015). Mechanical response of Ti-6Al-4V octettruss lattice structures. International Journal of Solids and Structures, 60, 107-124. https://doi.org/10.1016/j.ijsolstr.2015.02.020

12. Dong, L., \& Wadley, H. (2015). Mechanical properties of carbon fiber composite octettruss lattice structures. Composites Science and Technology, 119, 26-33. https://doi.org/10.1016/j.compscitech.2015.09.022

13. Evans, A. G., He, M. Y., Deshpande, V. S., Hutchinson, J. W., Jacobsen, A. J., \& Carter, W. B. (2010). Concepts for enhanced energy absorption using hollow micro-lattices. International Journal of Impact Engineering, 37(9), 947-959. https://doi.org/10.1016/j.ijimpeng.2010.03.007 
14. Fan, H., Yang, L., Sun, F., \& Fang, D. (2013). Compression and bending performances of carbon fiber reinforced lattice-core sandwich composites. Composites Part A: Applied Science and Manufacturing, 52, 118-125. https://doi.org/10.1016/j.compositesa.2013.04.013

15. Fleck, N. A., Deshpande, V. S., \& Ashby, M. F. (2010). Micro-architectured materials: past, present and future. Proceedings of the Royal Society A: Mathematical, Physical and Engineering Sciences, 466(2121), 2495-2516. https://doi.org/10.1098/rspa.2010.0215

16. Frank W. Zok, Ryan M. Latture, M. R. B. (2011). Periodic truss structures. Journal of the Mechanics and Physics of Solids, 59, 2082-2102. https://doi.org/10.1016/j.jmps.2011.07.001

17. Gibson, L., \& Ashby, M. (1997). Cellular solids: structure and properties. New York: Cambridge University Press.

18. Gümrük, R., Mines, R. A. W., \& Karadeniz, S. (2013). Static mechanical behaviours of stainless steel micro-lattice structures under different loading conditions. Materials Science and Engineering A, 586, 392-406. https://doi.org/10.1016/j.msea.2013.07.070

19. Harris, J. A., Winter, R. E., \& McShane, G. J. (2017). Impact response of additively manufactured metallic hybrid lattice materials. International Journal of Impact Engineering, 104, 177-191. https://doi.org/10.1016/j.ijimpeng.2017.02.007

20. Hawreliak, J. A., Lind, J., Maddox, B., Barham, M., Messner, M., Barton, N., ... Kumar, M. (2016). Dynamic Behavior of Engineered Lattice Materials. Scientific Reports, 6(1), 28094. https://doi.org/10.1038/srep28094

21. Heimbs, S., Cichosz, J., Kilchert, S., \& Klaus, M. (2009). Sandwich panels with cellular cores made of folded composite material: mechanical behaviour and impact performance. 17th International Conference on Composite Materials (ICCM-17), Edinburgh, UK, July 27-31, 2009. Retrieved from http://www.heimbsonline.de/Heimbs_2009_ICCM17.pdf

22. Kolopp, A., Rivallant, S., \& Bouvet, C. (2013). Experimental study of sandwich structures as armour against medium-velocity impacts. International Journal of Impact Engineering, 61, 24-35. https://doi.org/10.1016/j.ssi.2010.01.014

23. Lee, J.-H., Veysset, D., Singer, J. P., Retsch, M., Saini, G., Pezeril, T., ... Thomas, E. L. (2012). High strain rate deformation of layered nanocomposites. Nature Communications, 3(May), 1164. https://doi.org/10.1038/ncomms2166

24. Li, P. (2016). Simulating The Dynamic Deformation Behaviour Of Selective Laser Melted Stainless Steel Microlattice Structures. In Proceedings of the 2nd International Conference on Progress in Additive Manufacturing (pp. 469-474). https://doi.org/10.1063/1.2978249

25. Luxner, M. H., \& Pettermann, H. E. (2007). Modeling and Simulation of Highly Porous Open Cell Structures: Elasto-Plasticity and Localization Versus Disorder and Defects. IUTAM Symposium on Mechanical Properties of Cellular Materials (Vol. 12). https://doi.org/10.1007/978-1-4020-9404-0

26. Marbury, F. (2017). Characterization of SLM Printed 316L Stainless Steel and Investigation of Micro Lattice Geometry. Retrieved from http://digitalcommons.calpoly.edu/cgi/viewcontent.cgi $?$ article=1187\&context=matesp 
27. Maskery, I., Aboulkhair, N. T., Aremu, A. O., Tuck, C. J., \& Ashcroft, I. A. (2017). Compressive failure modes and energy absorption in additively manufactured double gyroid lattices. Additive Manufacturing, 16, 24-29. https://doi.org/10.1016/j.addma.2017.04.003

28. Maskery, I., Aboulkhair, N. T., Aremu, A. O., Tuck, C. J., Ashcroft, I. A., Wildman, R. D., \& Hague, R. J. M. (2016). A mechanical property evaluation of graded density Al-Si10-Mg lattice structures manufactured by selective laser melting. Materials Science and Engineering A, 670, 264-274. https://doi.org/10.1016/j.msea.2016.06.013

29. Maskery, I., \& Tuck, C. (2014). A comparative Finite Element study of cubic unit cells for Selective Laser Melting. International Solid Freeform Fabrication Symposium2.

30. Materialise NV. (n.d.). SLM Build Processor. Retrieved from materialise.com

31. McKown, S., Shen, Y., Brookes, W. K., Sutcliffe, C. J., Cantwell, W. J., Langdon, G. S., ... Theobald, M. D. (2008). The quasi-static and blast loading response of lattice structures. International Journal of Impact Engineering, 35(8), 795-810. https://doi.org/10.1016/j.ijimpeng.2007.10.005

32. Mines, R. A. W., Tsopanos, S., Shen, Y., Hasan, R., \& McKown, S. T. (2013). Drop weight impact behaviour of sandwich panels with metallic micro lattice cores. International Journal of Impact Engineering, 60, 120-132. https://doi.org/10.1016/j.ijimpeng.2013.04.007

33. Mines, R. A. W., McKown, S., Tsopanos, S., Shen, E., Cantwell, W., Brooks, W., \& Sutcliffe, C. J. (2008). Local Effects during Indentation of Fully Supported Sandwich Panels with Micro Lattice Cores. Applied Mechanics and Materials, 13-14(June), 85-90. https://doi.org/10.4028/www.scientific.net/AMM.13-14.85

34. Nguyen, M. Q., Jacombs, S. S., Thomson, R. S., Hachenberg, D., \& Scott, M. L. (2005). Simulation of impact on sandwich structures. Composite Structures, 67(2 SPEC. ISS.), 217-227. https://doi.org/10.1016/j.compstruct.2004.09.018

35. Ni, C. Y., Li, Y. C., Xin, F. X., Jin, F., \& Lu, T. J. (2013). Ballistic resistance of hybrid-cored sandwich plates: Numerical and experimental assessment. Composites Part A: Applied Science and Manufacturing, 46(1), 69-79. https://doi.org/10.1016/j.compositesa.2012.07.019

36. Ni, C., Jin, F., \& Lu, T. (2014). Penetration of sandwich plates with hybrid-cores under oblique ballistic impact. Theoretical and Applied Mechanics Letters, 4(2), 21001. https://doi.org/10.1063/2.1402101

37. Ozdemir, Z., Hernandez-Nava, E., Tyas, A., Warren, J. A., Fay, S. D., Goodall, R., ... Askes, H. (2015). Energy absorption in lattice structures in dynamics: Experiments. International Journal of Impact Engineering, 89, 49-61. https://doi.org/10.1016/j.ijimpeng.2015.10.007

38. Ozdemir, Z., Tyas, A., Goodall, R., \& Askes, H. (2017). Energy absorption in lattice structures in dynamics: Nonlinear FE simulations. International Journal of Impact Engineering, 102, 1-15. https://doi.org/10.1016/j.ijimpeng.2016.11.016

39. Plassard, F., Mespoulet, J., \& Hereil, P. (2011). Hypervelocity impact of aluminium sphere against aluminium plate : experiment and LS-DYNA correlation. 8th European LSDYNA Users Conference, (May 2011), 1-11. https://doi.org/10.1016/j.compstruct.2012.09.010 
40. Qi, C., Yang, S., Wang, D., \& Yang, L. J. (2013). Ballistic resistance of honeycomb sandwich panels under in-plane high-velocity impact. The Scientific World Journal, 2013. https://doi.org/10.1155/2013/892781

41. Ramesh, K. T. (2008). High Strain Rate and Impact Experiments. Handbook of Experimental Solid Mechanics, 874.

42. Ramirez, D. A., Murr, L. E., Li, S. J., Tian, Y. X., Martinez, E., Martinez, J. L., ... Wicker, R. B. (2011). Open-cellular copper structures fabricated by additive manufacturing using electron beam melting. Materials Science and Engineering A, 528(16-17), 5379-5386. https://doi.org/10.1016/j.msea.2011.03.053

43. Rashed, M. G., Ashraf, M., Mines, R. A. W., \& Hazell, P. J. (2016). Metallic microlattice materials: A current state of the art on manufacturing, mechanical properties and applications. Materials and Design, 95, 518-533. https://doi.org/10.1016/j.matdes.2016.01.146

44. Showalter, D. D., Gooch, W. A., Burkins, M. S., \& Koch, R. S. (2008). Ballistic Testing of Ssab Ultra-High Hardness Steel for Armor Applications, (October).

45. SLM Solutions. (2018). 3D Metals: Discover the variety of Metal Powders.

46. Smith, M., Cantwell, W., Guan, Z., Tsopanos, S., Theobald, M., Nurick, G., \& Langdon, G. (2011). The quasi-static and blast response of steel lattice structures. Journal of Sandwich Structures \& Materials, 13(4), 479-501. https://doi.org/10.1177/1099636210388983

47. Smith, M., Guan, Z., \& Cantwell, W. J. (2012). Finite element modelling of the compressive response of lattice structures manufactured using the selective laser melting technique. International Journal of Mechanical Sciences, 67, 28-41. https://doi.org/10.1016/j.ijmecsci.2012.12.004

48. Tancogne-Dejean, T., Spierings, A. B., \& Mohr, D. (2016). Additively-manufactured metallic micro-lattice materials for high specific energy absorption under static and dynamic loading. Acta Materialia, 116, 14-28. https://doi.org/10.1016/j.actamat.2016.05.054

49. Tsopanos, S., Mines, R. A. W., McKown, S., Shen, Y., Cantwell, W. J., Brooks, W., \& Sutcliffe, C. J. (2010). The Influence of Processing Parameters on the Mechanical Properties of Selectively Laser Melted Stainless Steel Microlattice Structures. Journal of Manufacturing Science and Engineering, 132(4), 041011. https://doi.org/10.1115/1.4001743

50. Ullah, I., Brandt, M., \& Feih, S. (2016). Failure and energy absorption characteristics of advanced 3D truss core structures. Materials and Design, 92, 937-948. https://doi.org/10.1016/j.matdes.2015.12.058

51. Umbrello, D., M'Saoubi, R., \& Outeiro, J. C. (2007). The influence of Johnson-Cook material constants on finite element simulation of machining of AISI $316 \mathrm{~L}$ steel. International Journal of Machine Tools and Manufacture, 47(3-4), 462-470. https://doi.org/10.1016/j.ijmachtools.2006.06.006

52. VanderKlok, A., Stamm, A., Dorer, J., Hu, E., Auvenshine, M., Pereira, J. M., \& Xiao, X. (2018). An experimental investigation into the high velocity impact responses of S2glass/SC15 epoxy composite panels with a gas gun. International Journal of Impact Engineering, 111(May 2017), 244-254. https://doi.org/10.1016/j.ijimpeng.2017.10.002 
53. Vangapally, S., Agarwal, K., Sheldon, A., \& Cai, S. (2017). Effect of Lattice Design and Process Parameters on Dimensional and Mechanical Properties of Binder Jet Additively Manufactured Stainless Steel 316 for Bone Scaffolds. Procedia Manufacturing, 10, 750759. https://doi.org/10.1016/j.promfg.2017.07.069

54. Vrana, R., Koutny, D., \& Palousek, D. (2016). IMPACT RESISTANCE OF DIFFERENT TYPES OF LATTICE STRUCTURES MANUFACTURED BY SLM. MM Science Journal, June, 15791585. https://doi.org/10.17973/MMSJ.2016

55. Vrana, R., Koutny, D., Palousek, D., \& Zikmund, T. (2015). IMPACT RESISTANCE OF LATTICE STRUCTURE MADE BY SELECTIVE LASER MELTING FROM AISi12 ALLOY. MM Science Journal, 665-669. https://doi.org/10.17973/MMSJ.2015

56. Wadley, H. N. G., O'Masta, M. R., Dharmasena, K. P., Compton, B. G., Gamble, E. A., \& Zok, F. W. (2013). Effect of core topology on projectile penetration in hybrid aluminum/alumina sandwich structures. International Journal of Impact Engineering, 62, 99-113. https://doi.org/10.1016/j.ijimpeng.2013.05.008

57. Wadley, H. N. G. (2002). Cellular metals manufacturing. Advanced Engineering Materials, 4(10), 726-733. https://doi.org/10.1002/15272648(20021014)4:10<726::AID-ADEM726>3.0.CO;2-Y

58. Wang, B., Zhang, G., Wang, S., Ma, L., \& Wu, L. (2014). High velocity impact response of composite lattice core sandwich structures. Applied Composite Materials, 21(2), 377389. https://doi.org/10.1007/s10443-013-9345-4

59. Williams, C. B., Cochran, J. K., \& Rosen, D. W. (2011). Additive manufacturing of metallic cellular materials via three-dimensional printing. International Journal of Advanced Manufacturing Technology, 53(1-4), 231-239. https://doi.org/10.1007/s00170-0102812-2

60. Xiao, L., \& Song, W. (2017). Additively-manufactured functionally graded Ti-6Al-4V lattice structures with high strength under static and dynamic loading: Experiments. International Journal of Impact Engineering, 111(June 2017), 255-272. https://doi.org/10.1016/j.ijimpeng.2017.09.018

61. Xiao, L., Song, W., Wang, C., Tang, H., Fan, Q., Liu, N., \& Wang, J. (2016). Mechanical properties of open-cell rhombic dodecahedron titanium alloy lattice structure manufactured using electron beam melting under dynamic loading. International Journal of Impact Engineering, 100, 75-89. https://doi.org/10.1016/j.ijimpeng.2016.10.006

62. Xiong, J., Mines, R., Ghosh, R., Vaziri, A., Ma, L., Ohrndorf, A., ... Wu, L. (2015). Advanced Micro-Lattice Materials. Advanced Engineering Materials, 17(9), 1253-1264. https://doi.org/10.1002/adem.201400471

63. Yan, C., Hao, L., Hussein, A., \& Raymont, D. (2012). Evaluations of cellular lattice structures manufactured using selective laser melting. International Journal of Machine Tools and Manufacture, 62, 32-38. https://doi.org/10.1016/j.ijmachtools.2012.06.002

64. Yan, C., Hao, L., Hussein, A., Young, P., Huang, J., \& Zhu, W. (2015). Microstructure and mechanical properties of aluminium alloy cellular lattice structures manufactured by direct metal laser sintering. Materials Science and Engineering A, 628, 238-246. https://doi.org/10.1016/j.msea.2015.01.063 
65. Yan, C., Hao, L., Hussein, A., Young, P., \& Raymont, D. (2014). Advanced lightweight 316L stainless steel cellular lattice structures fabricated via selective laser melting. Journal of Materials\&Design, 55, 533-541. https://doi.org/10.1016/j.matdes.2013.10.027

66. Yungwirth, C. J., Radford, D. D., Aronson, M., \& Wadley, H. N. G. (2008). Experiment assessment of the ballistic response of composite pyramidal lattice truss structures. Composites Part B: Engineering, 39(3), 556-569. https://doi.org/10.1016/j.compositesb.2007.02.029

67. Yungwirth, C. J., Wadley, H. N. G., O’Connor, J. H., Zakraysek, A. J., \& Deshpande, V. S. (2008). Impact response of sandwich plates with a pyramidal lattice core. International Journal of Impact Engineering, 35(8), 920-936. https://doi.org/10.1016/j.ijimpeng.2007.07.001

68. Zhou, J. (2015). The University of Liverpool The Energy-Absorbing Behaviour of Novel Aerospace Composite Structures. University of Liverpool.

69. Heat tint (temper) colours on stainless steel surfaces heated in air. (2017). Retrieved from http://www.bssa.org.uk/topics.php?article $=140$

70. Plastic Theory of Bending. (2018). Retrieved July 4, 2018, from http://www.codecogs.com/library/engineering/materials/plastic-theory-of-bending.php 
APENDIX A: UNIT CELL MODELS AND MACROSCOPIC INSPECTION OF UNIT CELLS

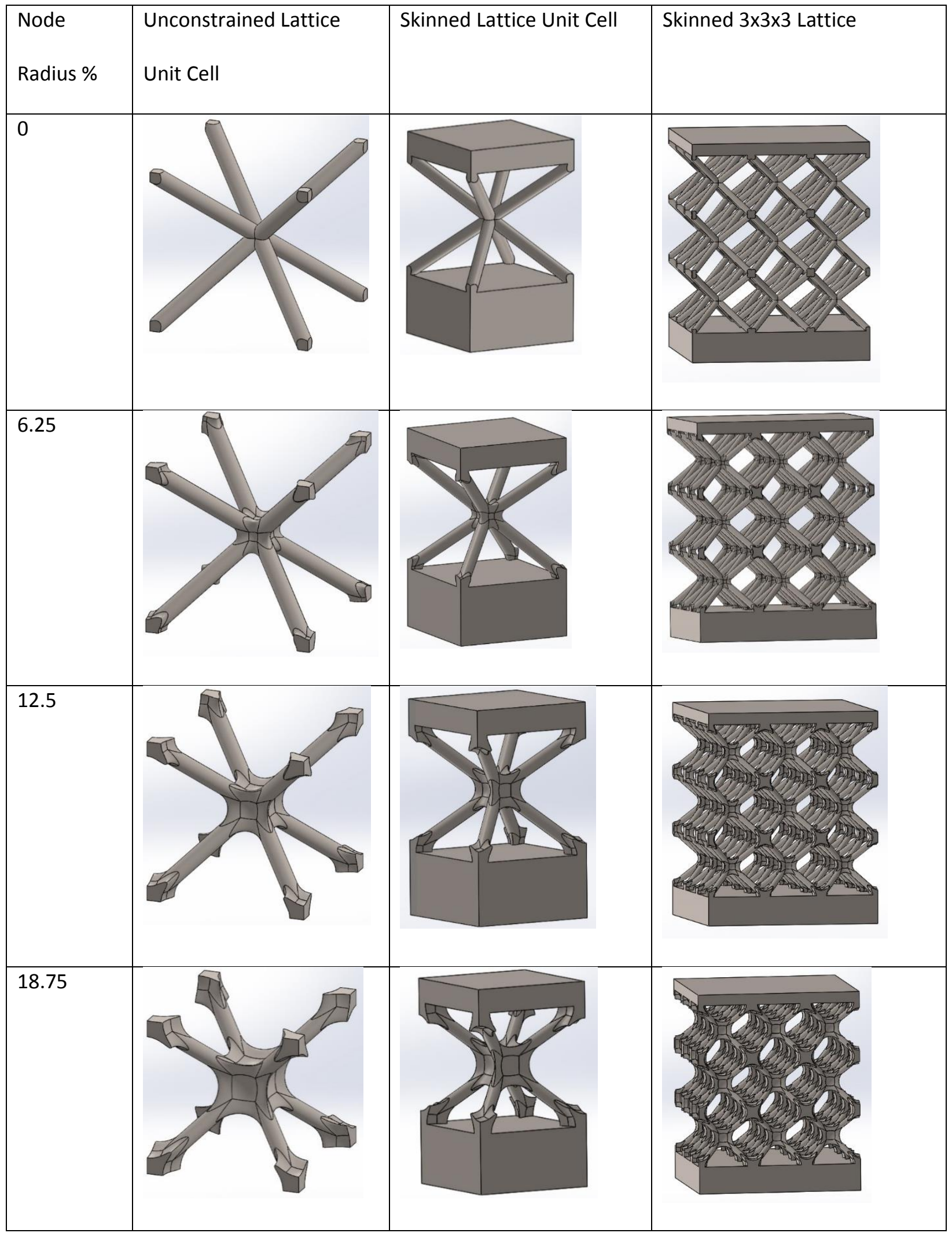




Strut Angle




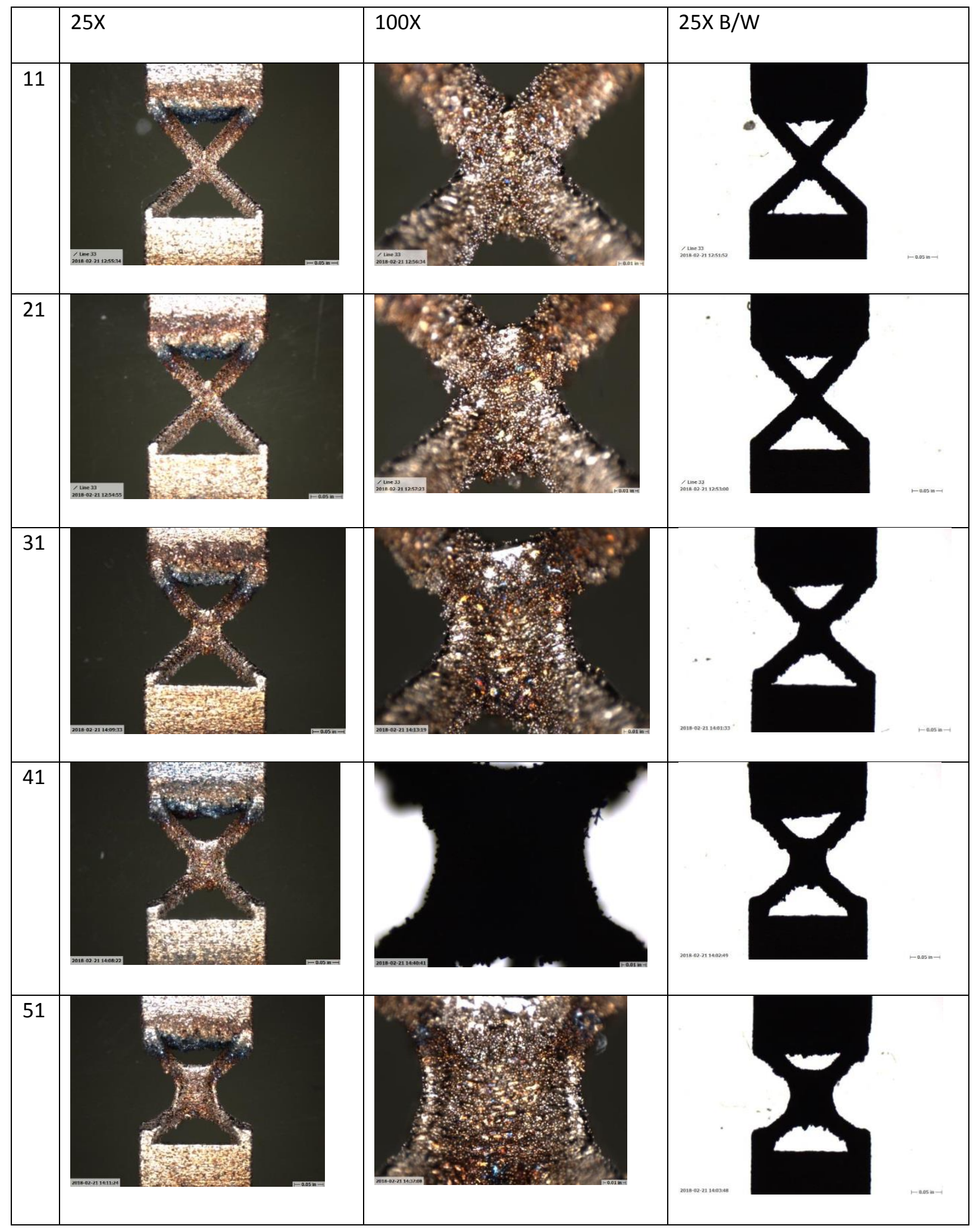




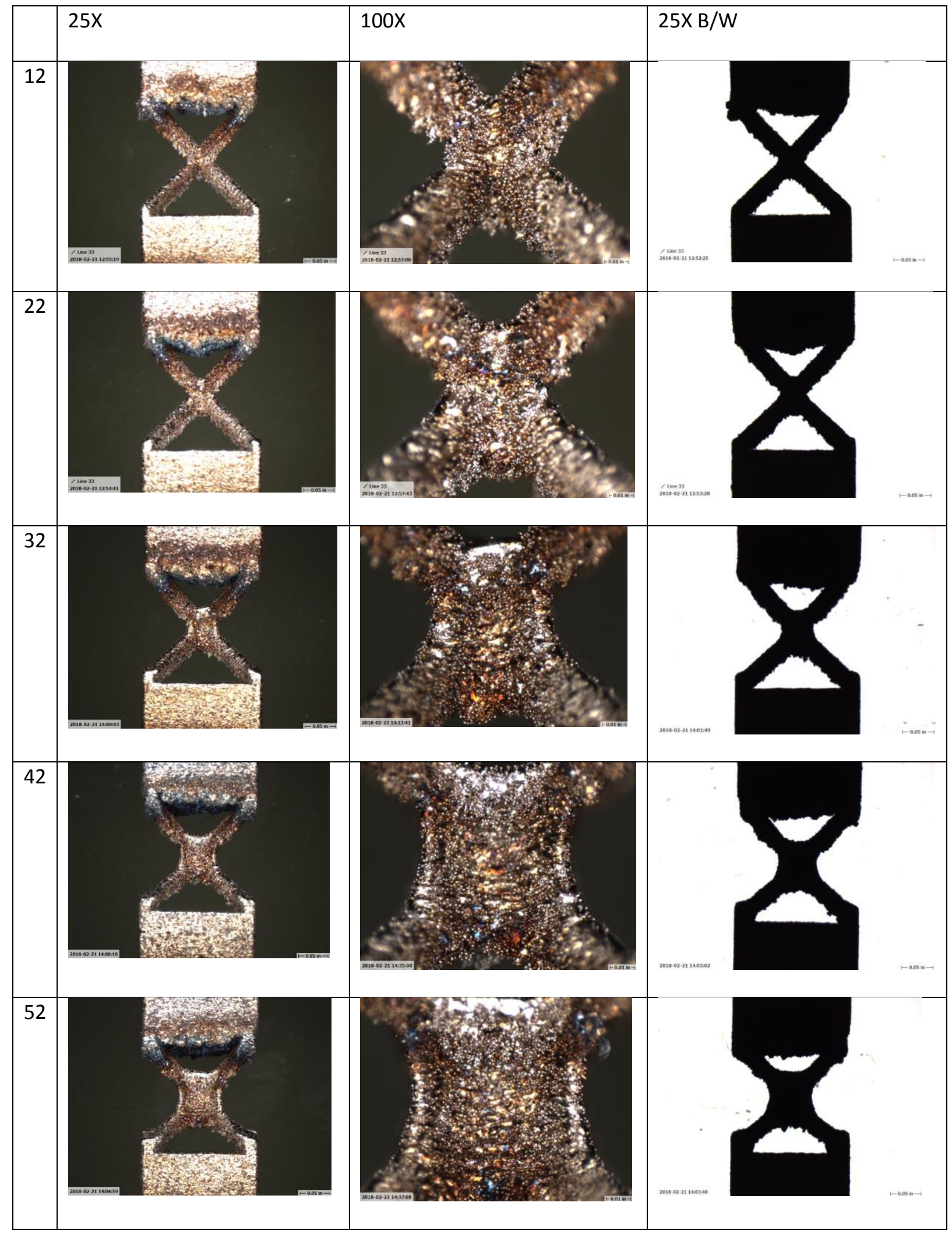




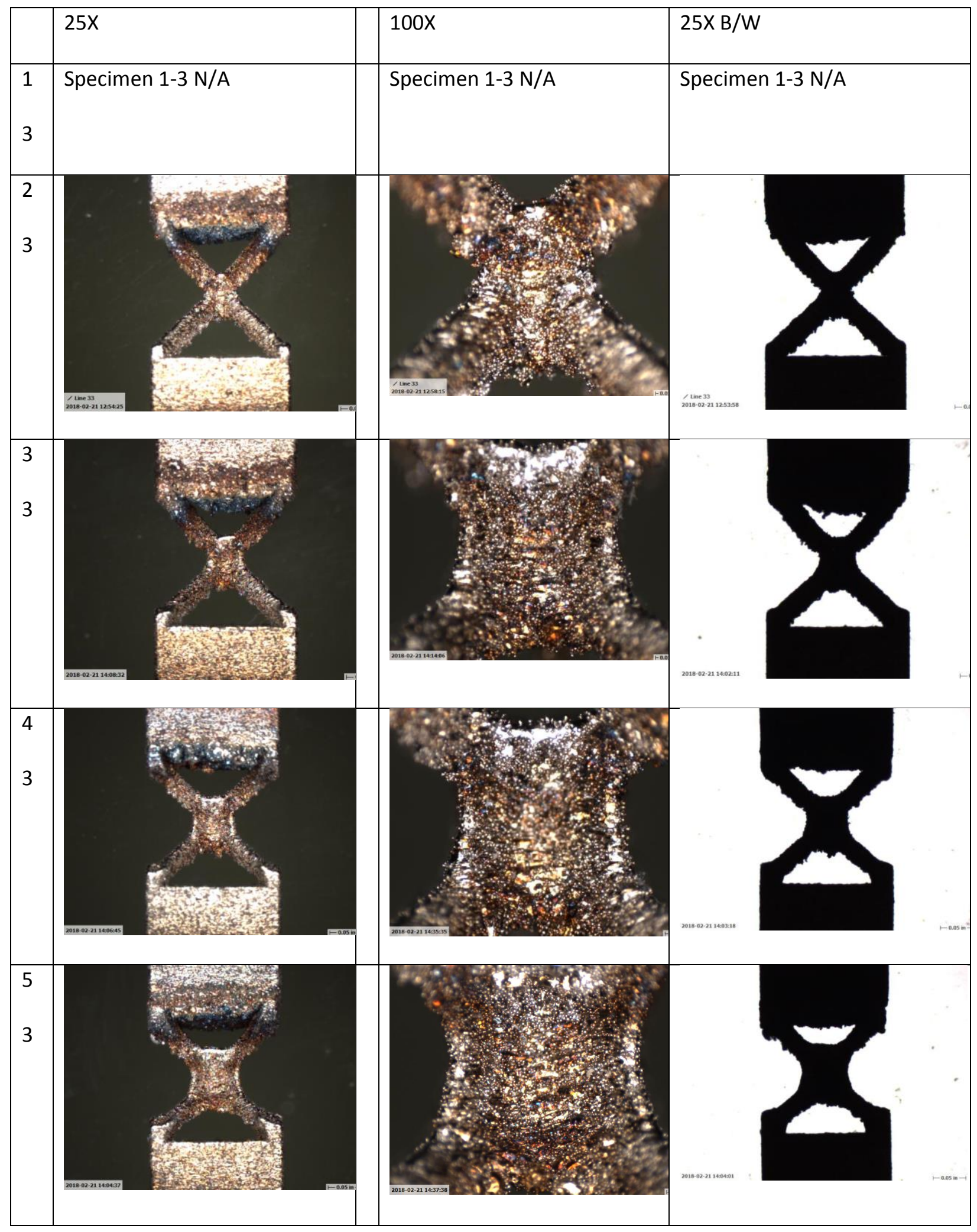




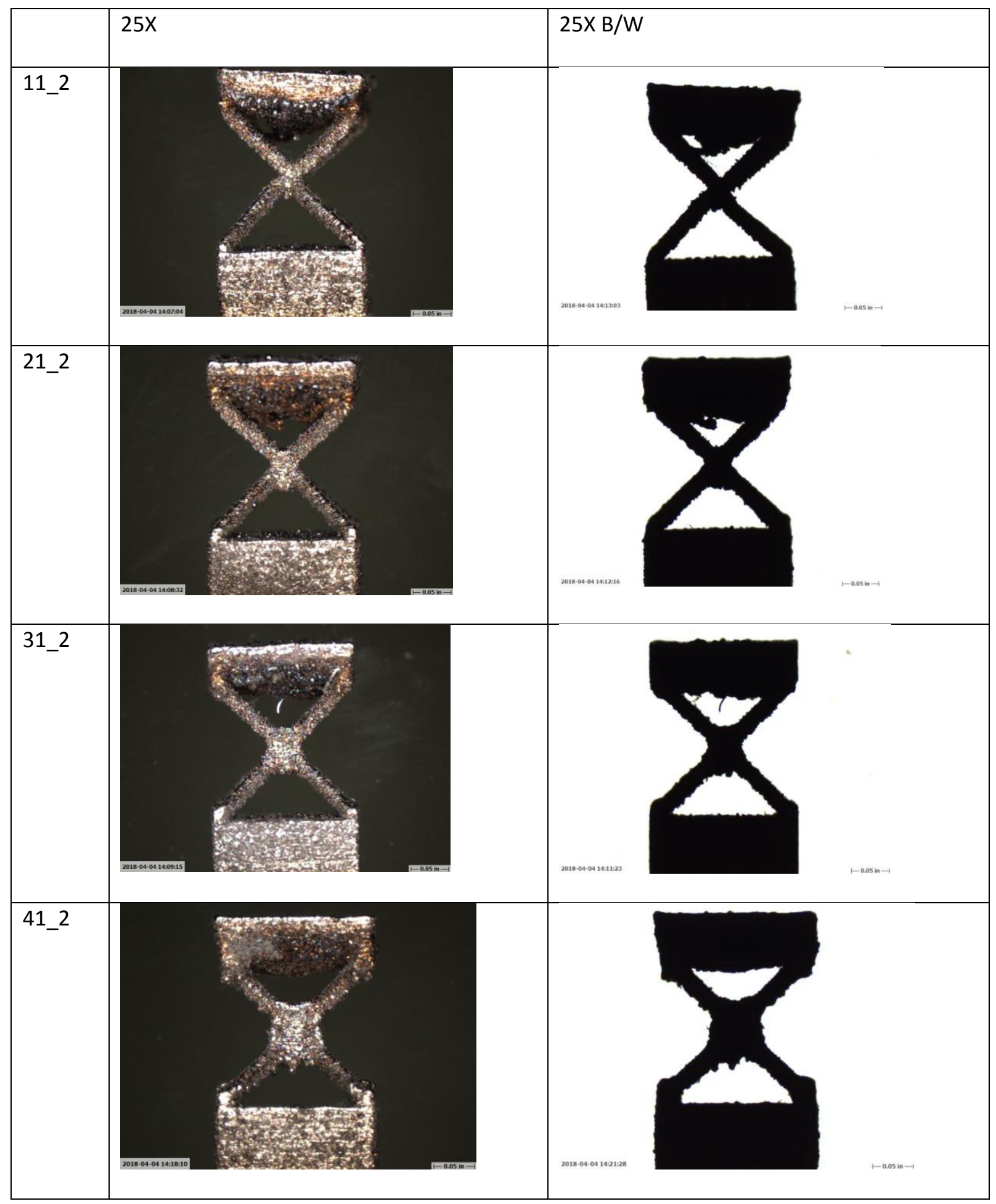




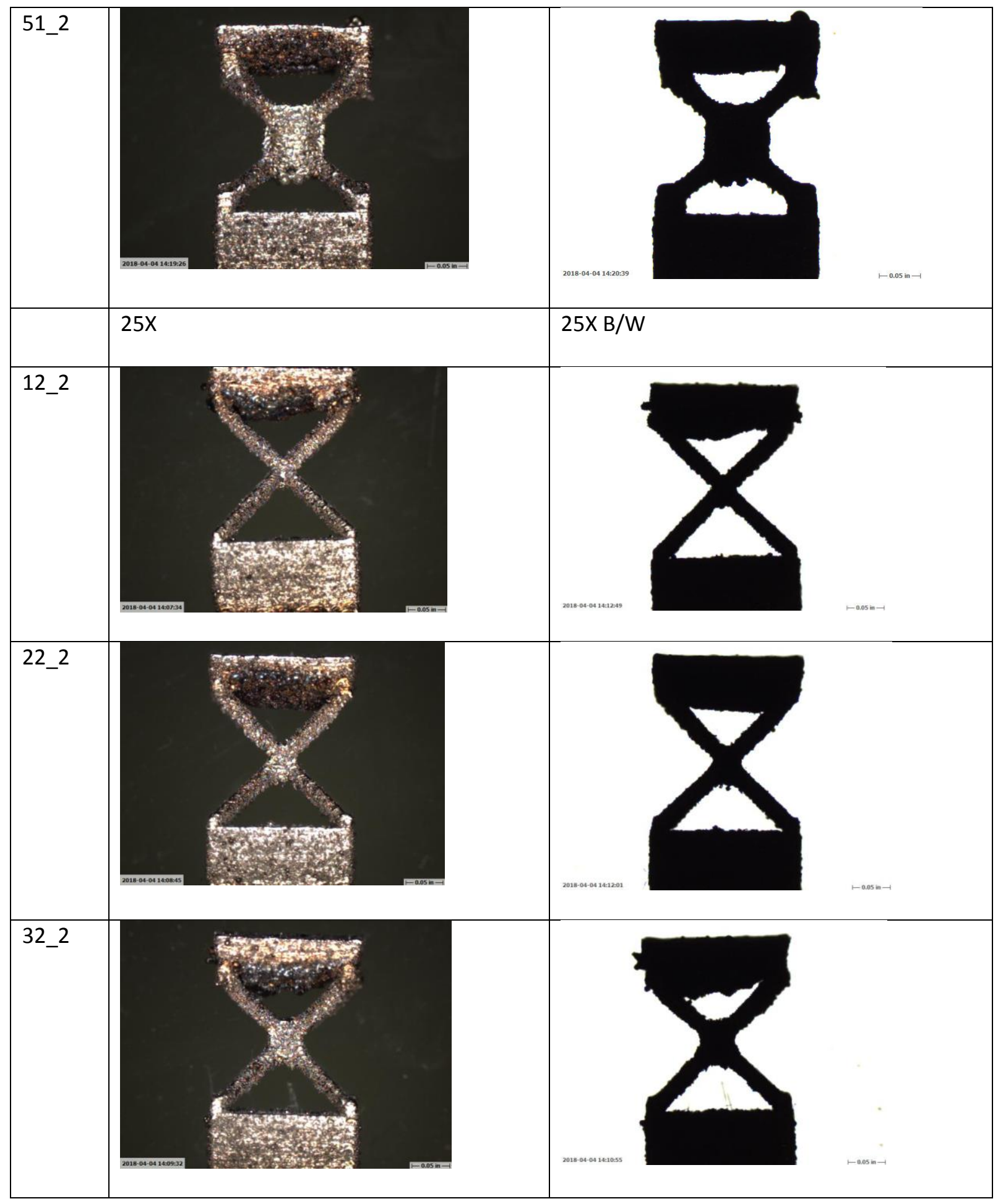




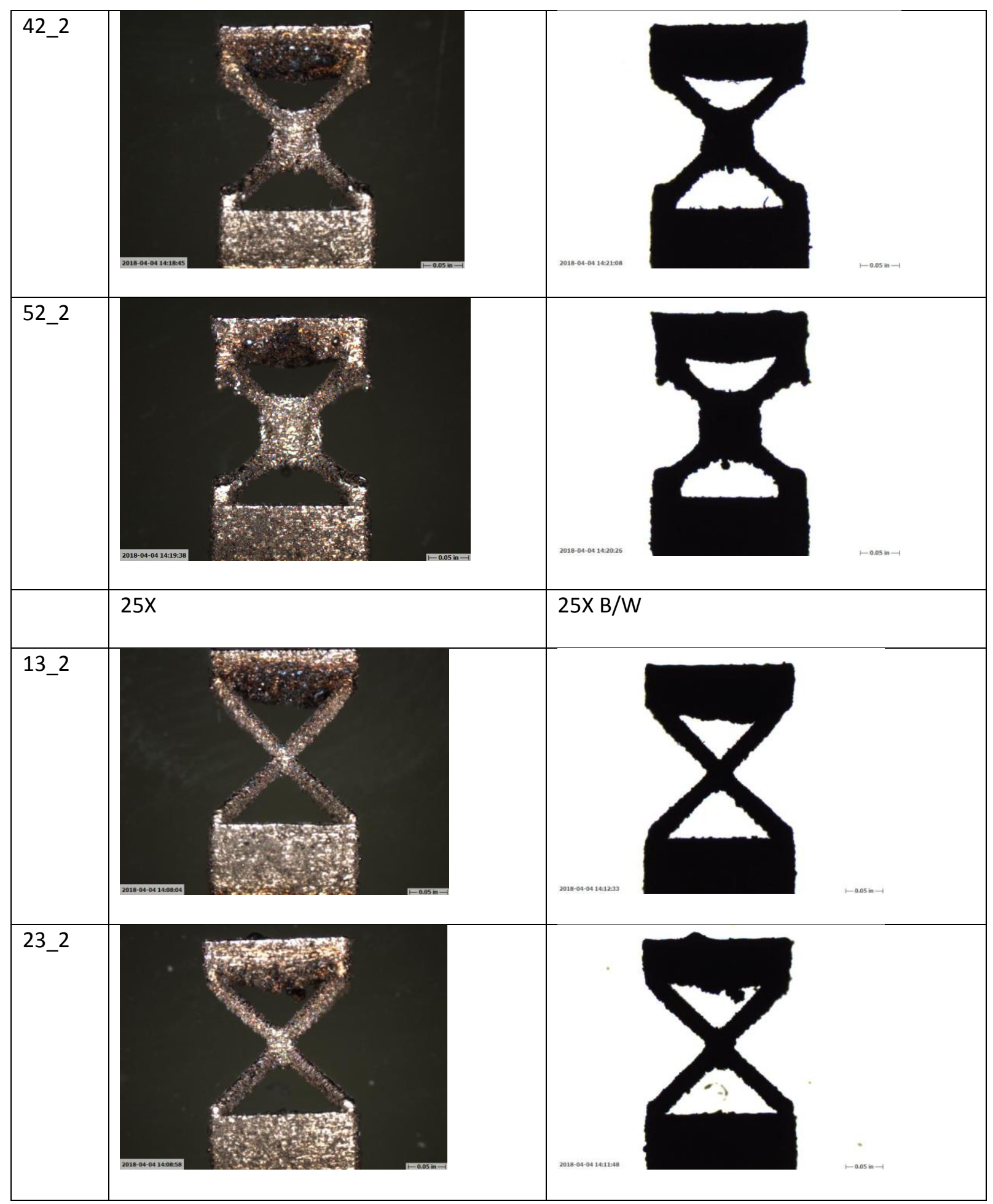




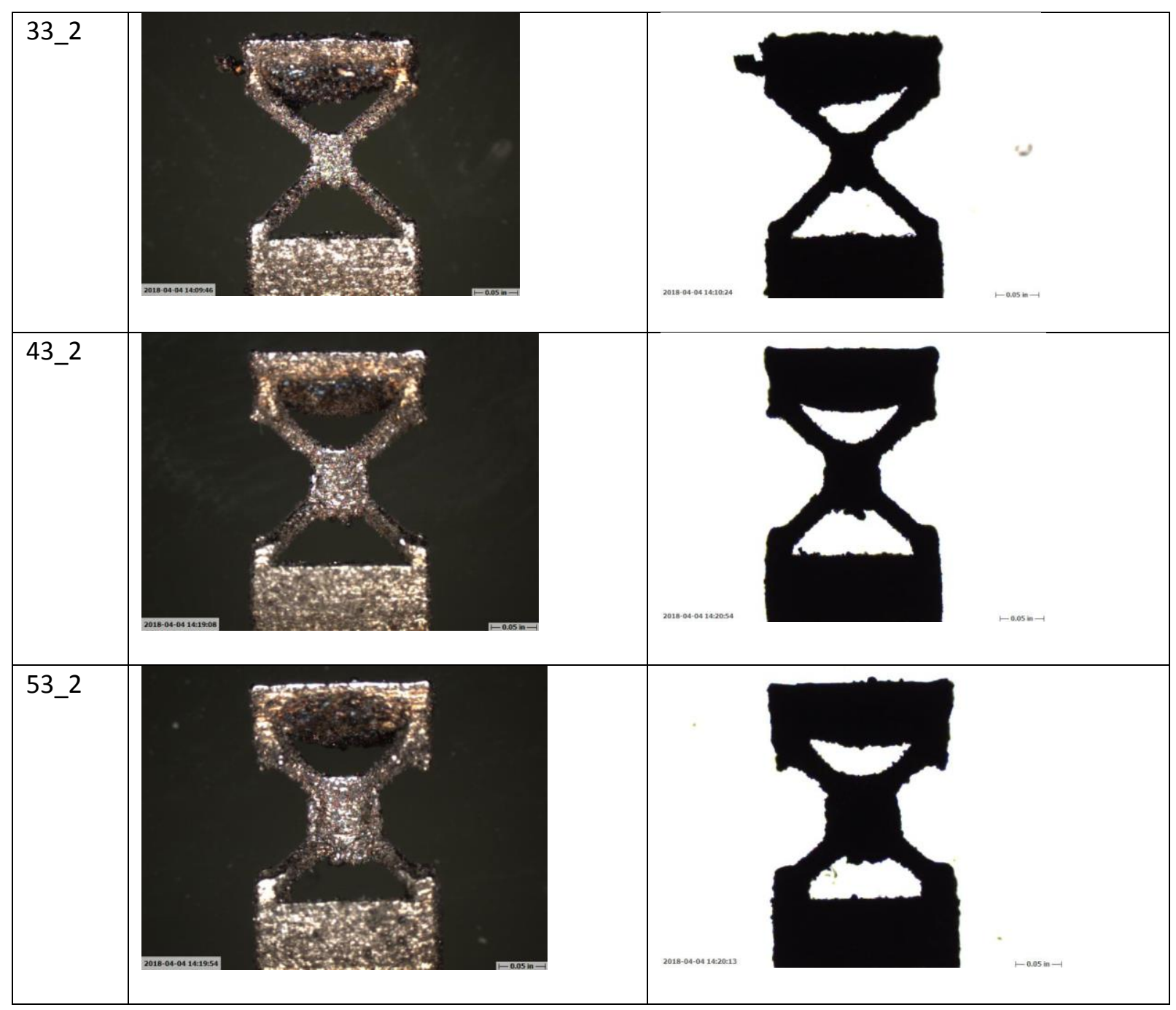


APPENDIX B: STRESS STRAIN CURVES AND TESTING OBESERVATIONS

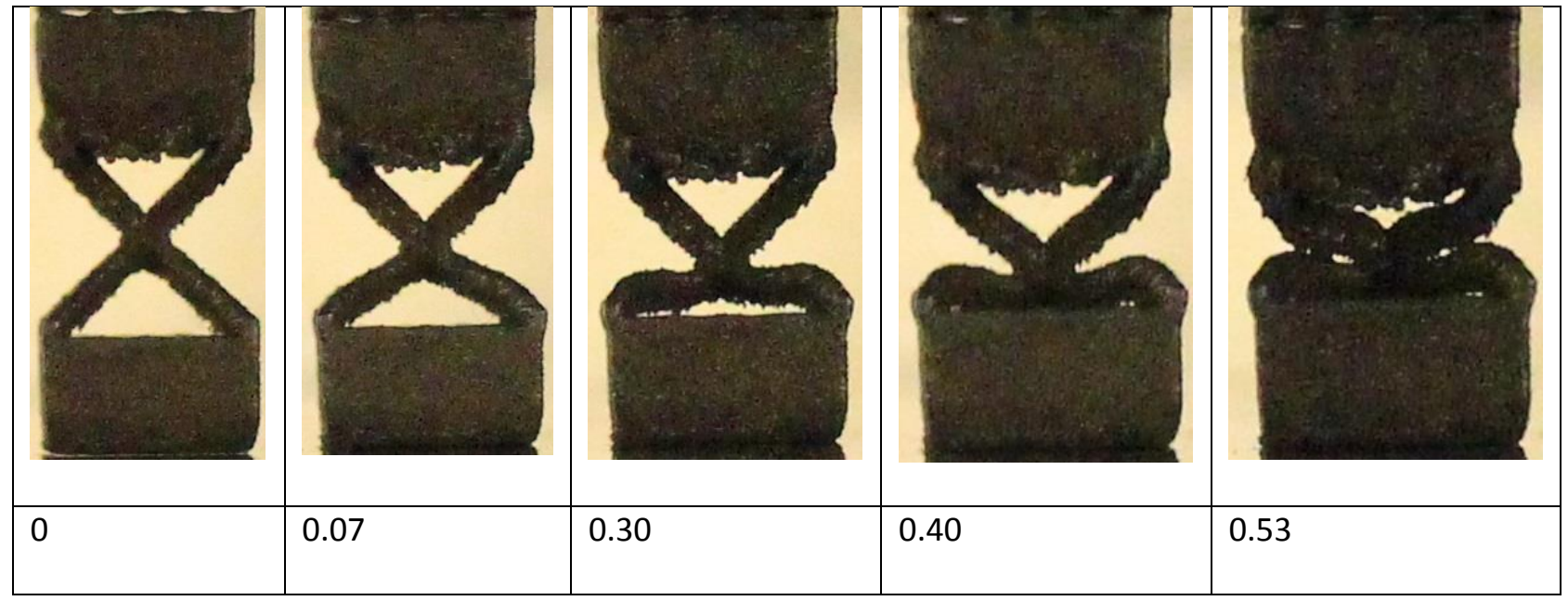

BCC 5mm Unit Cell 0\% Radius Compressive Stress - Strain

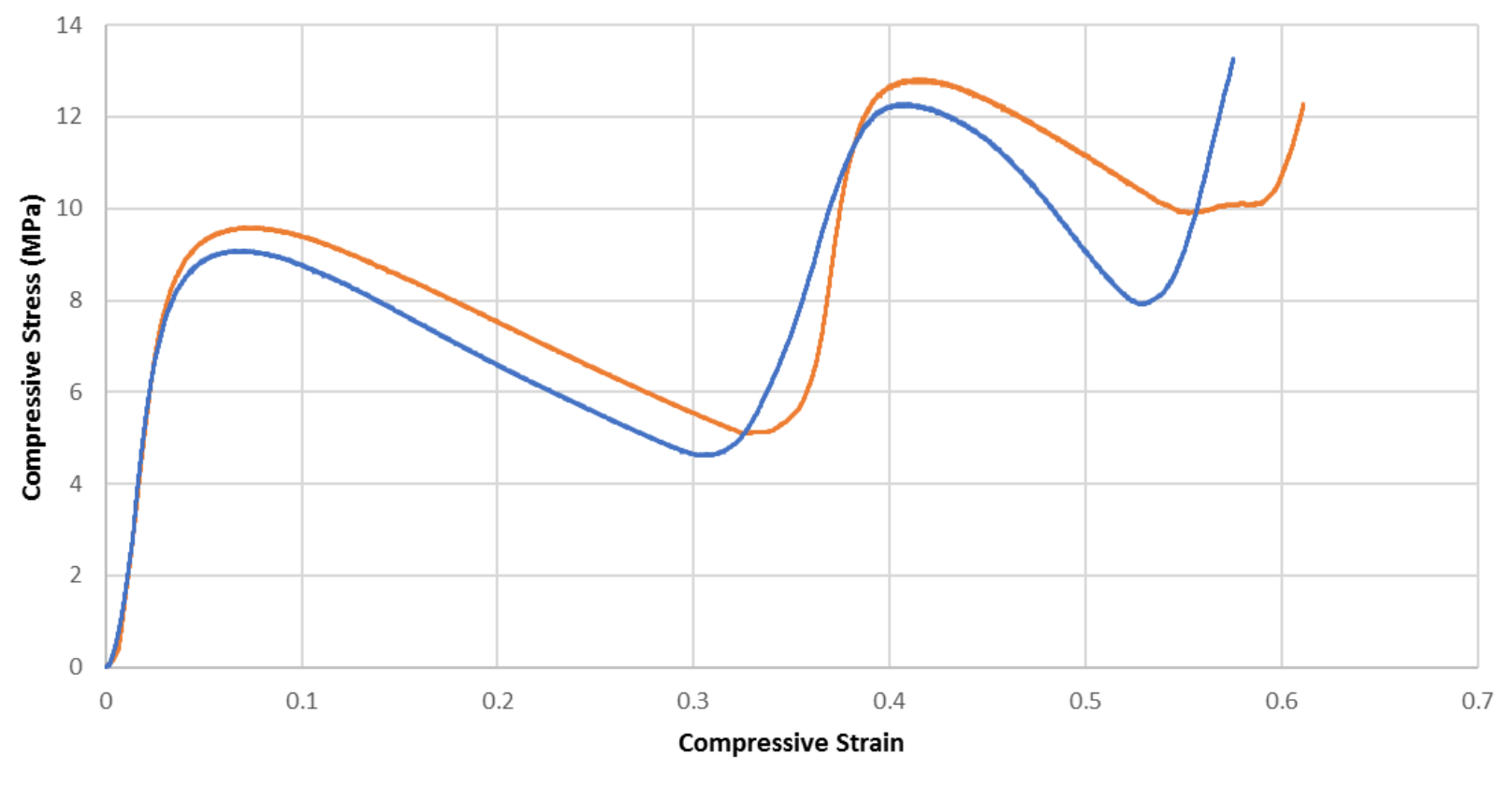



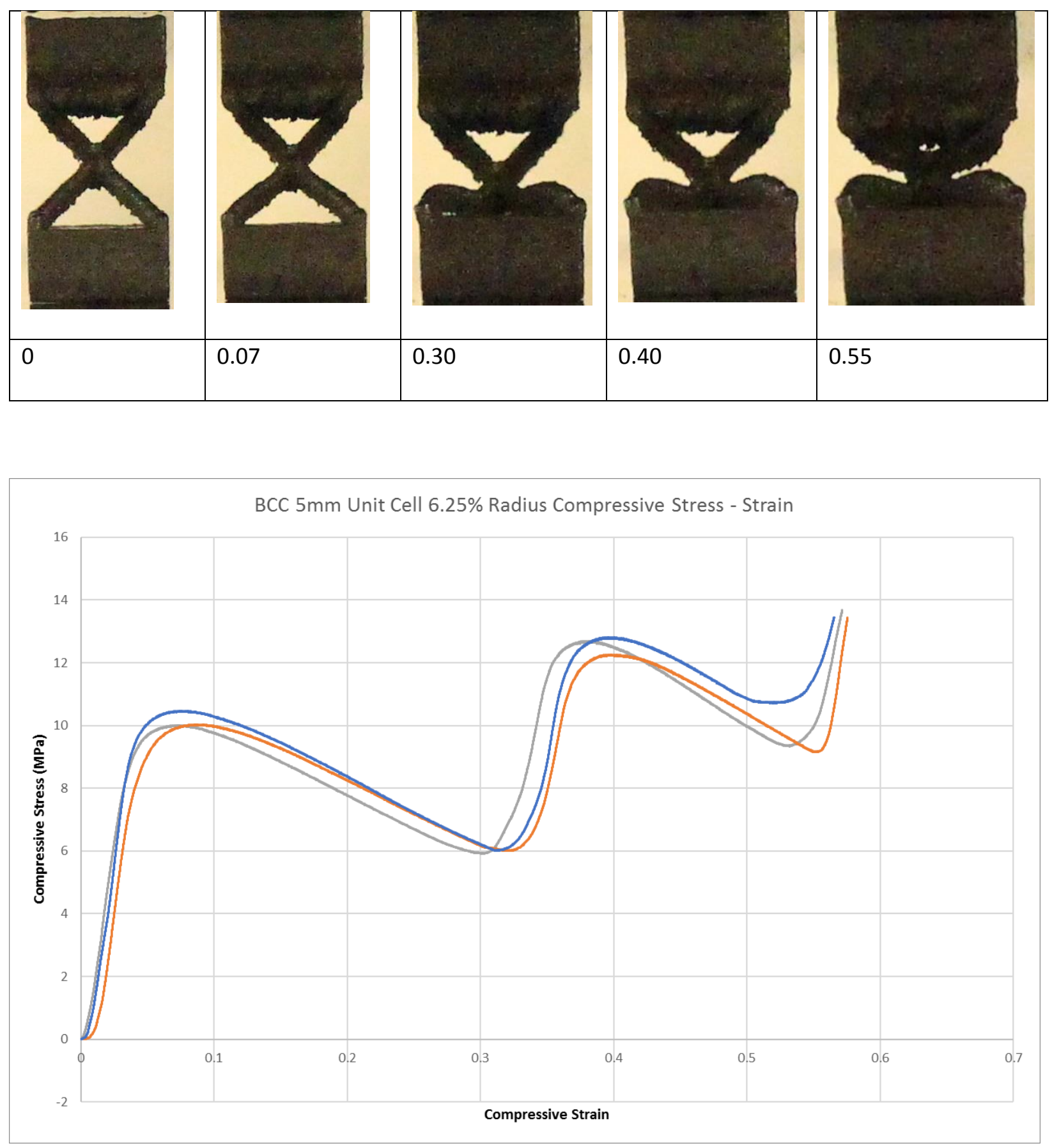

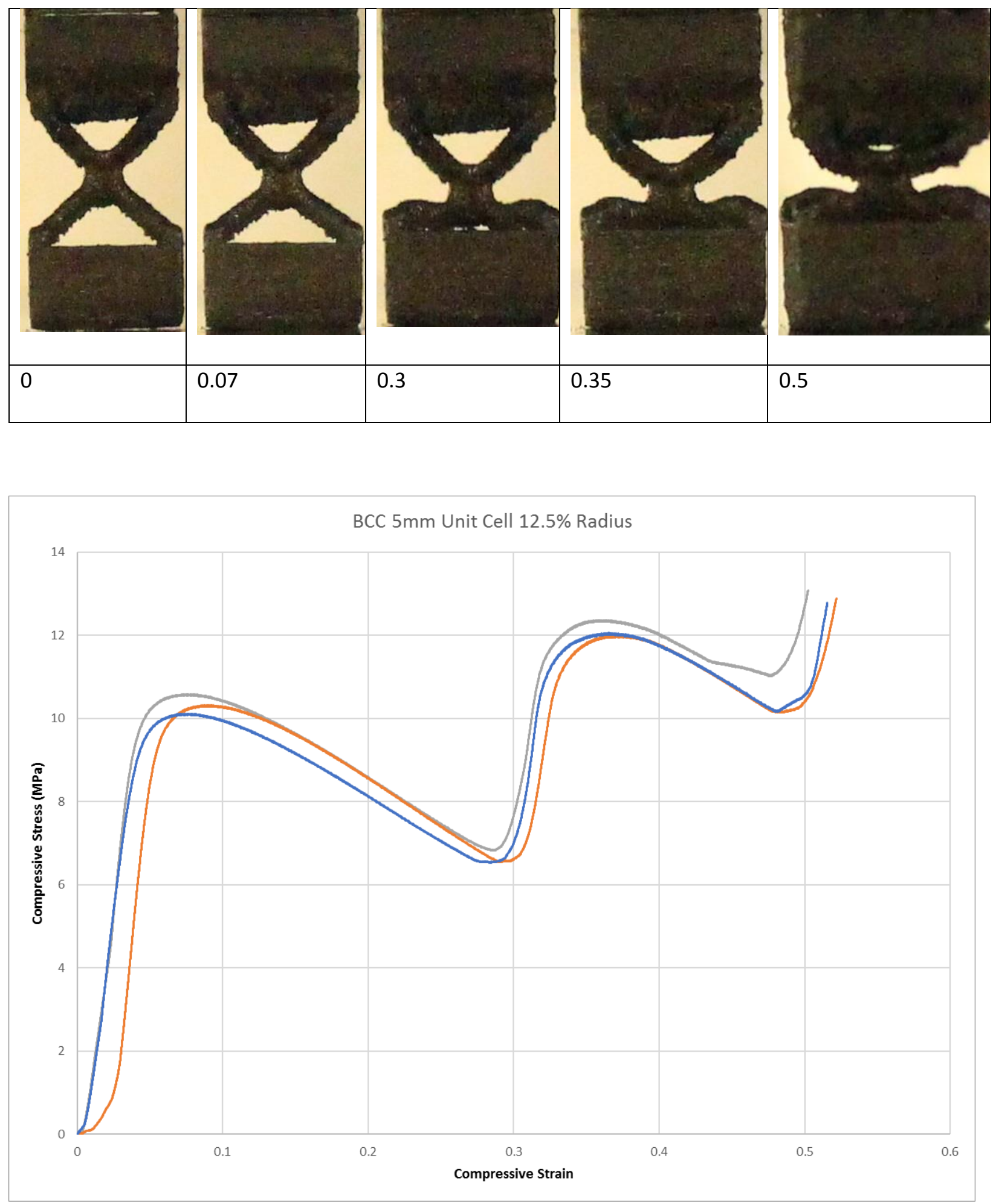


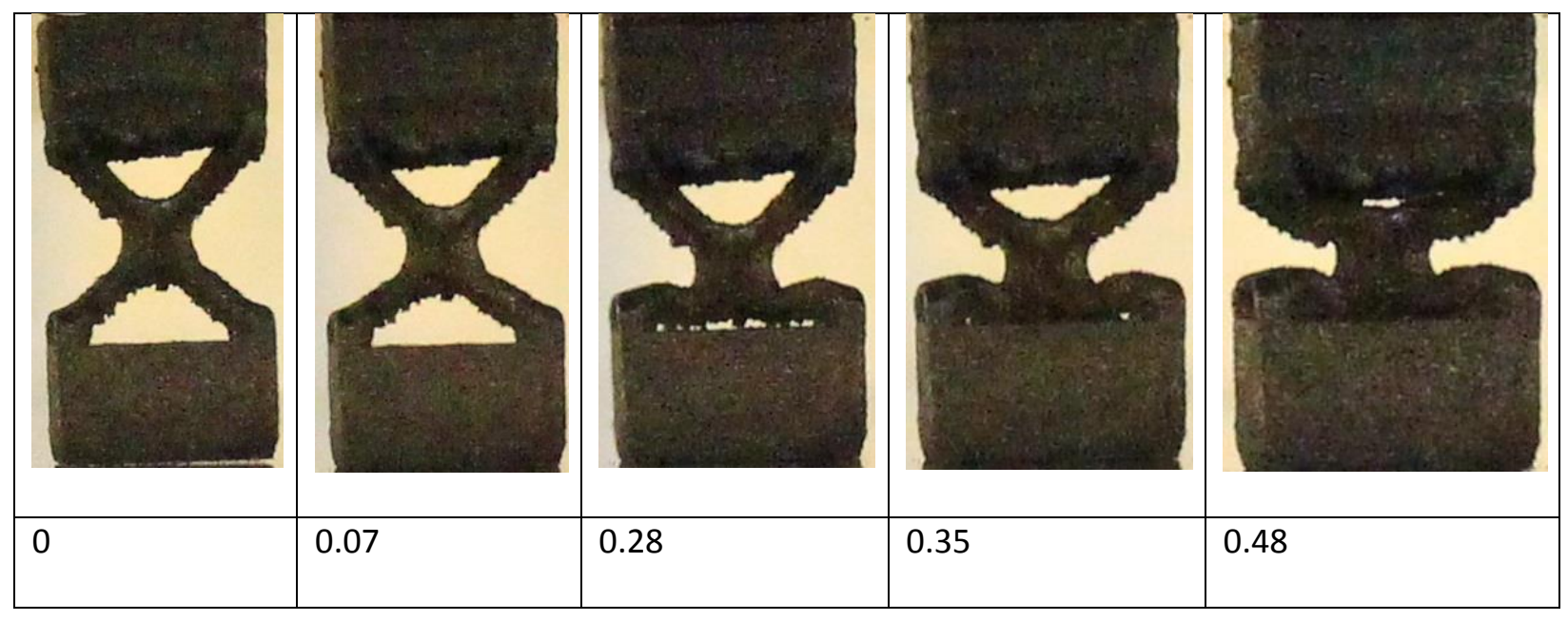

BCC 5mm Unit Cell 18.75\% Radius Compressive Stress - Strain

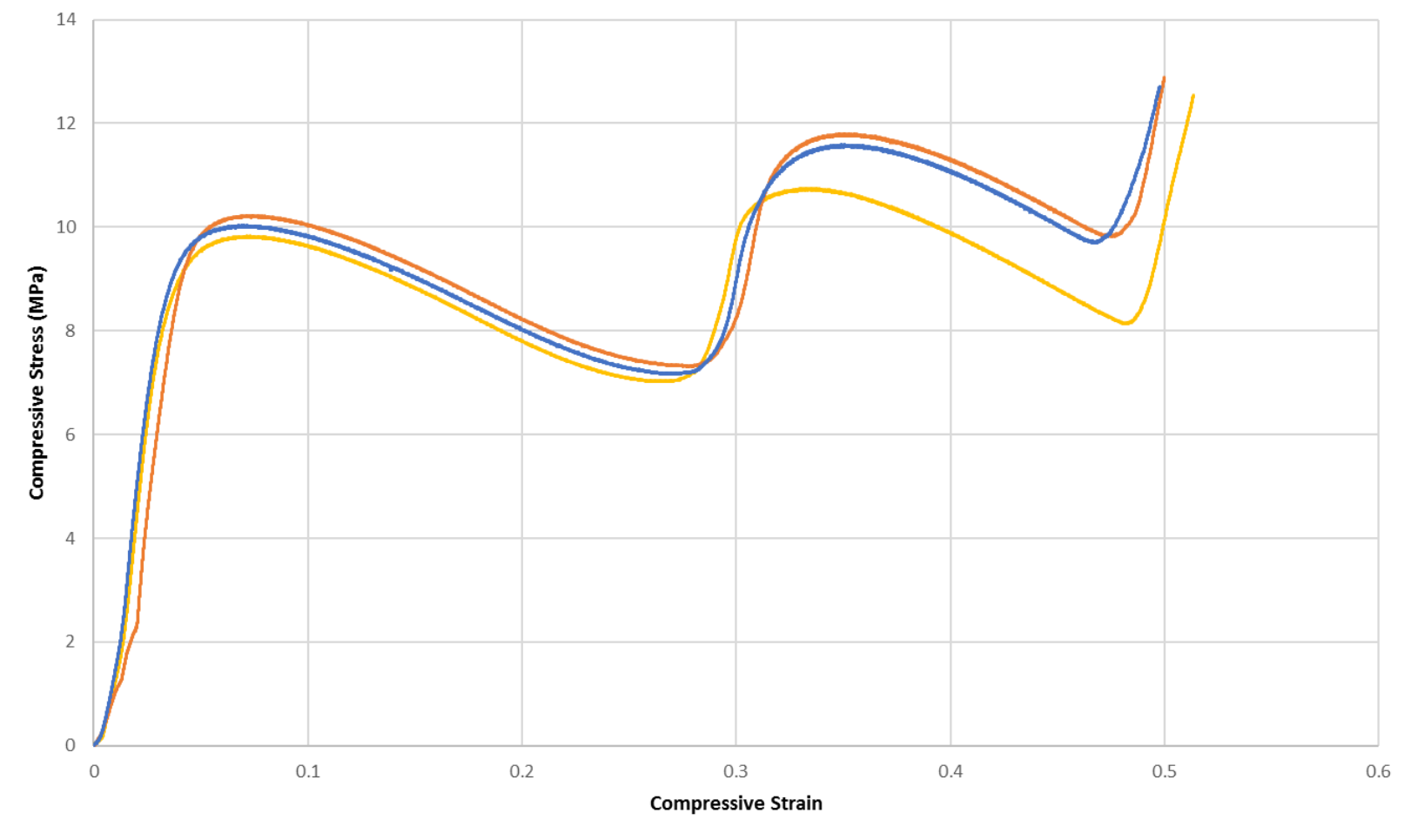



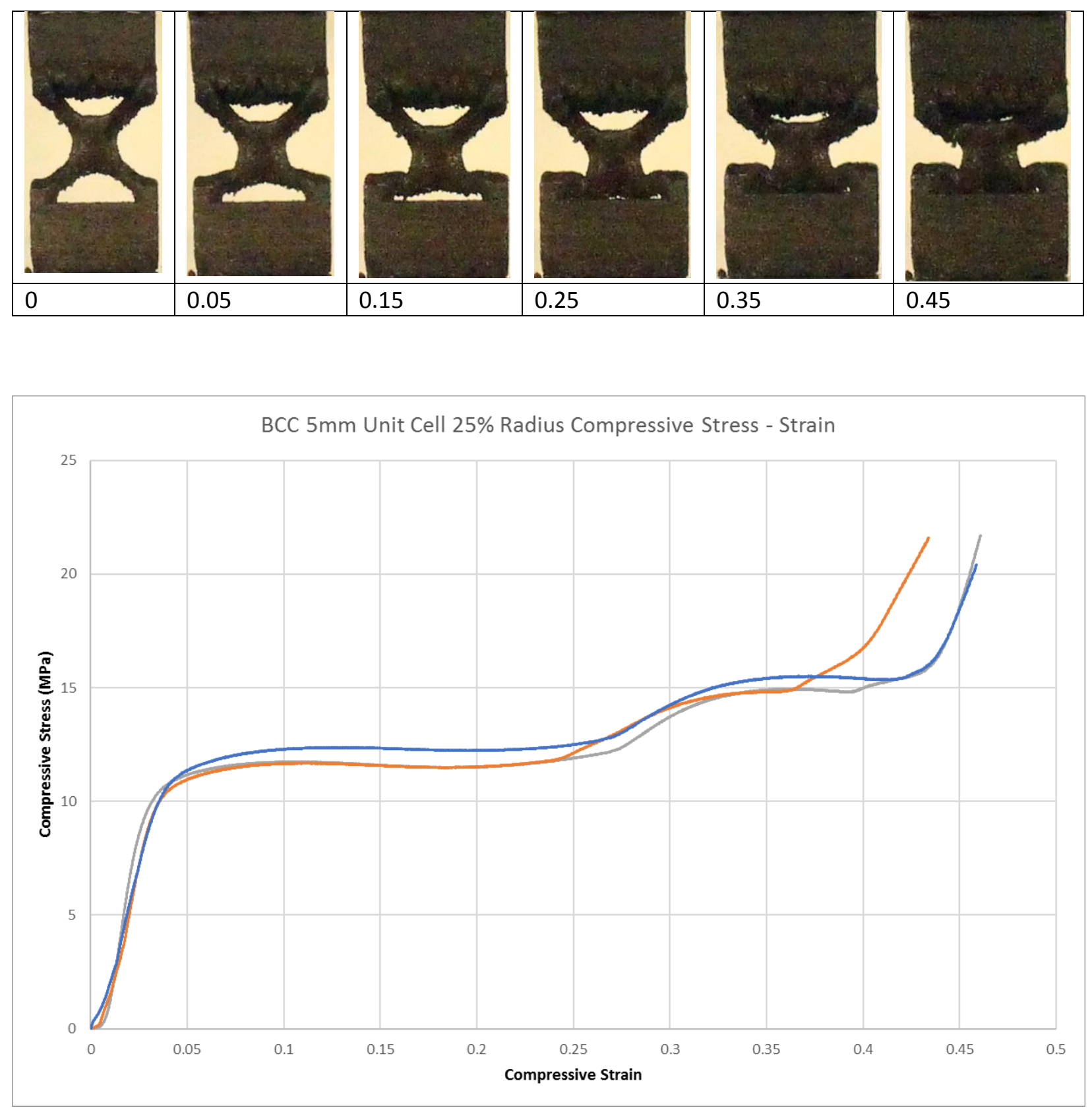


\section{APPENDIX C: SPECIMEN MEASUREMENTS AND MANUFACTURING PARAMETERS}

\begin{tabular}{|c|c|c|c|c|c|}
\hline Structure ID & Lattice Height (mm) & Lattice Width (mm) & $\begin{array}{l}\text { Lattice Length } \\
(\mathrm{mm})\end{array}$ & Color & Mass (g) \\
\hline$\{1 \mathrm{BCC}\}^{1}$ & 4.6 & 4.8 & 4.71 & orange & 1.093 \\
\hline$\{1 \mathrm{BCC}\}^{1}$ & 4.5 & 4.66 & 4.72 & dark purple & 1.083 \\
\hline$\{1 \mathrm{BCC}\}^{1},\|6.25\|$ & 4.51 & 4.82 & 4.63 & light blue & 1.08 \\
\hline$\{1 \mathrm{BCC}\}^{1},\|6.25\|$ & 4.54 & 4.87 & 4.58 & purple & 1.07 \\
\hline$\{1 \mathrm{BCC}\}^{1},\|6.25\|$ & 4.62 & 4.83 & 4.54 & dark purple & 1.076 \\
\hline$\{1 \mathrm{BCC}\}^{1},\|12.5\|$ & 4.62 & 4.89 & 4.8 & light blue & 1.096 \\
\hline$\{1 \mathrm{BCC}\}^{1},\|12.5\|$ & 4.69 & 4.86 & 4.79 & light blue & 1.077 \\
\hline$\{1 \mathrm{BCC}\}^{1},\|12.5\|$ & 4.62 & 4.86 & 4.72 & light blue & 1.089 \\
\hline$\{1 \mathrm{BCC}\}^{1},\|18.75\|$ & 4.61 & 4.89 & 4.83 & light yellow & 1.1 \\
\hline$\{1 \mathrm{BCC}\}^{1},\|18.75\|$ & 4.69 & 4.85 & 4.8 & light yellow & 1.098 \\
\hline$\{1 \mathrm{BCC}\}^{1},\|18.75\|$ & 4.64 & 4.9 & 4.88 & light yellow & 1.091 \\
\hline$\{1 \mathrm{BCC}\}^{1},\|25\|$ & 4.6 & 4.89 & 4.81 & dark purple & 1.121 \\
\hline$\{1 B C C\}^{1},\|25\|$ & 4.68 & 4.89 & 4.85 & orange & 1.119 \\
\hline$\{1 \mathrm{BCC}\}^{1},\|25\|$ & 4.64 & 4.88 & 4.83 & light yellow & 1.114 \\
\hline$\{1 B C C\}^{1},\langle 0.862,0.862,1.232\rangle$ & 5.5 & 3.98 & 3.9 & light yellow & 0.583 \\
\hline$\{1 B C C\}^{1},\langle 0.862,0.862,1.232\rangle$ & 5.63 & 3.78 & 4.01 & light yellow & 0.598 \\
\hline$\{1 B C C\}^{1},\langle 0.862,0.862,1.232\rangle$ & 5.57 & 3.86 & 4.06 & light yellow & 0.58 \\
\hline$\{1 B C C\}^{1},\langle 0.862,0.862,1.232\rangle$ & 5.61 & 3.78 & 4.1 & light yellow & 0.575 \\
\hline$\{1 B C C\}^{1},\langle 0.862,0.862,1.232\rangle$ & 5.66 & 3.9 & 4.07 & light yellow & 0.565 \\
\hline$\{3 \mathrm{BCC}\}^{3}$ & 14.5 & 15.17 & 15.13 & silver & 10.576 \\
\hline$\{3 \mathrm{BCC}\}^{3},\|25\|$ & 14.7 & 15.12 & 15.04 & silver & 11.52 \\
\hline$\{3 \mathrm{BCC}\}^{3},\langle 0.862,0.862,1.232\rangle$ & 21.55 & 10.44 & 10.76 & dark purple & 4.061 \\
\hline
\end{tabular}




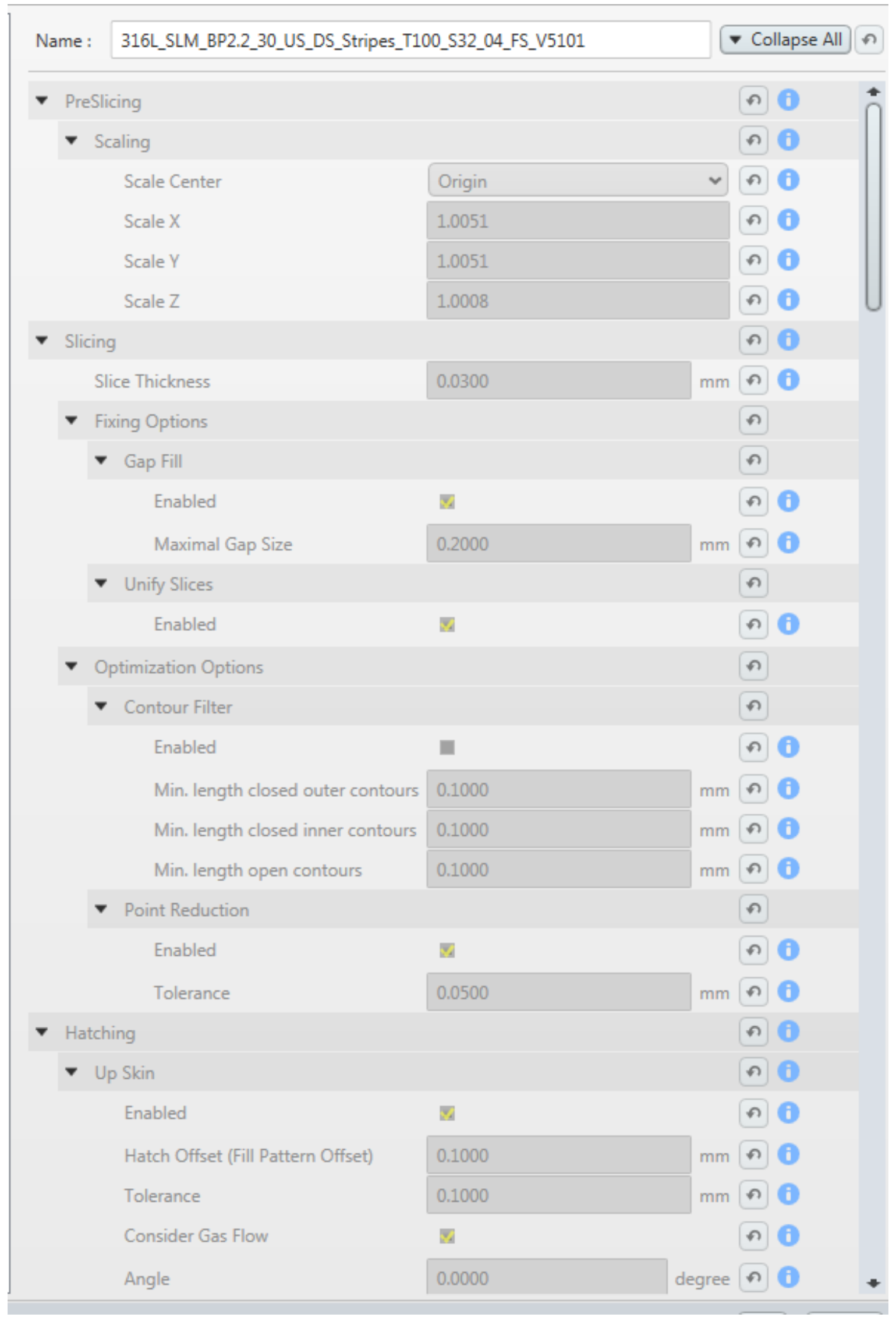




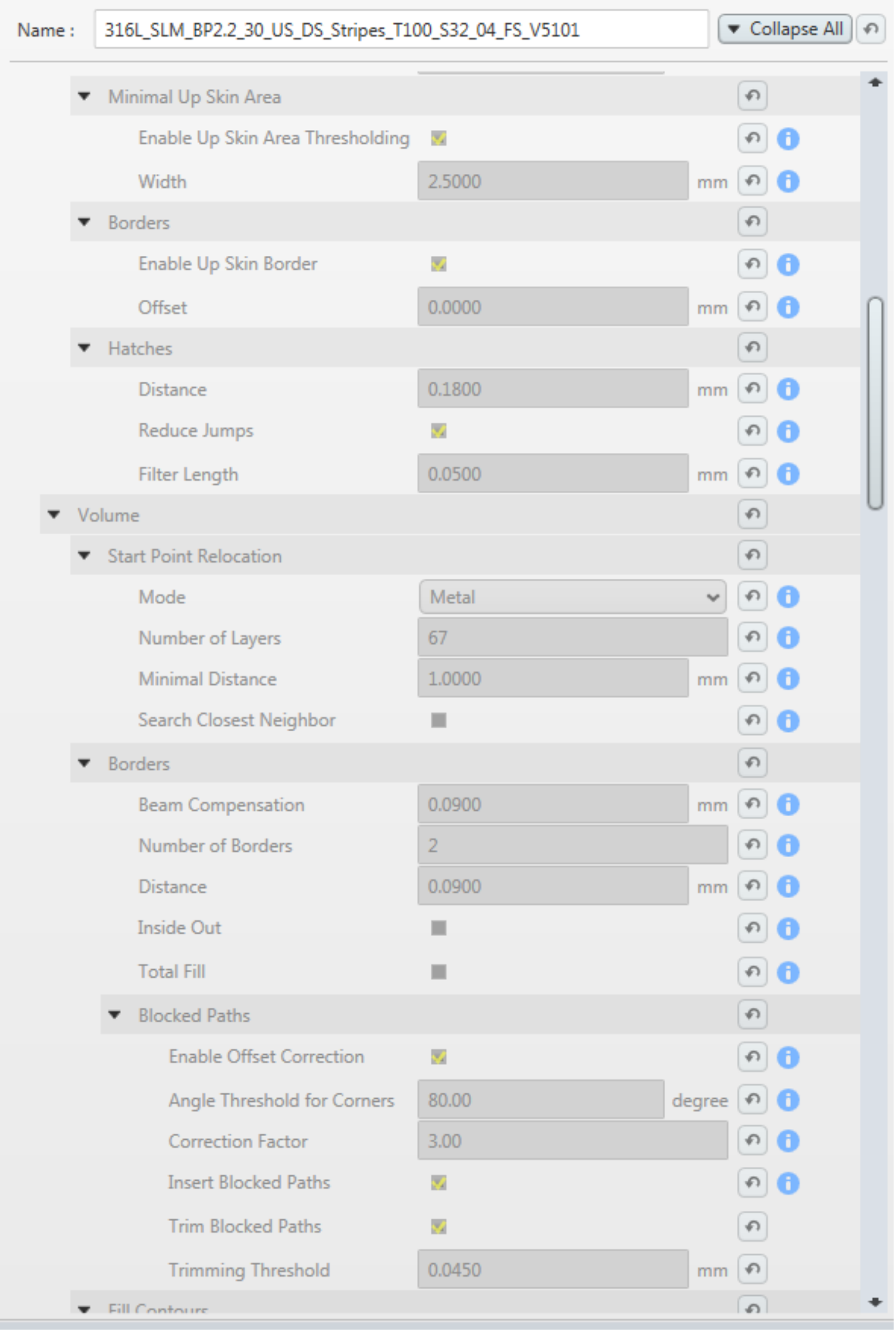




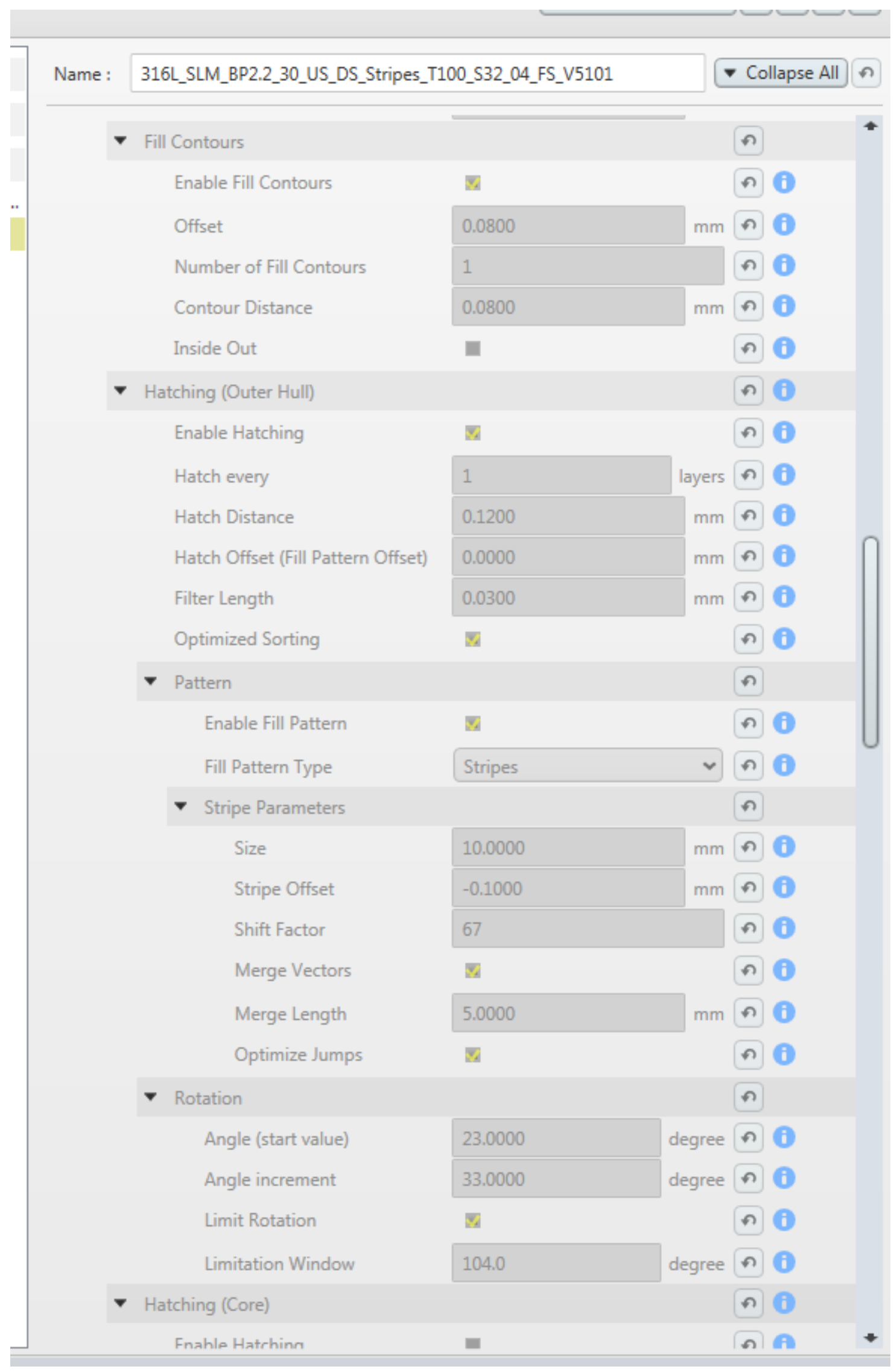




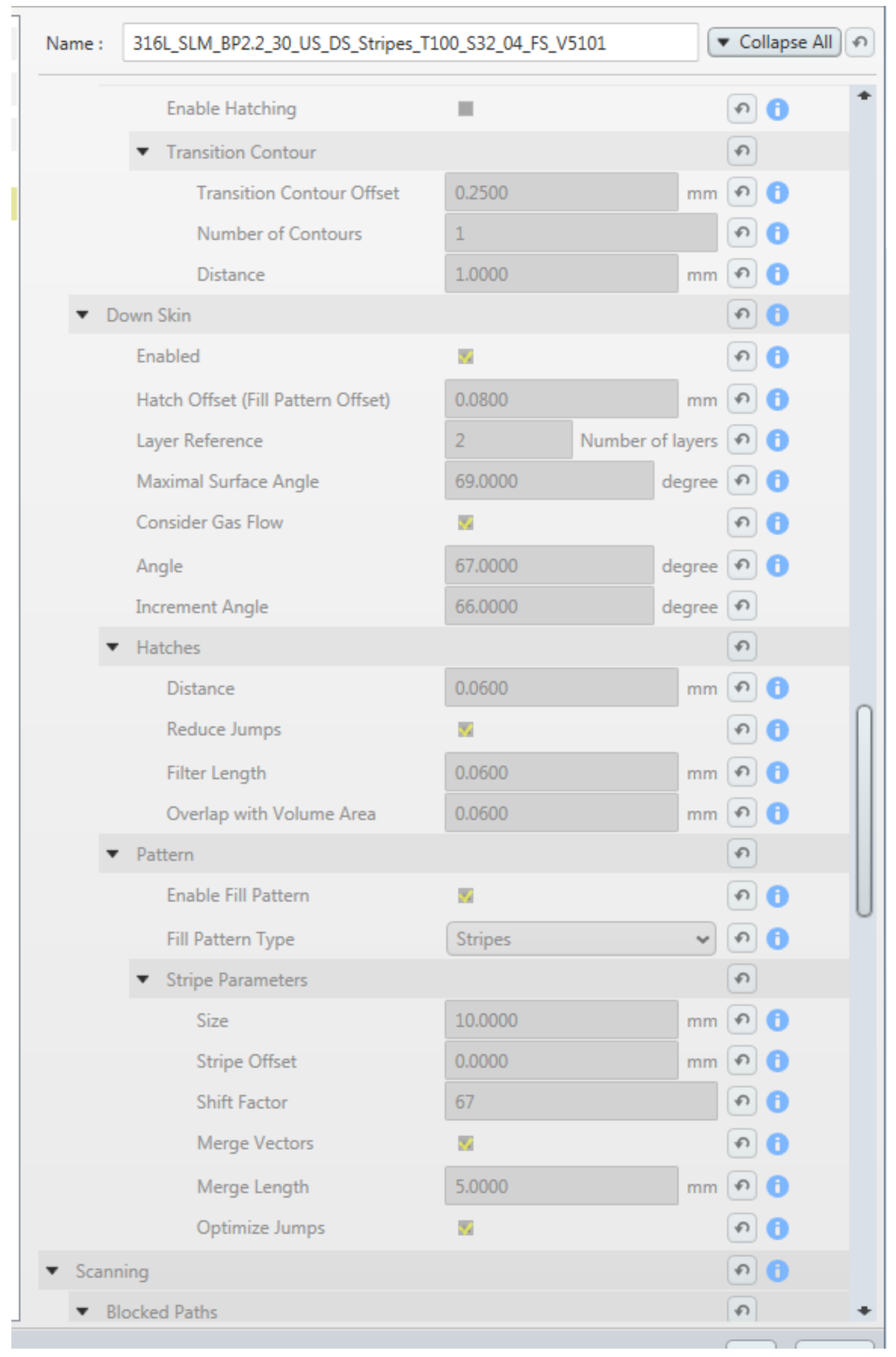




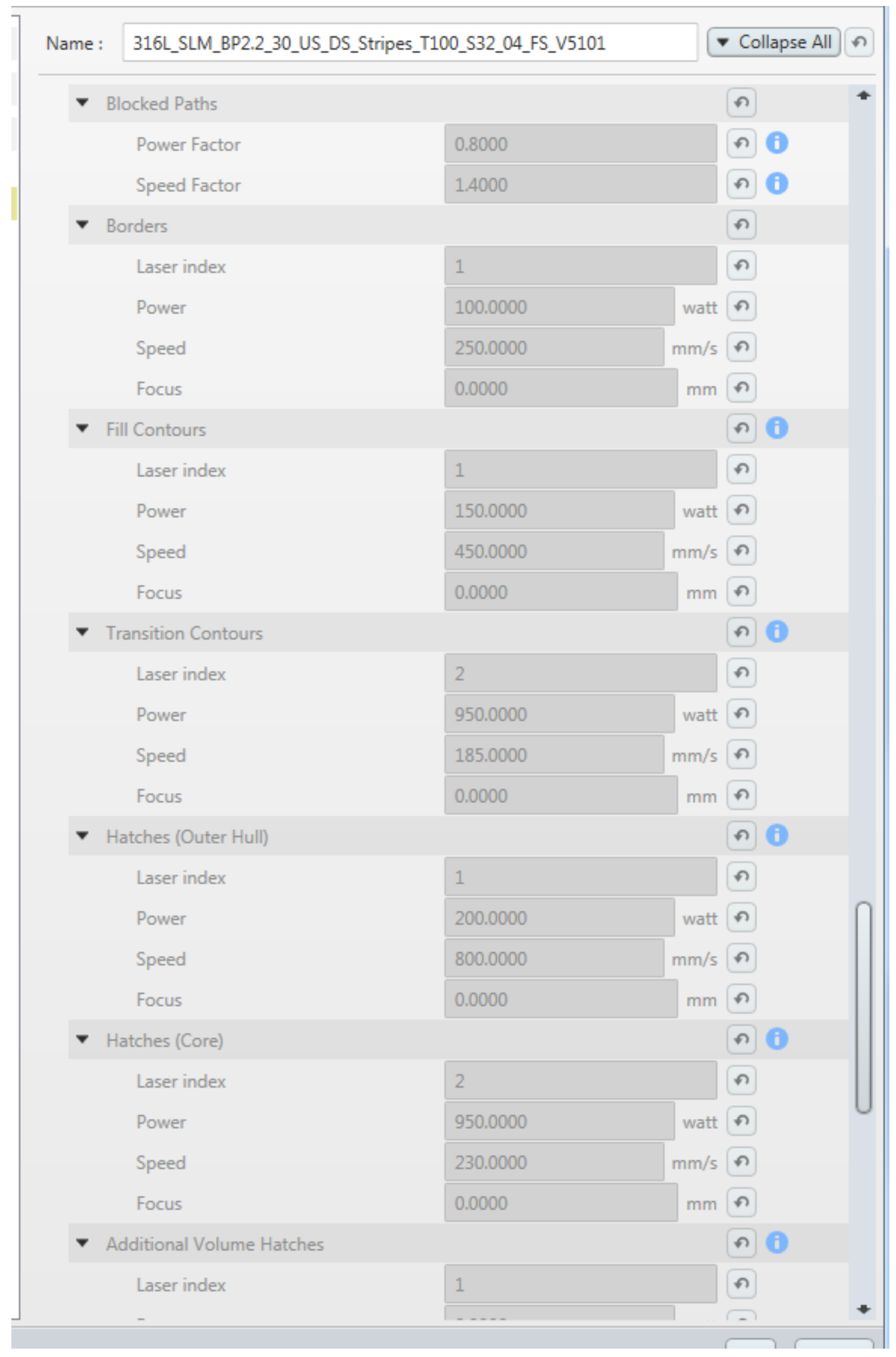




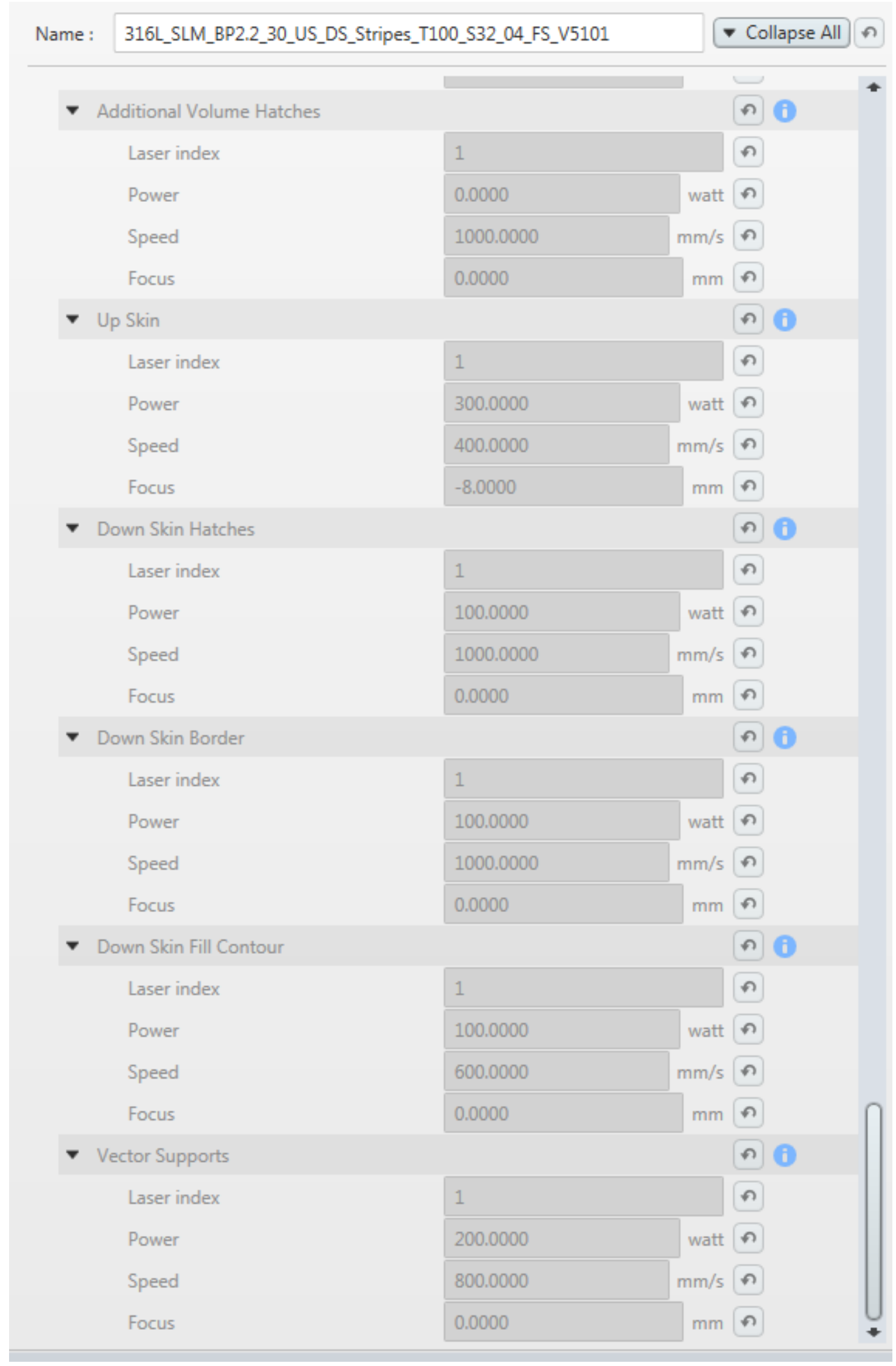

